\title{
Targeting Neoepitopes to Treat Solid Malignancies: Immunosurgery
}

\author{
Eric de Sousa ${ }^{1}$, Joana R. Lérias ${ }^{1}$, Antonio Beltran ${ }^{2}$, Georgia Paraschoudi ${ }^{1}$, \\ Carolina Condeço ${ }^{1}$, Jéssica Kamiki ${ }^{1}$, Patrícia Alexandra António ${ }^{1}$, Nuno Figueiredo ${ }^{3}$, \\ Carlos Carvalho ${ }^{3}$, Mireia Castillo-Martin ${ }^{2}$, Zhe Wang $^{4}$, Dário Ligeiro ${ }^{5}$, Martin Rao ${ }^{1}$ \\ and Markus Maeurer ${ }^{1,6^{*}}$
}

\begin{abstract}
${ }^{1}$ ImmunoSurgery Unit, Champalimaud Centre for the Unknown, Lisbon, Portugal, 2 Department of Pathology, Champalimaud Clinical Centre, Lisbon, Portugal, ${ }^{3}$ Digestive Unit, Champalimaud Clinical Centre, Lisbon, Portugal, ${ }^{4}$ Jiangsu Industrial Technology Research Institute (JITRI), Applied Adaptome Immunology Institute, Nanjing, China, ${ }^{5}$ Lisbon Centre for Blood and Transplantation, Instituto Português do Sangue e Transplantação (IPST), Lisbon, Portugal, 6 I Medical Clinic, Johannes Gutenberg University of Mainz, Mainz, Germany
\end{abstract}

\section{OPEN ACCESS}

Edited by:

Nikolaos G. Sgourakis, University of Pennsylvania, United States

Reviewed by: Juliane Liepe, Max Planck Institute for Biophysical Chemistry, Germany Karen Taraszka Hastings, University of Arizona, United States

*Correspondence: Markus Maeurer markus.maeurer@ fundacaochampalimaud.pt

Specialty section: This article was submitted to Cancer Immunity and Immunotherapy, a section of the journal

Frontiers in Immunology

Received: 06 August 2020 Accepted: 07 May 2021 Published: 15 July 2021

Citation:

de Sousa E, Lérias JR, Beltran A, Paraschoudi G, Condeço C, Kamiki J, António PA, Figueiredo N, Carvalho $C$, Castillo-Martin M, Wang Z, Ligeiro D,

Rao $M$ and Maeurer M (2021)

Targeting Neoepitopes to Treat Solid

Malignancies: Immunosurgery.

Front. Immunol. 12:592031. doi: 10.3389/fimmu.2021.592031
Successful outcome of immune checkpoint blockade in patients with solid cancers is in part associated with a high tumor mutational burden (TMB) and the recognition of private neoantigens by T-cells. The quality and quantity of target recognition is determined by the repertoire of 'neoepitope'-specific T-cell receptors (TCRs) in tumor-infiltrating lymphocytes (TIL), or peripheral T-cells. Interferon gamma (IFN- $\gamma$ ), produced by T-cells and other immune cells, is essential for controlling proliferation of transformed cells, induction of apoptosis and enhancing human leukocyte antigen (HLA) expression, thereby increasing immunogenicity of cancer cells. TCR $\alpha \beta$-dependent therapies should account for tumor heterogeneity and availability of the TCR repertoire capable of reacting to neoepitopes and functional HLA pathways. Immunogenic epitopes in the tumor-stroma may also be targeted to achieve tumor-containment by changing the immune-contexture in the tumor microenvironment (TME). Non protein-coding regions of the tumor-cell genome may also contain many aberrantly expressed, non-mutated tumor-associated antigens (TAAs) capable of eliciting productive anti-tumor immune responses. Wholeexome sequencing (WES) and/or RNA sequencing (RNA-Seq) of cancer tissue, combined with several layers of bioinformatic analysis is commonly used to predict possible neoepitopes present in clinical samples. At the ImmunoSurgery Unit of the Champalimaud Centre for the Unknown (CCU), a pipeline combining several tools is used for predicting private mutations from WES and RNA-Seq data followed by the construction of synthetic peptides tailored for immunological response assessment reflecting the patient's tumor mutations, guided by MHC typing. Subsequent immunoassays allow the detection of differential IFN- $\gamma$ production patterns associated with (intra-tumoral) spatiotemporal differences in TIL or peripheral T-cells versus TIL. These bioinformatics tools, in addition to histopathological assessment, immunological readouts from functional bioassays and deep T-cell 'adaptome' analyses, are expected to advance discovery and development of next-generation personalized precision medicine strategies to improve clinical outcomes in cancer in the context of i) anti-tumor vaccination 
strategies, ii) gauging mutation-reactive T-cell responses in biological therapies and iii) expansion of tumor-reactive T-cells for the cellular treatment of patients with cancer.

Keywords: T-cells, antigens, TIL, neoepitopes, precision medicine, vaccination, T-cell receptor, immunotherapy

\section{INTRODUCTION}

'Personalized immunotherapy is all the rage, but neoantigen discovery and validation remains a daunting problem' echoed an Editorial in Nature Biotechnology 2017 (1). Advances in the last three years in whole exome sequencing (WES), RNA sequencing (RNA-Seq) and combinational peptide vaccination trials combined with checkpoint inhibitors addressed some of the unanswered questions and challenges in therapeutic vaccinations using neoepitopes. Biologically and clinically relevant immune responses happen in distinct immunological contexts, they are dependent on antigen processing, presentation and on the available T-cell receptor (TCR) repertoire that is shaped by previous encounters with antigens. The immune synapse between the major histocompatibility complex (MHC)-peptide and TCR interaction is the center of T-cell activation, which is orchestrated by cells of the innate and adaptive immune response that guides and edit neoepitopespecific T-cell responses. We will therefore review various immune cell types that contribute to successful cellular immune responses and expansion of neoepitope-directed Tcells. Finally, we address in practical terms how neoepitopes are identified in cancer tissue specimens starting with immunohistology, WES, RNA-Seq and epitope prediction algorithms using standard prediction programs.

Tumor mutational burden (TMB) is a key factor in determining the response of patients with cancer to immunotherapy with immune checkpoint inhibitors (anti-programmed cell death 1 [PD-1] or anti-cytotoxic T lymphocyte-associated antigen 4 [CTLA-4]) (2-7). The 'mutanome', the summary of mutations developing over the course of disease is unique from one patient to another, thus making the TMB a unique biological signature comprising of druggable targets and epitopes to elicit anti-cancer immune responses. Alexandrov and colleagues elegantly showed that varying degrees of TMB are associated with different cancer types, and that disease-specific mutational signatures may either be widespread (e.g. melanoma and lung cancer) or restricted (e.g. pancreatic cancer) to certain parts of the genome - thus influencing the number of mutant genes and inevitably the availability and immunogenicity of neoantigens (8). A large proportion of favorable clinical responses rely on a rich reservoir of tumor-infiltrating lymphocytes (TIL) as well as circulating tumor-directed T-cells and, therefore, TCRs which recognize neoepitopes presented by human leukocyte antigen (HLA) molecules on tumor cells (9-19). The number of mutations which are identified through bioinformatics directly influence the repertoire size of immunogenic targets that may induce $\mathrm{T}$-cell responses and potentially anti-tumor directed T-cell responses (Figure 1). Although companion diagnostics for PD-1, programmed deathligand 1 (PD-L1) and CTLA-4 are actively used prior to initiating immunotherapy to confirm expression in tumor tissue samples, mutations in the HLA pathways may often be overlooked - which will impair or abolish productive anti-cancer directed cellular immune responses. In addition, other immunologically relevant mutations or natural variations which may inherently affect immune function and T-cell responses deserve equal attention if these factors influence the quality and quantity of anti-cancer directed immune responses. The TMB is still considered a key factor in predicting clinical responsiveness or to gauge the possibility of the immune system to productively react against cancer cells. Yet the TMB represents only the substrate of potential immune reactivity and the immune system is not objectively considered and analyzed. The TMB is therefore increasingly viewed as an important yet 'imperfect' surrogate marker for clinical responsiveness and the corresponding elements in orchestrating a cellular immune response, namely the MHC genetic background as well as the T-cell receptor repertoire capable of reacting to potential cancer neopitopes, are now considered to be analyzed as well to gauge for immune response analysis (20). The nature and the histological location of T-cells that serve to functionally test for immune recognition of neoepitopes are therefore also considered in this review. We will also highlight in this review relevant findings from clinical and translational studies pertaining to personalized cancer immunotherapy. We discuss HLA mutations in tumor lesions from patients with cancer and discuss how this information is necessary for designing personalized immunotherapy clinical trials. Finally, we propose the combined use of well-established techniques such as immunohistochemistry (IHC) and flow cytometry in conjunction with next-generation sequencing methods to assist in making better informed clinical decisions for treatment regimens, a concept that has been implemented at the ImmunoSurgery Unit and Anatomic Pathology Clinical Service at the Champalimaud Centre for the Unknown (CCU) and the Champalimaud Clinical Centre (CCC) in Lisbon, Portugal (Figure 2).

\section{NEXT-GENERATION SEQUENCING: THE FUEL OF PRECISION ONCOLOGY}

Advances in next-generation sequencing (NGS) techniques such as WES and RNA-seq form the bedrock of personalized precision medicine in neoantigen-directed immuno-oncology $(22,23)$. Immunoediting leading to neoantigen generation and turnover in the tumor microenvironment (TME) influencing Tcell infiltration and survival in patients with advanced cancer (24-26). This also goes hand-in-hand with the MHC background of the patient as well as the capacity to present the 'best' neoepitope candidates to evoke meaningful and clinically 

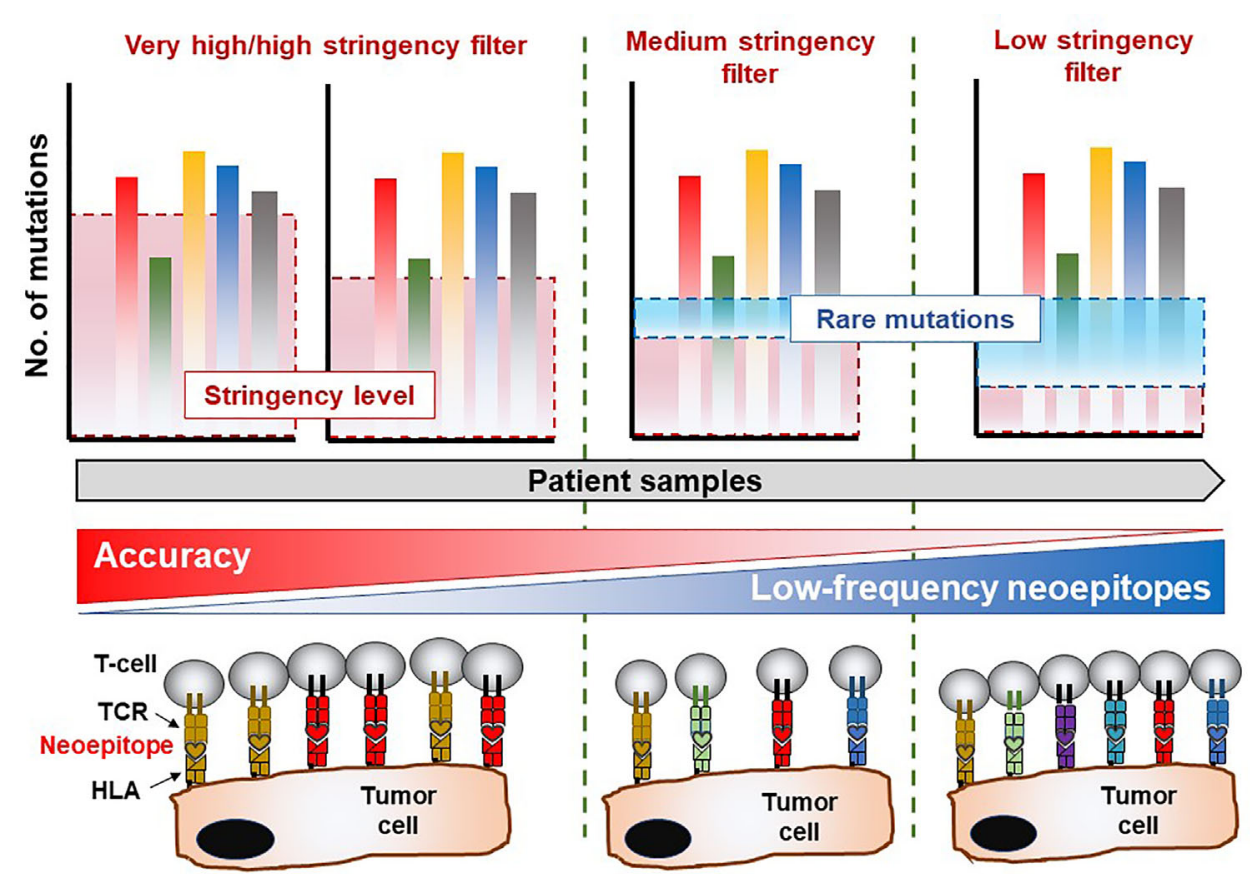

FIGURE 1 | Mutation analysis reveals immune-recognition profile in the TME. Whole-exome sequencing data allows for mining of private somatic mutations in tumor samples compared to healthy (non-transformed) tissue or cells, which is unique to each patient. The stringency of the filtering parameters applied in bioinformatics and statistical analysis of the sequencing data will greatly influence the number of mutations recovered, which are essential for downstream characterization of immune responses of T-cell products. Highly stringent parameters may yield a lower number of mutations albeit with an exceptional level of accuracy. Nevertheless, this approach suffers the risk of overlooking several infrequent mutations which also give rise to immunogenic (T-cell reactive) neoepitopes in the patient. On the contrary, reducing the stringency levels of analysis may reveal rare mutations which facilitate the identification of potentially immunogenic molecular targets recognized by certain TCRs capable of eliciting a biologically relevant anti-tumor immune response. The drawback in the latter scenario is that a high degree of false positive hits may be obtained and included in the final list of legitimate cancer-associated somatic mutations. Thus, a balanced yet wholistic approach is required to identify all immunogenic mutations in tumor tissue which will be instrumental in developing personalized cancer therapies.

beneficial T-cell responses (27-29). Importantly, juxtaposition of tumor-specific T-cells to the tumor cells themselves provides promising prognosis, suggesting that the local 'cell-cell' interaction between neoepitope-specific lymphocytes and tumor cells is clinically beneficial and desirable (30). Treatments affecting the activity of cancer-associated fibroblasts (CAF) or tumorassociated macrophages (TAM) (e.g. monoclonal antibodies such as anti-CD47 or anti-CD40) redirect T-cells to these nominal target cells which appear to be associated with improved anti-tumor responses in a clinical setting (31-36). Furthermore, evolution of the neoantigen landscape under treatment pressure, such as standard chemotherapy, immune checkpoint blockade or active cellular therapy/adoptive cell transfer (ACT) is an essential determinant of how patient immune response patterns are modulated and change over time $(37,38)$. In line with this, neoantigen fitness - the propensity of mutated host targets which differ significantly enough from the wildtype form to be able to produce a biologically meaningful anti-tumor response, further to their HLA-binding strength - can be mathematically modeled to predict survival dynamics of patients and aid in the selection of promising neoepitope candidates for immunotherapy protocols (39). The fitness of a (cancer) cell clone is defined by several factors, e.g. the recognition potential of the (immunodominant) neoepitopes by nominal anti-cancer directed TCRs that will aid to estimate the future size of the cancer cell population. 'Immunodominance' can be gauged by comparing the affinity of the wildtype and the corresponding mutant candidate target epitope that would impose selective pressure on the clonal pool of available TCRs that recognize the $\mathrm{MHC}$-peptide complex.

Clinically, TIL therapy targeting individual neoepitopes has been proven to be successful, with the capacity to promote durable anti-tumor responses in patients with solid tumors (17, 40). Clinical responses appear to be associated with the frequency of neoepitope-specific T-cells in the T-cell product (40). Mutant KRAS-directed TIL and TCR transfer therapy has also shown great clinical promise, albeit in an HLA allele-dependent manner (41). In addition to neoantigens, non-coding regions of the cancer genome giving rise to previously undefined, nonmutated peptides with immunogenic properties can also be mined for, using NGS strategies (42), as well as peptides resulting from novel gene fusions (43). This pattern may differ from patient to patient, necessitating the use of in-silico analyses to select matching HLA-epitope sets for a personalized therapy protocol. Thus, private and shared neoantigens as well as hitherto unknown immunogenic peptides can trigger beneficial clinical responses in patients with advanced cancer $(16,44,45)$. 

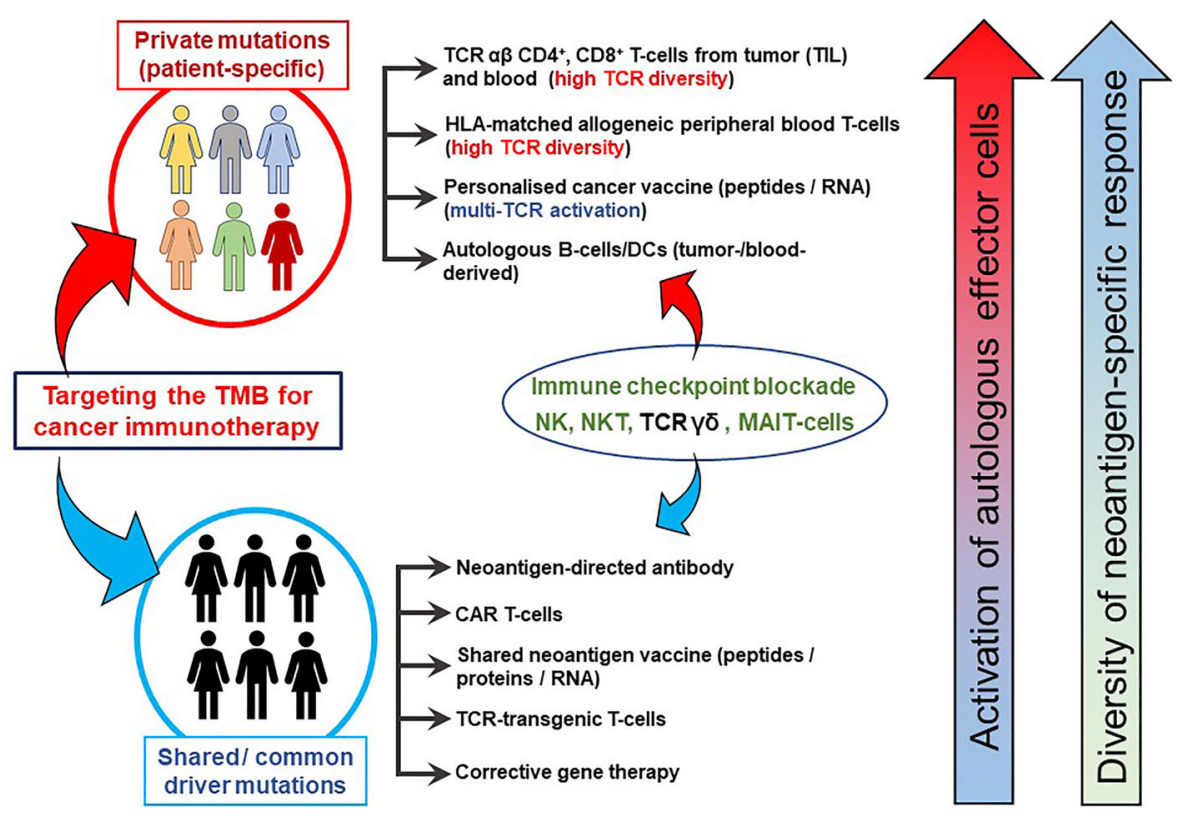

FIGURE 2 | TMB-directed immunotherapy approaches at the Champalimaud Centre for the Unknown. The schematic shows strategies aimed at therapeutic targeting of private (personalized and patient-specific) and shared (often driver) mutations. For personalized therapy, $\mathrm{CD}^{+}{ }^{+}$and $\mathrm{CD} 8^{+} \mathrm{T}$-cells from $\mathrm{TIL}$ or peripheral blood expressing a highly diverse TCR $\alpha \beta$ repertoire recognizing a private neoepitopes can be procured. HLA-matched, healthy donor-derived TCRs have also been shown to recognize patient-specific neoepitopes (21). Personalized cancer vaccines, comprising private neoepitopes as a peptide formulation or as RNA constructs, promote durable immune responses in patients with advanced cancer. Autologous B-cells can be used as a source of APCs as well as cytokine producers, in addition to their differentiation into plasma cells to secrete tumor antigen-specific antibodies in vivo. Approaches targeting shared mutations serve as excellent 'offthe-shelf' options which can be used for larger groups of patients simultaneously. Cancer vaccines based on shared mutations are also clinically important, provided the patients' HLA profiles are matched to the epitope binding characteristics. Antibodies derived from tumor-infiltrating B-cells or from peripheral blood B-cells targeting surface-bound shared neoantigens may mediating cellular cytotoxicity and aid in the development of CAR T-cells. Gene therapy to correct shared driver mutations may promote tumor susceptibility to immune attack. Immune checkpoint blockade has been placed between the two domains as its clinical activity targets both private and shared mutated targets. Similarly, NK, TCR $\gamma \delta$ T-cells and possibly NKT T-cells or MAIT-cells may be instrumental in patients presenting with private and/or shared HLA pathway mutations and can be derived from allogeneic sources for treatment.

NGS readouts combined with recent advancements in immunebased analysis of patient-derived tumor and blood samples are able to provide a wealth of information concerning the presence of dynamics of cancer-specific T-cells suitable for immunotherapy development or for immuno-monitoring following treatment, including neoepitope specificity and TCR tracking (14, 18, 4649). Neoepitope screening has enabled the identification of private mutation-directed TIL from pancreatic cancer $(18,45,50)$ and glioblastoma (14) demonstrating that tumor histologies previously considered poorly immunogenic may also contain a broad repertoire of neoantigen-reactive immune cells $(11,16,51-53)$. Specific neoepitopes involved in eliciting productive immune responses that promote tumor regression either by engaging cellular cytotoxicity or by cytokine production (e.g. IFN- $\gamma$ ) are therefore particularly attractive for developing personalized therapies within the framework of precision cancer medicine (54, 55). However, there is also a need to identify target neoepitopes which are most likely to induce regulatory $\mathrm{T}$-cell responses among TIL to the effect of dampening productive anti-tumor reactivity in patients (56).

Druggable mutations (e.g. those associated with ROS1, ALK, tropomycin receptor kinase [TRK] and NTRK1/2/3 chromosomal fusions) which have been implicated to be responsible for clinical responses in pediatric central nervous system (CNS) malignancies provide a roadmap for how NGS is able to support precision oncology based on selected small molecules (i.e. Entrectinib and Larotrectinib) (57). Hitherto unknown mutational events can be captured via NGS, possibly expanding the use of existing targeted cancer drugs and, in addition, newly devised immunotherapeutic strategies. These probable candidates can be tested for T-cell and antibody reactivity in vitro, and positive results can then be followed up with more detailed analysis to enable the formulation of personalized cancer vaccines (PCVs) or cellular immunotherapy development (chimeric antigen receptor T-cells [CAR-T], TCR transfer, ACT of TIL and/or memory B-cells), paving the way for combination therapies, e.g. with tyrosine kinase inhibitors (TKIs) and immune-based interventions.

\section{PERSONALIZED CANCER VACCINES}

Building on the therapeutic value of targeting cancer-associated mutations, mutation-directed cancer immunotherapy based on PCVs represent a highly specialized approach to induce clinically 
relevant and specifically tailored anti-tumor immune responses in patients with advanced malignancies $(54,58,59)$. A central point is whether epitopes can be presented by HLA class I or II molecules based on their fitting into the epitope-binding groove and be tailored in silico, or whether natural processing by antigen-presenting cells (APCs) in the host or dendritic cell (DC)-based vaccines would be more advantageous (e.g. if antigens were delivered as "long peptides") (60-62), or in a vectored format (e.g. genetically-reengineered viruses and bacteria) (63-68). A carefully selected panel of private and shared cancer-related mutations (e.g. common driver mutations in genes such as KRAS, SMAD4, TP53) identified by WES that bind to the HLA class I and II restriction elements of the patient constitute the formulation of some PCVs $(27,69-72)$. New research based on high-throughput NGS data shows that the hydrophobicity of predicted neoepitopes could, in part, determine better HLA-binding capacity (28). Longer peptide sequences are likely to contain both HLA class I and class II peptides and would, therefore, activate tumor-directed $\mathrm{CD} 8^{+}$and $\mathrm{CD}^{+}{ }^{+} \mathrm{T}$-cells facilitated by cross presentation of antigens in antigen-presenting cells (i.e. DC, macrophages, B-cells as well as tumor cells) $(58,73)$. PCV constituent peptides may also be used as lead molecules to construct HLA tetramers or as T-cell stimulants to screen for the presence of neoantigen-specific TCRs in blood samples of patients with cancer $(16,44,74)$.

A number of trials to test neoantigen-based PCVs in patients with advanced cancer - including pancreatic cancer - have been registered $(58,59,75)$. PCV strategies which have been clinically evaluated are based on direct delivery of messenger RNA (mRNA) sequences of private neoepitopes to the lymph nodes (76), dendritic cells loaded with the patient's tumor lysate, private mutated peptides (neoantigens) $(12,71,77-80)$ or clinical-grade neoepitope peptide sequences injected alongside a strong adjuvant or immunostimulant (i.e. poly-ICLC) $(69,72)$. Montanide ${ }^{\circledR}$, which is based on antigens from Mycobacterium tuberculosis (81-84), and QS-21, extract derived from the soap bark tree Quillaja saponaria $(85,86)$, are also candidates for use as adjuvants in PCVs based on previous clinical experience. $\mathrm{Hu}$ and colleagues have comprehensively summarized and elaborated on the current landscape in PCV development (23).

Pertaining to the clinical testing of cell-free, neoepitope-based peptide vaccines, Keskin and colleagues recently reported a phase 1b PCV clinical trial in eight patients with glioblastoma, where specific $\mathrm{CD}^{+} \mathrm{T}$-cell responses to a mutation-bearing sequence from Rho GTPase Activating Protein 35 (ARHGAP35), which is naturally processed and presented to the immune system, were demonstrated in one patient (72). Furthermore, the authors also noted increased T-cell infiltration into the tumor - concomitant with neoantigen-specific T-cell in peripheral blood - following PCV administration. In a previous study, the authors had treated six patients with advanced melanoma and showed, that despite including HLA class I-binding peptides (for $\mathrm{CD}^{+}$T-cell recognition) in the vaccine design, superior $\mathrm{CD}^{+}{ }^{+} \mathrm{T}$-cell responses directed against the patients' neoantigens was observed (69). There is until this point not a convincing biological model for the observation that presumed MHC class I binding peptides (87), delivered as 9mers, induce rather $\mathrm{CD}^{+} \mathrm{T}$-cell responses as compared to $\mathrm{CD}^{+}{ }^{+} \mathrm{T}$-cells; an observation that has been found to be true in several vaccination studies using tumor-associated mutant targets (69). In a different study, in patients with glioblastoma, CD4 ${ }^{+}$ $\mathrm{T}$-cell responses were dominant in the case if mutant (nested) $\mathrm{MHC}$ class I-restricted epitopes were used for vaccination. None of the mutant epitopes elicited solely a $\mathrm{CD}^{+} \mathrm{T}$-cell response (although MHC class I epitope clusters were used), yet rather immune responses restricted by $\mathrm{CD} 4^{+} \mathrm{T}$-cells alone or by $\mathrm{CD} 4^{+}$and $\mathrm{CD} 8^{+}$ T-cells were detected (88).

PCV-induced immune responses can also be enhanced with anti-PD-1 therapy $(62,69,76)$. The TCR repertoire identified in clinically relevant and successful immune checkpoint therapy responses is associated with different anatomical compartments (89) as well as distinct T-cell markers in antigen-specific T-cells including $\mathrm{CD}_{103^{+}} \mathrm{T}$-cells (90) or - more recently with an stemcell like $\mathrm{CD}^{+} \mathrm{CD}^{-} 9^{-} \mathrm{CD} 39^{-}$phenotype in TIL that is strongly associated with clinical responses (90).

The rationale for increasing clinical responsiveness to PCV with checkpoint inhibitors would be to mobilize mutationspecific $\mathrm{T}$-cells and $\mathrm{PD}-\mathrm{1}^{+} \mathrm{B}$-cell populations specific for cancer mutations (91-93). A different approach which may improve fine-tuning of anti-tumor responses following PCV treatment is the removal of non-productive inflammation caused by interleukin 6 (IL-6). Generally important for priming T-cell responses (94), IL-6 is a pleiotropic cytokine implicated in the pathogenesis of several cancer histologies, particularly gastrointestinal malignancies including pancreatic cancer and colorectal cancer $(95,96)$, one of the key factors being the suppression of productive immune responses in the TME (97-101). Treatments targeting IL-6 are approved for clinical use in patients with rheumatoid arthritis and Castleman's disease (102), although their use in patients with advanced cancer has yet to be fully realized despite promising results from preclinical models of solid tumors (94). Furthermore, IL-6 is among the cytokines released in large amounts following T-cell therapies for cancer (i.e., adoptive cell transfer ACT or CAR-T cell therapy) (103). IL-6 can lead to upregulation of PD-1 and immune exhaustion (104), while promoting interleukin 17 (IL-17) production - which can be a disadvantage in patients with cancer to subduing T-cell activity and augmenting tumor cell proliferation (105-107). Combined targeting of IL-6 and the PD1/PD-L1 axis has shown reversal of immunosuppression in the TME leading to immune activation and tumor rejection in murine models of human cancer $(108,109)$. Other approaches in increasing the amenability of the TME to therapeutic intervention are to target the extracellular matrix and tumor stroma which provide scaffold support for the cancer cells (110, 111) and TAMs which have a pro-tumor effect in the TME (112).

Recent peptide vaccine trials show the complex neoepitope selection process and validation process - and underline also the need for a more harmonized approach that will enable to compare results across different studies to gauge $\mathrm{T}$-cell responses against the immunizing peptides. In a clinical study for patients with melanoma (69), WES of the tumor was conducted, validated by RNA-Seq and mutant (tumor) 
peptides were selected based on the patient's HLA-A and -B alleles followed by production of long-peptides representing up to 20 neoepitopes per patient. The 'private vaccine' was administered with an TLR3 adjuvant (poly-ICLC). MHC class I binding was predicted via NetMHCpan v2.4 and neoepitopes were selected with a hierarchy of criteria: i) frameshift mutations where the algorithm predicted binding, ii) single nucleotide variants (SNVs) where the algorithm predicted binding due to the mutation being in an anchor residue, iii) SNVs where the algorithm predicted binding due to the mutation being in residues other than anchor residues, iv) frameshift mutations where the algorithm did not predict binding and v) SNVs where the algorithm predicted low binding. In addition to the criteria listed above, oncogenes were prioritized and biochemical constraints concerning peptide synthesis were considered. 'Long peptides' allow for antigen processing and presentation for both $\mathrm{CD}^{+}$and $\mathrm{CD}^{+}$T-cells. The immunological readout addressed biological and clinically relevant questions like the frequency of peptide-specific T-cells (in vitro) upon re-stimulation assays using peripheral blood mononuclear cell (PBMCs) as immune effector cells showing that T-cell responses could indeed be induced against each individual vaccine target antigen. This point has practical implications: target antigen peptides were screened for T-cell reactivity and the biological readout is usually IFN- $\gamma$ production. Non detectable IFN- $\gamma$ production could imply that - assuming that the candidate peptide shows MHC binding - the frequency of T-cells directed against the candidate epitope is either low or that there are no peptide specific TCRs available in an individual patient. Low T-cell frequencies specific for a candidate peptide implies that these T-cells have not yet been expanded in vivo. Such a candidate peptide may represent a viable neoepitope for vaccination or T-cell expansion particularly if it is able to recruit $\mathrm{T}$-cells from a stem cell pool with promising expansion potential and anti-cancer directed immune effector functions (90). Different peptide testing formats were used to gauge for the immune T-cell reactivity readout: a) peptides, b) minigenes (that allow the use of surrogate antigen presenting cells in order to test whether the peptides are naturally processed and presented, assuming that these minigenes are similarly processed as compared to the wildtype target tumor antigen), c) autologous tumor cells in order to test whether tumor cells are recognized by peptide-expanded $\mathrm{T}$-cells since antigen processing and presentation may be different in tumor cells as compared to non-transformed cells as reviewed in Vigneron (113). This example shows the critical steps in the workflow and decision making process for which antigens should be selected (oncogenes, frameshift mutations), the format for vaccination (long peptides), the nature of the adjuvant and the question whether candidate peptide-reactive $\mathrm{T}$-cells recognize naturally processed epitopes, the nature of the immune response, i.e., cytokine production (using intracellular cytokine staining to gauge for polyfunctional T-cells), a CD107a induction assay (to gauge for cytotoxicity), as well as a direct enumeration of MHCspecific T-cells using soluble MHC-peptide complexes. The list of different assays above reflects that peptide recognition may be tested positive in a specific biological readout (e.g. cytokine production), but not in another (e.g. cytotoxicity). Of practical interest is that $\mathrm{MHC}$-class II peptide-tetramer guided enumeration often underestimates antigen-reactive $\mathrm{CD} 4^{+}$ T-cell numbers since the MHC-peptide interaction is fixed. In contrast, the incubation time of candidate test peptides with PBMCs is usually a few hours (and takes place at a different temperature) - allowing to accommodate a more 'promiscuous' binding of peptide species to several MHC class II alleles. Analysis of peptide-reactive T-cells with soluble MHC-peptide complexes provides unbiased enumeration of MHC-peptide reactive T-cells since it enables ex vivo analysis without the need of in vivo T-cell expansion, it enables - via the co-staining of T-cell differentiation and activation markers (that define in which T-cell compartment the antigen-specific T-cells reside) to link the ex vivo analysis of antigen-specific T-cells with T-cell homing, differentiation, maturation or functional markers associated with cytokine production. This is clinically relevant since tumor-reactive T-cells that - upon adoptive transfer - lead to clinically relevant response reside preferentially in the central memory T-cell subset and/or exhibit distinct activation (CD69 $\mathrm{CD}^{\circ} 9^{-}$) phenotypes (90). Examples of two vaccination trials with peptides identified from glioblastomas addressed different, clinically relevant points, namely whether the presence of (candidate) antigen specific T-cells prior to vaccination would predict successful vaccination outcomes and whether the nature (mutant versus non-mutant targets) would make a difference in regard to T-cells expansion (88). This first, rather complex, clinical trial, was conducted using an 'off-the-shelf cocktail of non-mutant peptides of glioblastoma-associated antigens targeting HLA-A2 and HLA-A24-positive patients, plus candidate 'private peptides', either from mutant or non-mutant 'private' glioblastoma targets. Key observations were that i) binding of some candidate peptides to MHC molecules was confirmed by mass spectrometry, i.e., these peptides were found to be naturally processed and presented, ii) mass spectrometry allowed an unbiased analysis of the peptide repertoire displayed by cancer cells, within the detection limits, yet requires approximately $10 \mathrm{e}^{7}$ tumor cells for analysis (114), iii) MHCclass I restricted $\mathrm{CD}^{+} \mathrm{T}$-cell responses, usually residing in precursor T-cells, to non-mutant epitopes prior to vaccination predicted successful T-cell responses after vaccination, iv) some peptide vaccine-induced $\mathrm{T}$-cells recognized naturally processed and presented epitopes on the patients' autologous tumor cells, v) vaccination with $\mathrm{CD} 8^{+} \mathrm{T}$-cell epitopes induced $\mathrm{CD} 4^{+} \mathrm{T}$-cell responses, iv) some mutant vaccine epitope resulted in T-cells recognizing wildtype and mutant target antigens, v) none of the mutant epitopes evoked an exclusive $\mathrm{CD} 8{ }^{+} \mathrm{T}$-cell response, but rather $\mathrm{CD}^{+}$, or $\mathrm{T}$-cell responses in $\mathrm{CD}^{+}$and in $\mathrm{CD}^{+} \mathrm{T}$-cells, vi) $\mathrm{T}$-cells expanded from glioblastoma tissue harvested prior to vaccination did not contain $\mathrm{T}$-cells responding to the selected candidate target epitopes, vii) no preferential expansion of T-cells using mutant epitopes as compared to non-mutant epitopes. A different clinical trial, also in patients with glioblastoma, showed that T-cells induced by vaccination infiltrated into tumor lesions after peptide vaccination (115). 
This demonstration is clinically very relevant since only a few studies were able to demonstrate that $\mathrm{T}$-cell clones elicited by peptide vaccination - reacting against the immunizing peptide would then hone to the patient's tumor and aid to mediate tumor regression. This argues that it is necessary to obtain biopsies in progressing and regressing tumor lesions from patients with cancer who undergo peptide-based vaccination. Of particularly clinical relevance is i) that patients who received corticosteroids (which most patients with glioblastoma receive) during vaccinepriming failed to generate IFN- $\gamma$ production to vaccine peptides, ii) some vaccine-peptides induced $\mathrm{T}$-cells reacting against minigenes (coding for these targets, expressed as transgenes into surrogate recipient targets cells), but not to tumor cells, iii) that a round of in vitro stimulation was needed in order to detect antigen-specific T-cells, reflecting most likely low antigenspecific T-cell frequency, iv) peptide antigen-driven expansion in vitro and subsequent single cell PCR sequencing allowed to link TCR usage to peptide specificity. The identification of the unique peptide-specific TCR CDR3 motif allowed to 'trace back' the antigen specific T-cells to time points prior to vaccination (and post-vaccination samples) to the tumor sample used to identify the private mutations, as well as to post-vaccination tumor samples in case of tumor recurrence. Some mutant peptide specific TCRs were not detected prior to vaccination in PBMCs (which represent only $2 \%$ of the entire lymphocyte pool), nor have they been found in the tumor specimen used for mutational analysis, yet they were detectable in the tumor recurrence, an observation that was also observed in a rather more anatomically accessible basal cell cancer study (116). Such antigen-specific T-cells are mediating anti-tumor responses and their detection allow therefore a biologically relevant clue how neoepitope-specific T-cell therapies could be improved: Anticancer-directed T-cells after checkpoint inhibitor therapy were not 'rescued' or epigenetically rewired in response to checkpoint inhibitor therapies (117), yet rather 'new' T-cells were able to access the tumor site upon checkpoint inhibitor treatment. This phenomenon was dubbed 'clonal replacement' and would also support the notion that peptide-induced T-cells are able to access cancer lesions after vaccination (116). These observations are reminiscent of anti-cancer directed vaccine trials almost 2 decades ago. Although vaccination with (non-mutant) tumor associated antigens resulted in clinically relevant responses, the regressing tumor lesions showed 'spontaneous' anti-cancer immune reactivity, yet anti-cancer vaccine responses were not detected in the regressing cancer lesions suggesting that tumor vaccination aids to reinvigorate immune responses to private cancer antigens - and that a competent TCR is a prerequisite to achieve clinically meaningful $\mathrm{T}$-cell responses (118). The practical consequence of these observations is to perform 2 or $4 \mathrm{~mm}$ needle biopsies in accessible tumor lesions that would allow to gauge for deep TCR sequence analysis and to trace mutant-epitope specific T-cell clones. In addition, both studies targeting glioblastoma epitopes showed that mutant peptide epitopes favored expansion of cytotoxic $\mathrm{CD}^{+}{ }^{+} \mathrm{T}$-cells (115) and even if peptides were used to target $\mathrm{CD} 8^{+} \mathrm{T}$-cells, peptide antigen-specific $\mathrm{CD}^{+}{ }^{+} \mathrm{T}$-cell expansion was observed in both studies (88). These and other clinical trial data were recently excellently reviewed addressing the clinical utility of neoantigen identification, peptide processing and MHC presentation of candidate epitope targets for rational vaccine design (119).

\section{IMMUNE FUNCTION AND PERSONALIZED IMMUNOTHERAPY}

Personalized immunotherapy is based on the capacity of the immune system to recognize, to be activated, to clonally expand and ultimately to kill off or to contain cancer cells. This involves several biological pathways, including the recognition and response to danger-associated molecular patterns (DAMPs) by cognate receptors present on the surface of APCs, T-cells as well as parenchymal cells (120). DAMPs are either released into the environment [e.g. high-mobility group box 1 (HMGB1), adenosine triphosphate, calreticulin; reviewed in (121)] or they can be cell-bound (Fas ligand [FasL] (122), heat shock proteins (123), MHC class I polypeptide-related proteins A/B [MICA/B]) $(124,125)$, and upon encountering the suitable receptor, elicit a signaling program resulting in an pro-inflammatory response. Although DAMPs can lead to non-productive inflammation resulting in organ damage, they play nevertheless an essential role in promoting cancer-directed immune responses and form an integral component of personalized immunotherapy strategies (126). Equally important is the epigenetic regulation of DAMPs which aid to the successful orchestration of innate and adaptive immune responses in PCV trials and clinically relevant immune responses (127). The use of 'in-built', molecularly defined adjuvants such as non-coding RNA may also augment the capacity of immune cells to orchestrate a potent anti-tumor immune responses in vivo, e.g. by activating the RNA sensing molecule retinoic acid-inducible gene I (RIG-1) (128). Indeed, RIG-I and a related intracellular RNA-sensing molecular melanoma-differentiation factor 5 (MDA-5) have been discussed as potential players in amplifying anti-tumor immune responses following recognition of cancer-associated RNA structures (128, 129). Other players in immunosurveillance are the toll-like receptors (TLR) 3 and 7, that are also involved in recognizing RNA derived from pathogens, with TLR3-mediated immune activation playing an essential role in the clinically relevant immunogenicity of poly-ICLC, a synthetic, double-stranded RNA-based polymer used as an adjuvant in the formulation of personalized cancer vaccines $(69,72,76)$.

In a similar manner, different microRNA species are likely to be involved in immunomodulation and enhancement of local immune surveillance in cancer lesions (13, 130-132). Although the immunosuppressive TME may result in the downregulation of microRNA species, an unbiased identification of promising microRNAs and non-coding RNA sequences is possible via NGS and would allow to test synthetically produced RNA sequences as components in immuno-stimulation in PCV studies. MicroRNA species may also subdue expression of neoantigen-encoding genes, identifying microRNA using RNA-seq will therefore reveal additional layers of genetic regulation interfering with 
optimal anti-tumor immune responses, yet it also opens new molecularly defined ways to optimize anti-cancer directed therapies in a more evidence-based fashion.

The stimulator of interferon genes (STING) pathway augments as well anti-tumor cellular immune responses (previously reviewed (133-135)), including potent B-cell activation and antibody production (136). STING is encoded by the TMEM173 gene in humans and acts as an intracellular DNA-sensing molecule (thus a pattern recognition receptor $[\mathrm{PRR}]$ ) requiring cyclic guanosine monophosphate-adenosine monophosphate (GMP-AMP) synthase recognition of cytosolic DNA involved in expression of type I IFN-regulated pro-inflammatory genes. Activation of STING leads to transcription of IFN-stimulated response elements (ISREs) via TANK Binding Kinase 1 (TBK1) activation and interferon regulatory factor 3 (IRF3) localization into the nucleus to initiate gene transcription. Several clinical trials are underway, testing STING pathway agonists to induce anti-tumor immune responses in patients with cancer. A three-prime repair exonuclease 1 (TREX1) expression is involved in dampening STING-mediated immune activation by eliminating damaged DNA from the cytosol (135). However, it is possible that TREX1 mutations in patients with cancer may instead increase immune activation in cancer cell along with STING stimulation. Mutations in the STING pathway have been reported in patients with colorectal cancer, where STINGdeficient cancer cells were unable to produce interleukin $1 \beta$ (IL-1 $\beta$ ) in response to DNA damage (137). Preclinical research showed that STING-dependent immune activation was able to enhance neoantigen vaccine responses and changed favorably the TME immune profile (138-140). Thus, primary and secondary immunodeficiencies defined by NGS can be identified molecularly and should supplement the NGS information obtained from cancer cells. STING variants may be naturally occurring genetic aberrations (e.g. silencing mutations in TLRs or receptors recognizing DAMPs), be associated with infections (e.g. human immunodeficiency virus [HIV]) or with immunosuppressive therapies (e.g. solid organ/stem cell transplantation and therapies used for patients with autoimmune diseases $(120,141-144))$. NGS readouts allow also to visualize the mutational status of the STING pathway - among other immune-activating genes - in validating neoantigen-directed immune responses when designing PCVs and transgenic TCRbased cancer treatments. A comprehensive panel of mutations and natural variants in key molecules orchestrating the quality and quantity of anti-cancer directed immune responses is screened within the cancer NGS analysis in the ImmunoSurgery unit at the Champalimaud Foundation (see below) in order to better define immunological landscape of local and systemic immune responses that may influence immunotherapeutic strategies.

\section{ANTIGEN PROCESSING AND PRESENTATION MACHINERY MUTATIONS IN THE CONTEXT OF IMMUNOTHERAPY}

The antigen presentation machinery (APM), mainly constituted by the HLA class I and class II antigen processing and presentation pathway, are central to immune recognition and immune surveillance. While the HLA class I pathway generally processes and presents endogenous antigens derived from intracellular pathogens or autoantigens (such as neoantigens in cancer), the HLA class II pathway processes and presents exogenous antigens, which could be host- or pathogen-derived. $\mathrm{CD} 8^{+} \mathrm{T}$-cells are HLA class I restricted while $\mathrm{CD} 4^{+} \mathrm{T}$-cells recognize HLA class II epitopes (145). While all cells of the body (except erythrocytes) constitutively express the HLA class I pathway (except in the CNS, where MHC class I is downregulated); the HLA class II pathway can be activated in the presence of IFN- $\gamma$ via transcription of the class II transactivator, thus underlining the need for IFN- $\gamma$ in the TME (146). The standard APM in human cells is shown in Figure 3.

The antigen processing and presentation machinery is of major importance in immunosurveillance, as mutations occurring in the HLA class I and class II pathways bear great significance to cancer immunotherapy. Loss of MHC molecules may lead to immune-escape which may entail the failure of clinically relevant immune surveillance, loss of individual MHC class I loci in cancer lesions prohibits targeted therapy using PCV, since the identification of allelic losses limits naturally the choice of peptides to be used in a PCV. Thus, detailed analysis of the HLA haplotypes (HLA-A/B/C), is a prerequisite in selecting the 'best-fitting' neoepitopes in the design of personalized cancer vaccines as well as TCR-dependent T-cell therapies (28, 71, 147, 148). Downregulation of and loss-of-function mutations in the HLA class I and II pathways abrogate or dampen immune recognition of tumor cells in vivo (149-155), which goes along with TME evolution in response to immune activation $(26,156)$. Components of the HLA class I and class II pathways, if affected by genetic aberrations, may lead to 'tumor antigen loss variants' (thus the inability to process and present immunologically viable neoantigens) (157, 158). The 'hyper progression' effect described in patients treated with checkpoint inhibitors may, in fact, reflect an HLA loss in vivo while subtle MHC mutations may also have a similar deleterious effect on immune recognition by TIL if such mutations affect the nature and diversity of the peptide repertoire loaded onto the nominal MHC molecule. In accordance, mutations in the canonical HLA class I pathway (HLA-A/B/C) and its associated components in patients with cancer have been previously described, e.g. transporter associated with Antigen Processing 1/2 (TAP1/2), latent membrane protein 2/7 (LMP2/7) and $\beta 2$-microglobulin $(151,159-164)$. Some tumor cells may also contain alternate splice forms of tapasin that can alter the repertoire of peptides loaded into the MHC class I antigen presentation pathway (165), mutations in the MHC class II antigen processing and presentation pathway have also been described $(166,167)$, yet they are not reported as frequently as molecular defects in the HLA class I pathway. There has been however much attention given to MHC class II expression in various cancer types such as colorectal (168), cervical (169), lung (170), breast (171), melanoma (172) and pancreatic cancer (173), pointing also to the significance of $\mathrm{CD}^{+}$-mediated anti-tumor responses $(174,175)$. Components associated with HLA class II peptide loading (the invariant chain [CLIP]), as well as the "peptide editors", HLA-DMA/DMB/DOA/DOB also play a 


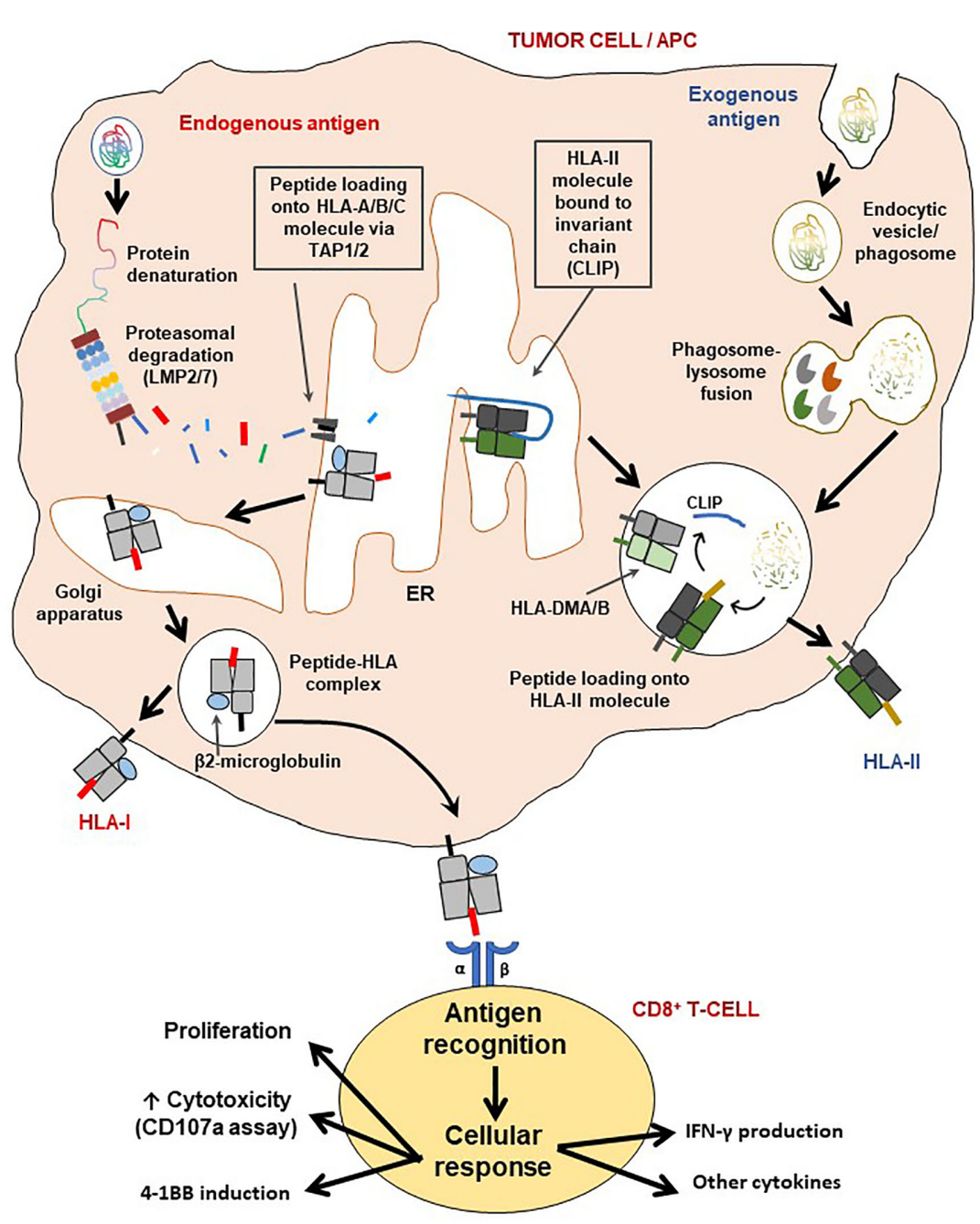

FIGURE 3 | Schematic representation of the HLA class I and II pathways and T-cell activation. The HLA class I pathway is also known as the intrinsic pathway as it processes and presents endogenous antigens while antigens derived from the extracellular environment are processed and presented via the HLA class II (extrinsic) pathway. LMP2/7 are immunoproteasome subunits necessary for generating short epitopes (7-11 amino acids along), which are then loaded on the HLA class I molecule for presentation to $\mathrm{CD} 8^{+} \mathrm{T}$-cells. The $\beta 2$-microglobulin $(\beta 2 \mathrm{M})$ is critical for the assembly and stable expression of HLA class I-peptide complexes on the cell surface. On the other hand, HLA class II molecules first exist with the class II-associated invariant chain (CLIP) for stability, which is then removed with assistance from the HLA-DMA/B complex, for loading of $\mathrm{CD}^{+}$T-cell epitopes generated via lysosomal degradation. Processed antigens are then presented by either HLA-II (extrinsic pathway) or HLA-I (intrinsic pathway), to T-cells to initiate an immune synapse followed by activation of the latter. Indeed, as a result of cognate antigen recognition, T-cells may produce one or a combination of effects: i) cellular proliferation (also involves IL-2), ii) increase in cytotoxicity (may be measured by surface CD107a induction assay), iii) induction of 4-1BB expression and/or iv) production of cytokines, such as IFN- $\gamma$, TNF- $\alpha$, IL-2, IL-17c.

significant role in producing meaningful $\mathrm{CD} 4^{+} \mathrm{T}$-cell responses $(153,168,169)$ and are needed to present tumor antigen derived epitopes to $\mathrm{CD} 4^{+} \mathrm{T}$-cells either by cancer cells directly or APCs in the TME cross-presenting tumor-associated antigens. This is of clinical relevance since PCV enriched for $\mathrm{CD}^{+} \mathrm{T}$-cell epitopes tend to induce target-specific $\mathrm{CD} 4^{+} \mathrm{T}$-cell responses as discussed above. The loss of HLA class I expression and therefore subsequent $\mathrm{CD}^{+} \mathrm{T}$-cell responses in a patient with pancreatic cancer has been observed to be compensated with HLA class IIrestricted $\mathrm{CD}^{+} \mathrm{T}$-cells (with cytokine production and cytolytic activity) (18) arguing that a molecular and immuno-histological examination of cancer lesions should include the MHC class I as well as the MHC class II antigen processing and presentation pathways that can be subject to therapeutic modulations, e.g. using HDAC inhibitors.

\section{A ROLE FOR UNCONVENTIONAL NEOANTIGEN PRESENTATION IN CANCER?}

Reduced expression of HLA-E (non-canonical HLA class I) has been linked to increased survival of patients with ovarian cancer (176), while it may also inhibit CD $8^{+}$TIL activity. MICA and MICB 
are expressed in the gastrointestinal epithelium, thus with relevance for metastatic GI cancers, e.g. colorectal or pancreatic cancer. Both MICA and MICB molecules are stress induced and bind to NKG2D in T-cell engagement, which could lead to activation of NK cells (or - not mutually exclusive - activation of TCR $\gamma \delta^{+}$T-cells) instead of the TCR $\alpha \beta^{+}$T-cells. HLA-G is yet another non-classical HLA class I member, whose expression is associated with a poor prognosis for patients with cancer, including patients with glioblastoma, colorectal and pancreatic cancer (177). Furthermore, HLA-G can be found in soluble form in blood while also secreted in exosomes; it can also be readily detected in IHC - thus making it feasible also for immunodiagnostics. Non-classical HLA molecules should also be considered in the development of antitumor directed vaccination - and future preclinical developments will target the identification of tumor-associated antigens presented by non-classical MHC-molecules to anti-cancer directed immune cells including the non-classical Major histocompatibility complex class I-related (MR1) molecule (178).

The presentation of non-peptide antigens by the cluster of differentiation 1 (CD1) family of molecules ( $a, b, c, d)$ - which is related to HLA class I - leads to activation of unconventional T-cell subsets, such as natural killer T-cells (NKT) (e.g. lipid antigens) and TCR $\gamma \delta$ T-cells (e.g. phosphoantigens), with CD1d being the most prominent member, expressed on epithelial cells - and epithelial cancer cells. Expression of CD1 molecules in cancer are associated with different clinical outcomes while associated with poor prognosis in renal cell carcinoma (179), CD1d promotes NKTmediated cytolysis of cancer cells in lung adenocarcinoma (180). A similar scenario exists for multiple myeloma and B-cell lymphoma, since CD1d is downregulated and associated with poor outcomes in contrast to higher CD1d expression levels in PBMCs from healthy individuals (181).

Nevertheless, neoantigen classes (and neoepitopes thereof) are limited to protein-based structures at this juncture due to their recognition by conventional HLA/TCR interactions involving $\mathrm{CD}^{+}$and $\mathrm{CD}^{+}{ }^{+}$-cells $(13,38,182)$. More research is necessary to project a more concise picture of the role of non-peptide entities, e.g. lipids and carbohydrates bearing cancer-associated molecular abnormalities in augmenting productive immune responses in patients. For example, overexpressed or aberrantly glycosylated carbohydrates (e.g. gangliosides) is now hailed as a CAR-T target to treat pediatric patients with solid tumors (183). Also, the recognition of several pathogen-derived carbohydrate structures by conventional T-cells has been previously reviewed (184). The clinical studies associated with such therapeutic approaches could provide a template for precision oncology methods e.g. investigating which sugar moieties harboring abnormalities would be recognized by specific T-cell subsets using NGS and immunological assays.

\section{ACCOUNTING FOR LYMPHOCYTE CLASSES IN PRECISION IMMUNOTHERAPY DESIGN}

Multimodal studies have shown that the local immune landscape as well as neoantigen expression are quintessential parameters in determining and driving clinical responses in patients with cancer
(13, 37, 185-188). Data from translational and clinical cancer immunotherapy studies collectively advocate for the development of 'composite lymphocyte grafts' comprising several immune-cell types interacting with a broad array of neoantigen profiles and subsequently a diverse set of effector functions with the unified aim to minimize disease progression, while eliminating existing cancer cell reservoirs in the patient $(189,190)$. Tumor infiltrating immune cells as well as tissue resident cells contribute to shape the immunological milieu, which is worthwhile to consider in precision immunotherapy protocols.

T-cells can be harvested and expanded for immunotherapy mainly from cancer tissue (TILs, inflamed tissue-derived cells), and/or PBMCs $(11,19,44,47,191-193)$, cells from pleural effusions may also serve to isolate tumor-reactive T-cells (194) as a possible $\mathrm{T}$-cell source, as well as immune cells from bronchoalveolar lavage (195), cerebrospinal fluid (196) or bone marrow aspirates (197). This biological material is a yet rather untapped source for future assessments in T-cell immunotherapy trials.

Not only the nature of the tissue specimen, yet also the different anatomical location of the T-cell harvest is critical if $\mathrm{T}$-cells are tested for recognition of neoepitopes, exemplified in Figure 4. Not only the frequency of $\mathrm{CD} 4 / \mathrm{CD} 8^{+} \mathrm{T}$-cells changes in relation from the tumor center to the tumor periphery, also the epitope target specificity changes, mutant KRAS reactive T-cells were detected in the tumor center, anti-mesothelin reactive T-cells were found in the tumor periphery. For clinical usage, it is important to emphasize that the location of the T-cell harvest has to be documented along with caution that different cancer tissue regions harbor different immune cell populations with different neoepitope specificities. While this is not surprising due to the tumor mutanome heterogeneity and consequent TCR diversity, it has to be taken into practical considerations as different areas of cancer specimens are harvested to expand TIL for cellular therapy. While TIL isolation and propagation for immunotherapy is feasible for some cancer types, patients with certain malignancies may present with cancer lesions that are - even with minimal invasive procedures or biopsies - very difficult to access (198). For those cases, PBMCs may be a viable and less invasive option, since peripheral blood T-cells are easily accessible and can be later used as a cell source for T-cell engineering to express a specific TCR or CAR $(199,200)$. HLA-matched donor-derived $\mathrm{T}$-cells from donor PBMCs reactive to patient-derived neoantigens also present a viable option for neoepitope directed cellular immunotherapy (21).

There is also a different source of T-cells that can be considered for anti-cancer directed cellular therapy and for screening of neoepitope-reactive T-cell population, namely tissue-resident memory T-cells (TRM), a population of nonrecirculating $\mathrm{CD}^{+}$T-cells, residing long-term in peripheral tissues. TRMs contribute to tumor surveillance and to protection against viral and bacterial infections (201, 202), TRMs express a variety of homing markers that allow them to recirculate in peripheral tissues, such as CD103 ( $\alpha$ e integrin) and CD49a (collagen-binding molecule antigen-1 (202-204), they 


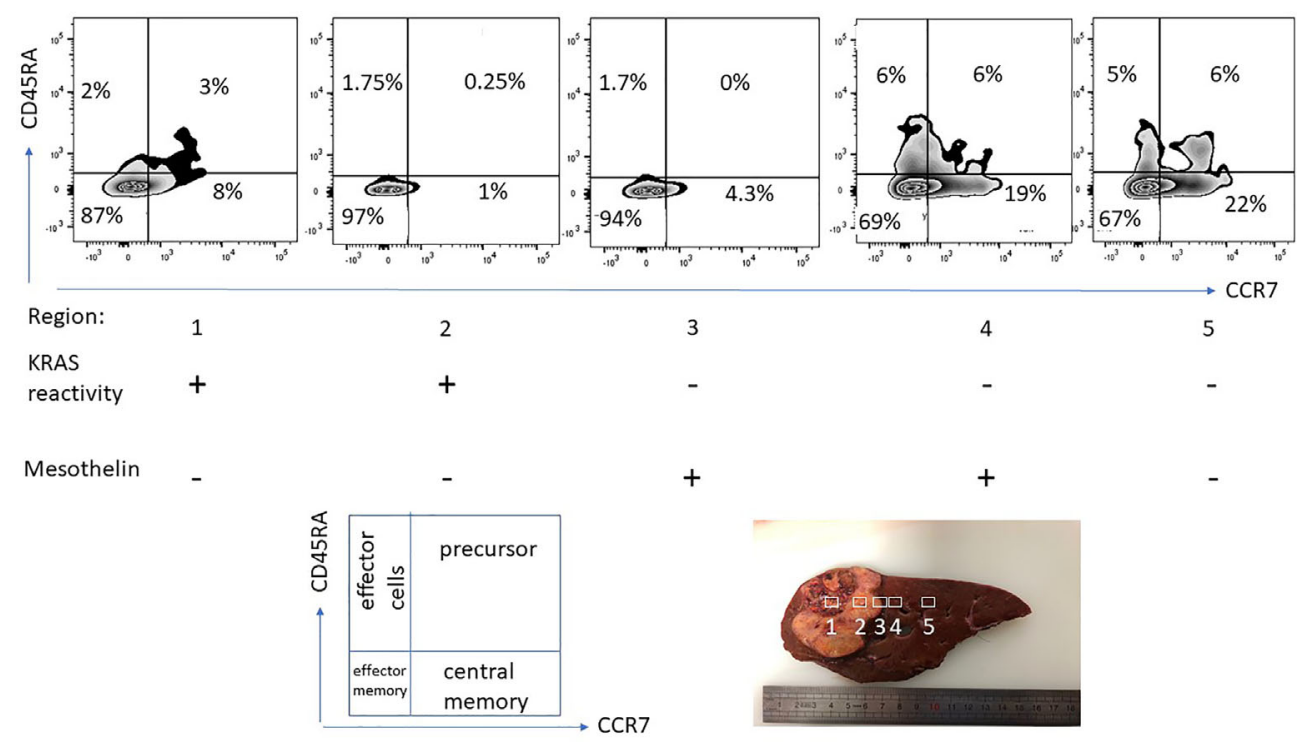

FIGURE 4 | T-cell phenotype and functional-spatial differences. TIL were expanded from different regions from a pancreas cancer lesion metastatic to the liver, 5 regions were harvested in different proximity to the tumor center. Note the different homing/maturation phenotype based on CD45RA/CCR7 expression, central memory T-cells in the tumor periphery. Thus, the quality of the T-cell response (to neoepitopes) is also associated with the immune cell maturation status. Reactivity to (mutant) KRAS or mesothelin was tested by pre-incubation of TIL for 5 days followed by IFN-gamma production analysis. Exclusive KRAS recognition in the tumor center versus mesothelin recognition in the tumor periphery and in macroscopically cancer-negative tissue demonstrating that the selection of neoepitope specific

T-cells depends on the anatomical location.

produce Th1-type cytokines, namely IFN- $\gamma$, tumor necrosis factor alpha (TNF- $\alpha$ ) and interleukin 2 (IL-2) upon stimulation (203, 205), yet may also elaborate Th17- or Th2-type cytokines (206208). The impact of TRM cells in tumor surveillance is also related to the fact that TIL that express TRM cellular markers have been identified in several human solid cancers (209-215) often in correlation with improved clinical outcome (216-220). Therefore, the presence of homing markers and TRM cells among TIL, in addition to the tumor localization from where TIL are being expanded merit more attention in clinical studies pertaining to their role in neoantigen recognition, tumor surveillance and the selection of TIL for improved cellular immunotherapy.

\section{CONVENTIONAL CD4 ${ }^{+}$AND CD8 ${ }^{+} \mathrm{T}^{-C E L L S}$}

T-cells bearing the conventional TCR $\alpha \beta$ have been associated with augmenting clinical responses in patients receiving immunotherapy - both cell-based (191) and immune checkpoint inhibitors (221) and, more recently, personalized vaccines $(78,222)$. Both $\mathrm{CD}^{+}$and $\mathrm{CD} 4^{+}$neoantigen-specific TCR $\alpha \beta$ responses in hard-to-treat cancers such as glioblastoma $(14,72)$, pancreatic malignancies (18), non-small-cell lung cancer (2, 3), melanoma $(69,76)$, bile duct $(40)$ and colorectal cancers $(41)$ are now regarded as vital to promote durable clinical responses in patients, further to the presence of suitable neoepitope restricting HLA elements (27, 223). Much focus has been placed on $\mathrm{CD}^{+}$TILs in mediating antitumor activity due to their cytotoxic capacity and responsiveness to immune checkpoint blockade in view of their neoantigen-directed immune reactivity (224). In contrast, $\mathrm{CD} 4^{+} \mathrm{T}$-cells are largely attributed with helper functions, i.e., production of effectors cytokines, such as IFN- $\gamma$ and TNF- $\alpha$ while responding to stimuli provided by IL-2, IL-6, interleukin 18 (IL-18), and IL-1 $\beta$ to list a few. Nevertheless, the cytotoxic activity of some tumor-directed CD4 ${ }^{+}$ $\mathrm{T}$-cell subsets is now considered an important arm of the MHC class II restricted immune defense (174), particularly in patients with a defective HLA-I pathway. Further to autologous TCRs, allogeneic T-cells from HLA-matched healthy donors can either naturally react to - as part of the naturally occurring TCR repertoire neoepitopes or they can be specifically selected and re-programmed to specifically react to neoepitopes and kill cancer cells without overt off-target toxicity $(21,225)$. Past and emerging studies consolidate the utility of conventional T-cells as sources of TCRs strongly reactive to peptide-HLA complexes based on the best-fitting epitopes to transduce PBMCs for developing possible 'off-theshelf TCRs options for patients with cancer expressing distinct tumor-associated antigens and sharing the respective restricting MHC allele (41, 226-230).

\section{NON-CONVENTIONAL T-CELLS: TCR $\gamma \delta$ AND INVARIANT NKT-CELLS}

The relevance of TCR $\gamma \delta$ T-cell subsets has received a substantial deal of attention in the last decade owing to clinically meaningful observations of anti-cancer reactivity in several cancer types (231-236). In patients with malignancies showing a defective 
HLA system, TCR $\gamma \delta$ T-cells may have the upper hand in immune recognition as they do not need the classical antigen presentation machinery for antigen recognition and activation (237). TCR $\gamma \delta \mathrm{T}$ cells participate in a wide array of immunological processes which can activate or dampen the ensuing $\mathrm{T}$-cell response, including the production of IL-17 which has been implicated in the pathogenesis of inflammatory disease as well as cancer (238-241). While several different gamma chains are known, two main delta chains have been described in humans TCR $\gamma \delta$ T-cells, namely $\mathrm{V} \delta 1$ and $\mathrm{V} \delta 2$, although ${\mathrm{V} \delta 3^{+}}^{+} \mathrm{T}$-cells have been isolated from the liver (238, 242). As mentioned earlier, an important feature of TCR $\gamma \delta$ cells is their expression of natural cytotoxicity receptors (NCRs), which are also present on NK-cells, namely NKG2D, NKp30 and DNAM$1(243,244)$. The most commonly occurring subclass of these cells are those expressing the V $\gamma 9 \mathrm{~V} \delta 2$ TCR which, via NKG2D, can bind to the HLA class I-like molecules MICA/B, akin to NK cells (244). Daley and colleagues recently showed that $\gamma \delta$ T-cells outnumber $\mathrm{CD}^{+} \mathrm{T}$-cells in human pancreatic adenocarcinoma tissues, and potentially dampen the anti-tumor activity of conventional TCR $\alpha \beta$ T-cells (245). Although anti-tumor $\gamma \delta$ T-cell subsets expressing TCR $\mathrm{V} \gamma 9 \mathrm{~V} \delta 2$ comprise a very small percentage in the tumor microenvironment, approximately $30 \%$ of circulating $\gamma \delta \mathrm{T}$-cells expressed $\mathrm{V} \gamma 9$. Apart from these, $\mathrm{V} \delta 1^{+} \mathrm{T}$-cell subsets have been shown to mediate productive immune responses against gastrointestinal tumors $(246,247)$, and are likely to be important players - in addition to the much studied $\mathrm{V} \gamma 9 \mathrm{~V} \delta 2$ subset - in developing cellular immunotherapies for cancer (238).

In addition to TCR $\gamma \delta \mathrm{T}$-cells, invariant natural killer (iNKT)-cells - bearing the invariant TCR V24 $\alpha$ chain may also be relevant in recognizing neoepitopes in cancer (248). Alpha-galactosylceramide-driven activation of iNKT-cells (afore-mentioned CD1d-mediated antigen presentation) in patients with solid tumors has resulted in stable disease and detectable immune responses, including in protocols involving DCs pre-activated with alpha-galactosylceramide prior to infusion into patients (248-250). iNKT-cells can also exhibit cytolytic activity akin to NK-cells and cytotoxic $\mathrm{CD} 8^{+} \mathrm{T}$-cells, requiring the NCRs NKG2D and NKp44. Considering the characteristics of 'non-conventional' T-cells and clinical studies that support their individual use in immunotherapy (251), the combination of these immune cells with $\alpha \beta$ T-cells should be considered in order to augment anti-cancer directed $\mathrm{T}$-cell responses.

While isolation and cultivation of autologous T-cells from patients with cancer is a tailor-made drug development strategy, it is also time-consuming and can only cater for a limited number of patients at a time. Importantly, not all patients qualify for surgery and tumor biopsies are not always sufficient for TIL propagation after allocation for histopathological analysis. Therefore, TCRs from peripheral blood T-cells - recognizing shared or common cancer mutations - can be used to generate a cellular product generation with heterologous expression in patient T-cells. This approach has been shown to be successful in a patient with metastatic colorectal cancer who received an HLA-Cw08*02-restricted TCR targeting the $\mathrm{KRAS}_{\mathrm{G} 12 \mathrm{D}}$ driver mutation (41). An integrated approach using NGS and immunology may be able to identify new neoantigens which are shared among certain patient groups to be adapted for developing transgenic TCR-based cellular drugs. The use of mucosal associated invariant T-cells (MAIT) and their respective targets for the potential use in personalized therapies is not discussed here.

\section{B-CELLS}

Unlike T-cells, B-cells have received the least attention although emerging evidence suggests that they should be accounted for in future treatment regimens due to their association with beneficial anti-tumor responses, including the production of cancer antigen-specific antibodies (252-254). TIB (tumor infiltrating B-cell) mediated responses, visualized by antibodies recognizing KRAS mutations, have been described in patients with pancreas adenocarcinoma (PDAC) (255), highlighting their clinical utility in anti-tumor immune responses. NGS platforms can supplement innovations in surgical oncology by the use of fluorescently-labelled antibodies and imaging to precisely mark the specific location of cancer disease for resection in the patient (256) coupled with in vitro laser microdissection of specific intratumoral regions of interest by identifying areas which are likely to represent varying mutational cancer profiles and matching $\mathrm{T}$ cell reactivities (257). New data has revealed that an intact B-cell compartment in patients with advanced melanoma undergoing immune checkpoint blockade therapy (anti-PD-1, anti-CTLA-4 or both) are predictive of improved patient survival, given that no immune-related adverse events (irAEs) occur (258). This observation was associated with an increased proportion of circulating $\mathrm{CD} 21^{+} \mathrm{B}$-cells and plasmablasts after therapy. Also, the role of antibodies in the recognition of cancer-specific mutated proteins such as KRAS (255) as well as CMV- and EBV-derived epitopes in the TME (259) and carbohydrates (183) cannot be dismissed and warrant deeper insights in clinical studies examining the role of TIBs in immune-recognition and immunomodulation in the tumor. Antibodies binding to neoantigens of interest can be used for designing CARs, provided these neoantigens are expressed on the tumor-cell surface (e.g. MUC4), for which TCRs in blood were recently described (44). Waltari and colleagues recently showed how combining NGS and immunoassays platforms, while incorporating RNA-Seq and downstream bioinformatics analysis followed by in vitro stimulation with $\mathrm{CpG}$ and clonal expansion, can help identify and isolate memory B-cells from blood with B-cell receptors (BCRs) for a specific antigen in association with protection from disease which, in this case, was influenza (260). A more recent study reported the use of RNAbased Repertoire and Gene Expression by Sequencing (RAGESeq) that was able to identify BCR and TCR species circulating in blood of a patient with breast cancer that facilitated the tracking of lymphocyte populations in different tissue compartments (261). Thus, novel innovations in NGS techniques may also aid the discovery of distinct neoantigen- and tumor-reactive lymphocytes with clinical applicability. Neoepitope vaccination strategies may also induce mutation-specific antibodies in 
antigen-driven expansion of B-cells that may also produce anticancer directed cytokines (262), functional TIB (263) that are associated with increased survival $(264,265)$ have been shown to produce antibodies that target TAAs, including mutant KRAS molecules (255). Thus, neoepitope-based vaccination immunomonitoring should also include screening of vaccine peptidespecific humoral immune responses in the peripheral circulation as well as in TIL, even if the vaccine peptides are designed for MHC class I or -class II binding.

\section{Laboratory-Based Platforms to Complement NGS and Facilitate Personalized Immuno-Oncology}

A close collaboration with the pathology unit at healthcare facilities and allowing their active involvement in all phases of the clinical trial is crucial. Routine as well as specialized immunohistology panels can be designed to aim at analyzing HLA profiles in patients with cancer before, during and after immunotherapy. Furthermore, antibodies that can differentiate between misfolded and native HLA class I molecules on paraffinized tissue samples would be an immense advantage, since aberrant HLA class I molecules on the surface of tumor cells are likely to be missed by $\mathrm{CD}^{+} \mathrm{T}$-cells. Reagents that recognize all components of the HLA class I pathway such as TAP $(151,266)$, tapasin, $\beta 2$-microglobulin-free HLA-A variants (151, 267, 268), LMP2/7 (151) and $\beta 2$-microglobulin (151) have been described before, while those that recognize HLA class II components are also commercially available. In addition, immunostaining panels for histology, encompassing mutant epitopes of cellular proteins which can identify cancer cells and indicate whether druggable mutations are present in cancer tissue would be of great clinical value. Expression of the TNFrelated apoptosis inducing ligand (TRAIL) molecules on the surface of cancer cell may also be a good indicator of their sensitivity to treatment-induced apoptosis (269). This approach may, in fact, serve as a means of 'companion diagnostics' to facilitate mutation-directed T-cell therapies. Circulating tumor cells (CTCs) that may be present in liquid biopsies can also be purified for immunocytochemistry (270-272). Two newly published reports describe how stable HLA molecules with an empty epitope-binding groove can be customized to bind peptides of interest and leveraged to screen for the best-fitting epitopes which induce an immune response $(273,274)$. Indeed, all of these methods could be exploited to screen for best-fitting neoepitopes using information arising from immunohistology and NGS data and obtain a better personalized anti-cancer vaccine and/or another treatment type, that may include preincubation of TILs with neoepitopes (to increase the frequency of TIL against mutant peptides). Multiparametric flow cytometry constitutes an integral part of screening for cellular immune responses and their physiological status is an addition to qualifying them for release as cellular products for personalized immunotherapy $(55,275)$. A wider panel of flow cytometrycompliant antibodies which can assess lymphocyte subsets present in cancer tissue based on phenotype and physiological status (e.g. exhausted vs. active, cytotoxic potential, type of recognition including $\mathrm{MHC}$ class $\mathrm{I} / \mathrm{II}, \mathrm{CD} 1, \mathrm{MIC1A} / \mathrm{B}, \mathrm{MR} 1$ restricted T-cells) prior to processing for cell culture would be an immense addition to clinical immunotherapy protocols (Table 1), augmenting findings from immunohistology analysis of tumor tissue. A dynamic set of flow cytometric analysis panels for further characterization of cellular products over the course of immune cell expansion for adoptive therapies will be of practical help, linked with immunohistology data from the resected tumor specimen. Ideally, functional T-cell data either from ex vivo expanded T-cells for adoptive therapy, or T-cell data obtained during immuno-monitoring in the context of peptidebased vaccination will yield extended information which can be amalgamated to the IHC data. Recent studies show that TP53 and KRAS mutations increase the expression of PD-L1 on tumor cells $(276,277)$, indicating that the presence of shared mutations can also be used as a companion diagnostic readout in personalized immunotherapy protocols.

\section{PEPTIDE-HLA STABILITY ASSESSMENT}

In addition to predicted HLA-matched neoepitopes, the use of an effective in vitro assay to measure the strength of peptide binding and stability may be able to improve the decision-making in selecting the most suitable neoantigens for personalized vaccine design. The measurement of the stability and half-life dynamics (also referred to as the 'off-rate'), which informs of how long a given peptide sequence can bind to the groove of the HLA molecule, was previously shown in the context of the TAA survivin (278), Mycobacterium tuberculosis protein TB10.4 (279, 280), HIV-1 epitopes (281), HA-1His autoantigen (282) and recently using $\mathrm{HLA}-\mathrm{B} 07^{\star} 02$-restricted myeloperoxidase (MPO) epitopes (226), allowing for the selection of strong binders capable of inducing optimal $\mathrm{T}$-cell recognition and cytokine responses and/or cytotoxicity $(283,284)$. The half-life of the peptide-HLA complex class I/II constitutes an important parameter in dictating immunogenicity - the duration of time for which the peptide-HLA complex can be stably be expressed on the surface of the APC (including transformed cells) and evoke a strong $\mathrm{CD}^{+}$or $\mathrm{CD}^{+} \mathrm{T}$-cell response $(281,283,285-288)$. A recent study demonstrated that the stability of the peptide appears to be a better correlate of immunogenicity than affinity (287), and this may suggest that highly stable epitopes (those with a long half-life) can have a very strong affinity for their cognate HLA allele $(283,284$, 289). The evaluation of peptide recognition defined by IFN- $\gamma$ production - as a result from tumor mutanome analysis either in the format of synthetic peptides or as minigenes - can be used to gauge for biological activity in TIL as proficiency assay to gauge for $\mathrm{T}$-cell reactivity against commonly strongly expressed mutant or non-mutant tumor associated antigens (290).

The absence of IFN- $\gamma$ in the TIL culture supernatants from assays probing antigen reactivity does not necessarily imply that the predicted peptides do not induce any type of effector response by the candidate testing $\mathrm{T}$-cells. For instance, matching TCR-HLA immune synapses may also lead to cytotoxicity instead of cytokine production, which can be 
TABLE 1 | Lymphocyte markers for use in IHC and flow cytometry studies to support clinical decision making in personalized cancer immunotherapy.

\begin{tabular}{|c|c|c|c|}
\hline Lymphocytes & Standard Analysis & Additional & Remarks \\
\hline $\begin{array}{l}\text { T-cells (TCR } \alpha \beta, \text { TCR } \\
\gamma \delta, \text { NKT, MAIT cells) }\end{array}$ & 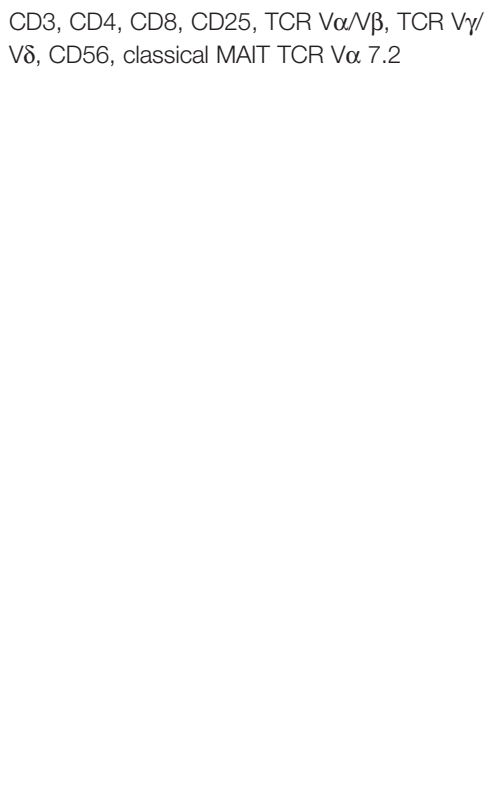 & 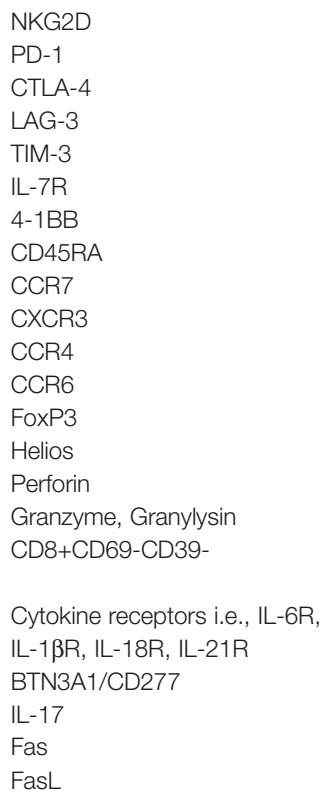 & $\begin{array}{l}\text { To assess the T-helper phenotype and tissue-penetration } \\
\text { capacity of T-cells } \\
\text { Transcription factor upregulated in activated T-cells and Tregs } \\
\text { Aids in Treg identification } \\
\text { Cytolytic effector molecule } \\
\text { Apoptosis-inducing effector molecule } \\
\text { CD8+ TIL with stem cell like properties and a CD69/CD39- } \\
\text { phenotype are associated with response to therapy } \\
\text { For T-cell activation by APCs, and may help identify high- } \\
\text { affinity antigen-specific cells } \\
\text { Antigen presentation to } \gamma \delta \text { T-cells } \\
\text { Can be useful as a marker for potentially pathogenic } \gamma \delta \text { T-cells } \\
\text { Involved in apoptosis induction }\end{array}$ \\
\hline $\begin{array}{l}\text { B-cells (also act as } \\
\text { APCs) }\end{array}$ & CD19, CD20 & $\begin{array}{l}\text { CD21 } \\
\text { FasL } \\
\text { Fas } \\
\text { HLA class I pathway } \\
\text { components } \\
\text { HLA class II pathway } \\
\text { components } \\
\text { BTK }\end{array}$ & $\begin{array}{l}\text { May have positive prognosis for patients with cancer } \\
\text { Involved in apoptosis induction } \\
\text { HLA alleles, TAP, tapasin, LMP2/7, } \beta 2 M \text {; to predict response } \\
\text { to immunotherapy } \\
\text { HLA-DR/DMADMB/DOA/DOB; to predict response to } \\
\text { immunotherapy } \\
\text { Bruton tyrosine kinase; may impede anti-tumor responses }\end{array}$ \\
\hline
\end{tabular}

determined by measuring surface CD107a induction or Fas expression. Production of granulocyte-macrophage colonystimulating factor (GM-CSF) in lieu of cytotoxicity by $\mathrm{CD}^{+}$ T-cells has been shown in the context of HLA-A1-restricted melanoma epitopes (291). The absence of cytokine production may also stem from the fact that the predicted neoepitope is not naturally processed and presented to the immune system. Alternatively, some of the TCRs which may recognize predicted peptides are present in the general TCR repertoire of the patient but they may not be present in the tissue sample harvested to test for T-cell recognition of the predicted epitopes. For instance, TIL may represent a rather focused and antigenspecific enriched TCR repertoire $(29,292)$ and PBMCs from a standard blood draw represent usually $2 \%$ of the entire T-cell pool. One of the 'gold' standards in gauging anti-neoepitopespecific T-cell responses is certainly whether peptide-reactive T-cells - after sorting by tetramers, IFN- $\gamma$-capture or by using activation markers (e.g. CD137)-are able to recognize the patient's own tumor cells. This would strongly argue that epitope-specific T-cells recognize as well naturally processed and presented peptides - and that the selected candidate epitopes are biologically relevant. A different 'reversed' procedure is the repetitive stimulation with autologous tumor cells and the subsequently enriched T-cells are then tested for epitope specific reactivity (18).

\section{'REAL WORLD' DATA: APPROACH AT THE CHAMPALIMAUD CLINICAL CENTRE}

The points discussed above guide the immunotherapy program at the Champalimaud Foundation termed 'ImmunoSurgery' to underline i) the seamless connection with the surgical team and the subsequent examination of the resected tissue specimens from a clinical pathologist. The tissue used to produce TIL - and to perform tumor exome sequencing - requires documentation and histopathological information about the functional locoregional diversity of the T-cell infiltrate into the tumor tissue which can be further assessed by deep TCR sequencing, ii) that $\mathrm{T}$-cells expanded from surgical specimens are tested for neoepitope specificities as defined by tumor mutanome analysis and represent a 'biological knife'.

The workflow used for tissue procurement, neoepitope identification and T-cell screening is provided in Figure 5, factors that may impact on the nature of neoepitopes, neoepitope generation and factors shaping the responding T-cell repertoire are compiled in Figure 6. Tumor-epitope identification by WES and RNA-Seq is guided by careful selection of the tumor area for genetic analysis. A more recent excellent review addressed the clinical utility of neoantigen identification, peptide processing and $\mathrm{MHC}$ presentation of candidate epitope targets for rational vaccine design (119). Ideally, a tumor area that shows more than 
$80 \%$ of transformed cells is selected (Figure 7). In order to better define the tumor specimen, a standard analysis for the immunecontexture is carried out at our institution. A general (HLA-A, B and C) MHC class I loss would exclude patients from entering into peptide vaccination trials. $\mathrm{CD}^{+}, \mathrm{CD}^{+}{ }^{+}$and $\mathrm{CD} 8^{+} \mathrm{T}$-cells are being described along with the presence of $\mathrm{CD}^{+} 8^{+}$macrophages, the presence of MHC class I antigens (HLA-A, B and C), the presence of HLA-DR, the expression of tumor-associated antigens (e.g. NYESO-1, mesothelin or survivin) to test for T-cell responses directed against non-mutant target antigens, as well as molecules associated with immune-suppression/evasion (e.g. PD-1, PDL-1 and CD47) along with the description if immune cells reside within the tumor or rather around, as single cells, or in clusters (Figure 8). The immune microenvironment imposes a strong pressure in untreated non-small-cell-lung cancers that subsequently show different routes of immune evasion. Different qualities of immune cell infiltration are associated with immune-editing (and therefore the diversity of neoepitopes available for T-cell expansion), MHC loss and defects in the antigen processing and presentation pathways (293). This may be differently associated with distinct tumor locations, ideally, parallel immunohistological sections are selected for WES and RNA-Seq. We combine different platforms to identify mutations in tumor exome data, combining the results of four different tools [Mutect2 (294), Varscan2 (295), Strelka2 (296) and Lancet (297)] and keep only mutations that are identified by at least two of these platforms. pVACtools takes results from the exome sequencing, complemented with mutations and fusions found in the transcriptomics data set which is then combined with several prediction algorithms resulting in a consensus ranking of neoantigens based on four criteria: rank of peptide binding affinity to the nominal MHC allele, rank of fold change between mutant and wild-type alleles, rank of mutant allele expression and the rank of DNA variant allele fraction (298). We test routinely two peptide formats to screen for cancer associated antigens in TIL or in PBMCs, namely i) peptides with 15 residues where the mutation is centered (and 7 amino flanking the mutation) or ii) the full downstream protein sequence in case of a frameshift. These different formats are used for immunoassays to gauge for INF- $\gamma$ production in a 96-well format and supernatants are harvested at days 3 and 7 (see Table 2 for references). Peptides

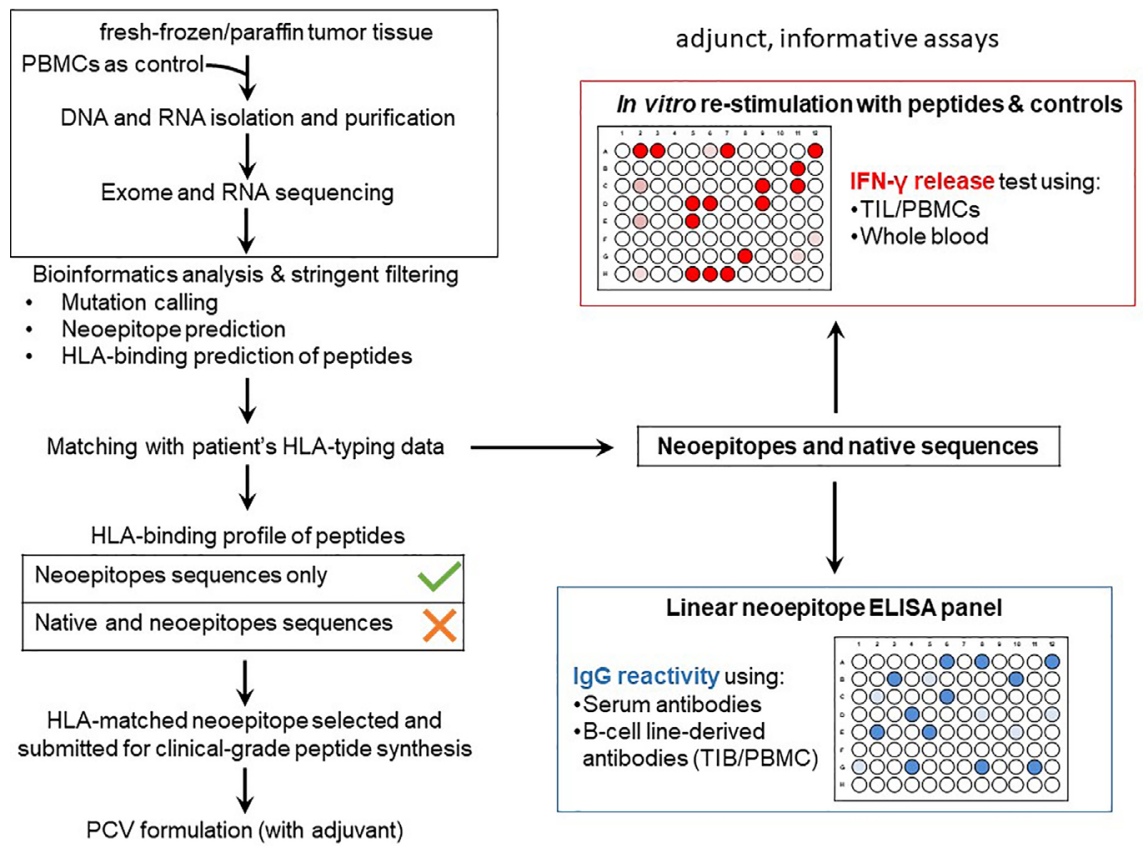

FIGURE 5 | PCV development and immuno-analyses workflow at the ImmunoSurgery Unit. Formalin-fixed paraffin-embedded (FFPE) or fresh-frozen tissue samples prepared by the Pathology Unit at the CCC is submitted for WES of tumor DNA with the patient's PBMCs as an internal control for downstream analysis, RNA-Seq is also sometimes performed to tumor RNA. The WES and RNA-Seq raw data is then analyzed at the ImmunoSurgery Unit at the CCU to predict private mutations followed by HLA class I and II binding prediction matched to the patients' HLA restriction profile to select candidates for inclusion in the PCV formulation. Only HLAbinding, neoepitope-containing peptides but not the wildtype counterparts are considered. The same and also 15-mer equivalent but non-clinical grade peptides, alongside the corresponding native sequences, are used for gauging TIL and/or PBMCs reactivities based on IFN- $\gamma$ production (the peptide is at a concentration $1 \mathrm{ug} / \mathrm{mL}$ tested with $10 \mathrm{e}^{4}$ responder T-cells; the fixed T-cell number allows to compare results obtained at different timepoints or from tissues harvested from different tumor areas). This part of the immunological evaluation of the neoepitopes is used in the follow-up phase of the trial which aims to assess T-cell responses of patients to the PCV and TIL therapies (possibly also for patients receiving immune checkpoint inhibitors). A different platform is an ELISA panel comprising the patient's neoepitopes in linear format to assess IgG reactivity using antibodies from serum as well as those secreted by TIB and PBMC-derived B-cell lines. Neoepitopes are also screened for TIL recognition since TIL are routinely generated to gauge for differences in TIL versus PBMC recognition. This will allow to describe whether selected neoepitopes are recognized in the tumor lesion that was used to identify the tumor neoepitopes (by NGS), it also allows to screen for differences in TIL recognition from tumor lesions harvested at different anatomical sites or at different timepoints in the course of the disease. 


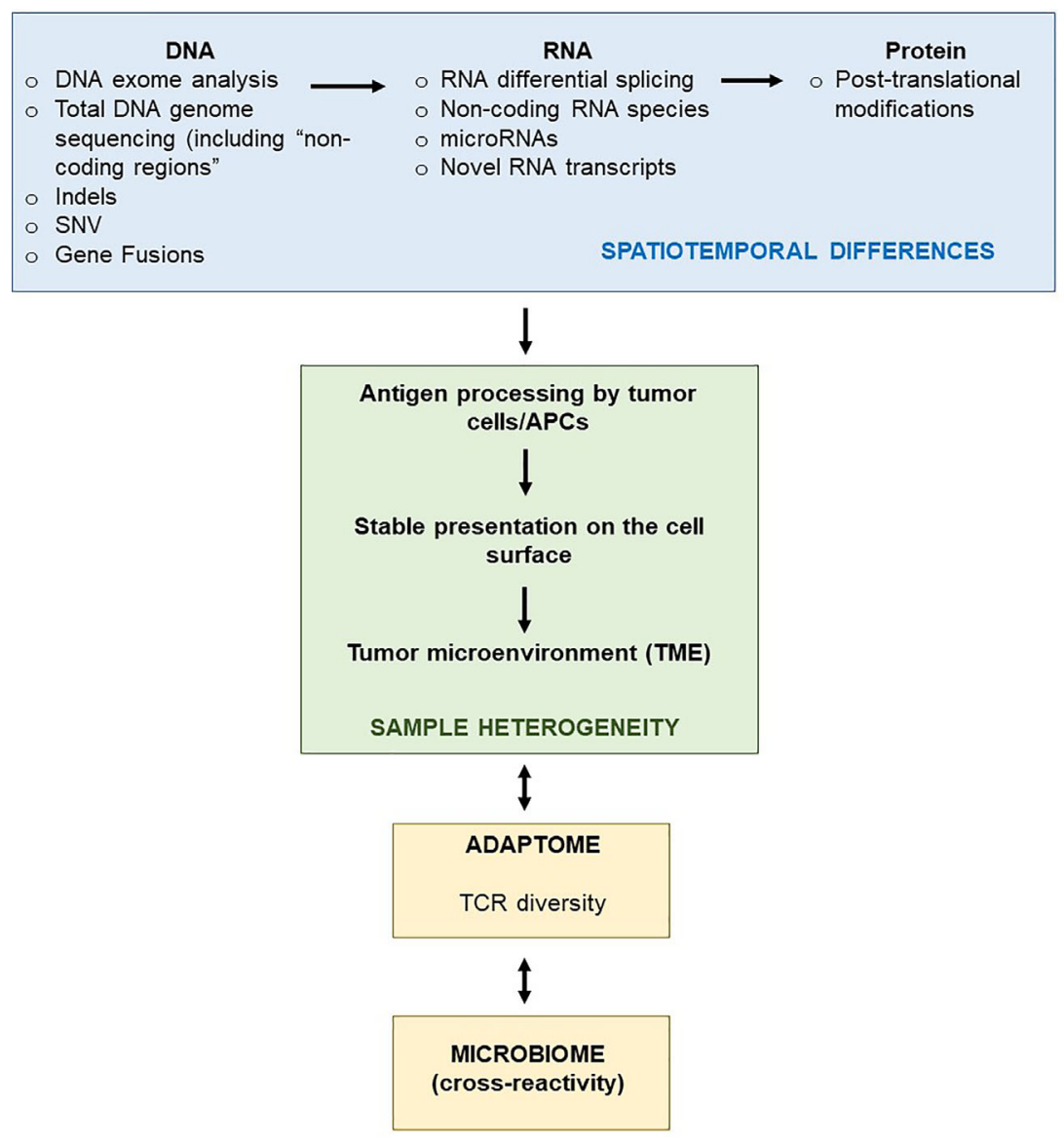

FIGURE 6 | Schematic representation of the general molecular paradigm of neoantigen recognition in the TME. The process of transcription of DNA to RNA and then to protein (antigens) is prone to generate heterogeneity in the context of cancer, i.e., the same DNA molecule may be differentially transcribed (due to RNA alternative splicing or mutations) and then translated to different proteins isotype (also as a result of post-translation modifications) or there might be gene fusions that result in novel RNA transcripts. The heterogeneous expression of tumor antigens, as a result of spatial-temporal differences in DNA to antigen production, results in different antigens being presented to the immune system by HLA complexes (as well as whole antigens) at the cell surface of a tumor cell and, therefore, contributing to different sub-regional TMEs within the same tumor tissue sample. These are likely to be neoantigens, as they are not present in healthy (non-transformed) tissue. The TCR diversity ("adaptome") will also change depending on the specific TME, i.e., different TCRs will be encountered depending on intratumoral spatial differences. Along the same lines, molecular structures associated with the microbiome present in the tumor tissue may cross-react with some T-cells, depending on the presence of absence of TCRs that recognize such microorganisms. The possible cross-reactivity, if present, may favor the expansion of the relevant immune-cell populations and, therefore, change the TCR repertoire.

of different lengths tailored according to the MHC typing of the patient are selected for candidates for PCVs based on i) if they are driver mutations, ii) strong expression in RNAseq, iii) superior binding of the mutant epitope as compared to the wildtype sequence, iv) frameshift mutations and v) practical considerations concerning peptide synthesis. If there are obvious different areas in the tumor specimen (Figure 7), micro-dissection of such areas is considered to estimate differences in tumorheterogeneity. We are currently testing whether neoepitope directed $\mathrm{T}$-cell responses are different in the primary cancer lesion as compared to metastatic lesions - that are usually harvested at a later time point during the cancer disease. Recognition analysis of MHC class I or -class II restricted epitopes defined by IFN- $\gamma$ production in PBMCs versus TIL as a predictor of which neoepitopes are most likely immunogenic and also lead to clinically relevant responses in the course of a peptidebased vaccination strategy can only be tested in a phase I clinical trial that is currently being prepared.

In general, the resected cancer specimen is the result of already immuno-edited cancer cell clones, areas of potential neoantigen depletion and clinical tumor progress, despite the presence of immune infiltrates (24). The timing of cancer lesion harvest is also clinically relevant in the context for vaccination, if we presume that the landscape of tumor mutations within the same tumor lesion, and also at different spatiotemporal lesions, represents an active process between cancer evolution and the immune system. Not only tumor cells may be edited, also the available T-cell repertoire undergoes selective pressure. Timing of the tumor lesions for selection of vaccine epitopes determines the mutational burden, yet also the TCR repertoire that changes 


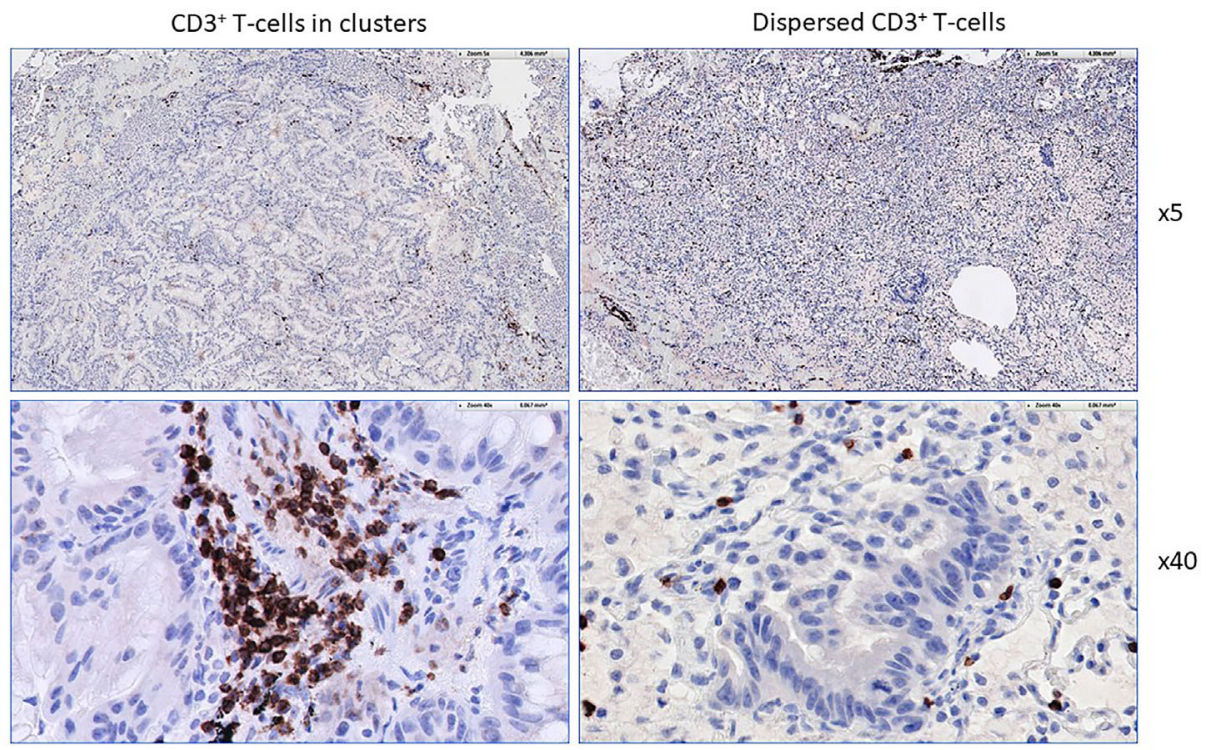

FIGURE 7 | Different immune-textures in cancer lesions. Starting point for WES and RNA-Seq. Definition and documentation of the immune cell infiltrate. Parallel slices of the paraffin-embedded tissues are procured and subjected to DNA and RNA analysis. Note the different patterns of CD3 ${ }^{+} T_{-}$-cell clusters (left) versus individual $\mathrm{CD}^{+} \mathrm{T}$-cells in close proximity to tumor cells. RNA isolated from this tumor section would also allow for deep TCR-sequencing and allow to trace back individual TCR CDR3 motifs in case if neoepitope specific TCRs are identified.
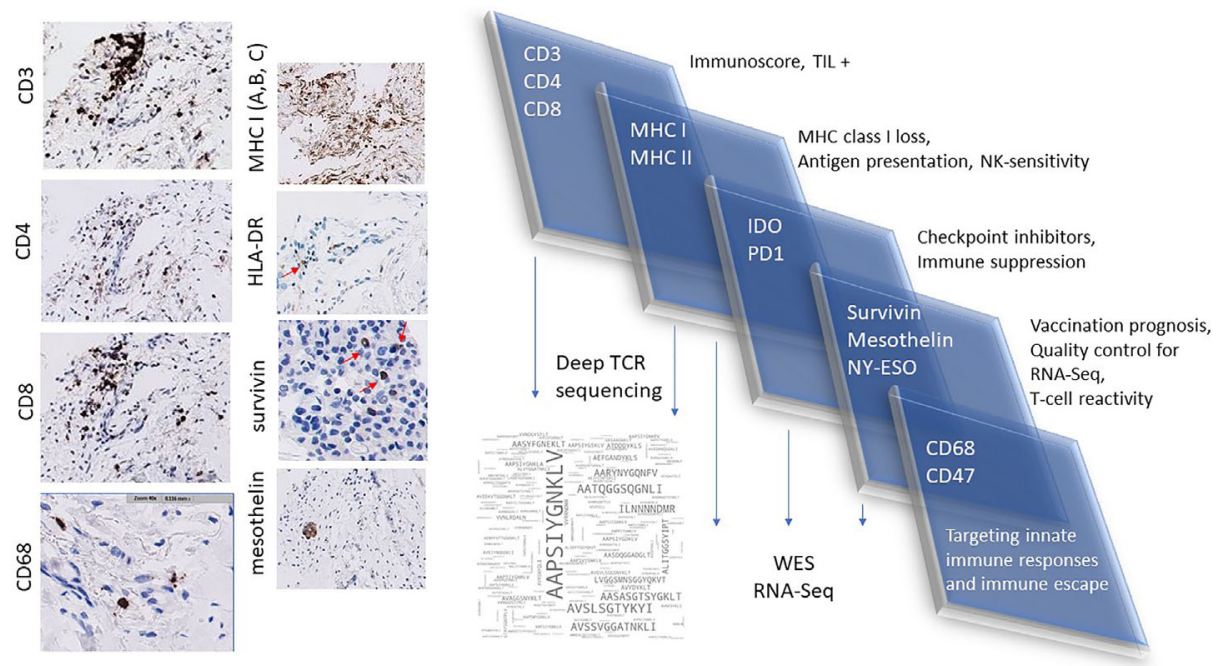

FIGURE 8 | Example of a standard immuno-histological analysis of a tumor sample at the Clinical Pathology Unit. Analysis of $\mathrm{CD}^{+}, \mathrm{CD}^{+}$and $\mathrm{CD} 8^{+} \mathrm{T}$-cell infiltrates along with tumor-associated CD68 ${ }^{+}$macrophages. Testing for MHC class I (HLA-A, B and C) expression to screen whether transformed calls can be recognized by $\mathrm{CD}^{+} \mathrm{T}$-cells, general MHC class I loss would not support vaccination strategies of adoptive T-cell therapy targeting TCR alpha/beta T-cells as the immune effector population. CD47, PD-1 and PDL-1 expression to gauge immune escape. Examination of commonly shared, non-mutant TAAs (NY-ESO-1, survivin, mesothelin) to identify T-cell responses in TIL and in corresponding PBMCs. Expression analysis of TAAs aids in quality control concerning RNA-Seq (of the corresponding gene coding for the TAA) and deep TCR analysis of T-cells reacting to TAAs.

over time (314). These very basic considerations bear very concrete consequences, i.e., usually tumor specimens are collected to choose mutant target epitopes in vaccine trials should be harvested for analysis after the most recent (standard) chemotherapy or immuno-therapy to reflect potential changes in the neoantigen landscape. Some of these practical considerations that are already currently discussed in clinical decision making or considered in future clinical trials are 
TABLE 2 | Examples of molecular analysis guiding future therapeutic decision making.

Analysis
WES or RNAseq
Mutations in
immunological
response genes,
i) e.g. induced by
radiation, ii) germline
mutations, iii) or
natural variants that
impact on immune
function.

CHIP analysis, WES and RNAseq

\section{Deep TCR sequencing}

TCRalpha, beta, gamma and delta chain. Bulk sequencing may be sufficient for most clinical questions. Single cell analysis possible. TCR infiltrate to objectively
Not only mutations in bona fide immune response genes, yet in cancer-associated genes, i.e. ARIDA, shape the quality of immune responses and $\mathrm{T}$-cell infiltration

\section{Examples of target genes}

Immune responses genes in innate or adaptive immune responses including immune cell signaling, e.g. C2, CD163L1, FC $\gamma R 2 A$

Detailed molecular description of describe the situation prior to therapy. Different TCR repertoires in spatiotemporal cancer lesions.
Potential biological and clinical effects

Gene variants or mutated genes edit immune infiltration, quality and quantity of the tumor-microenvironment

b
Despite identification of neoepitopes for neoepitope
vaccination therapy plus checkpoint inhibitors, the innate or adaptive immune response may be blunted. The anti-cancer vaccination effect may not be achieved due to the incapacity to mount strong Other therapeutic strategies are to be considered and cancer antigen specific immune response.

Reference

$(299,300)$
ARID1A aberrations may lead to differential chromatin accessibility and therefore to blunted anti-cancer directed immune responses, e.g. by reduction of overall IFN-gamma production, diminished immune cell infiltration and insufficient long- term immune memory responses.

A focused TCR repertoire can represent a relevant clonal immune response. Clonal immuno-editing may occur and lead to antigen - loss variants. 'Clonal replacement' appears to be associated with response to checkpoint inhibitors.
Epitope specific recognition defined by IFN or other cytokines in TIL from surgically removed tumor specimens and PBMCs

Immuno-

histology, RNA expression of commonly shared tumor associated antigens
Either 'private mutations' or commonly shared tumor associated antigens, i.e. NY-ESO1 , mesothelin, or common infectious pathogen antigens, e.g. EBV or CMV, provide a 'recognition fingerprint' to follow the immune response pattern in immunological therapies NY-ESO-1, survivin or mesothelin expression

Clonal spatiotemporal evolution in metastatic cancer lesions

bulk or single sequencing
Standard chemotherapy or immunological therapies shape the immune-competence to indicator targets (private antigens, TAAs or infectious disease targets).
Awareness that immunological treatment strategies may be challenging due to reduced IFN-gamma production. Detailed molecular analysis may aid to decipher how an effective anti-cancer directed milieu could be achieved without ARIDA1A interference

TCR convergence in PBMCs or tumor lesion (biopsies) and/or clonal convergence as companion diagnostics for immunological treatments.

Knowledge of neoepitope specific TCR allows to follow antigen-specific reactivities. Broader TCR repertoire may provide more possibilities to react to neoepitopes imposed by the structural constraints of the $\mathrm{MHC}$ - peptide complexes.

Long term neoepitope specific responses have been identified in patients with melanoma after peptide vaccination with different TCR clonotypes (directed against the identical epitope, this allows to link epitope-specific recognition with TCR diversity and functional avidity.

Loss of anti-EBV or CMV recognition in peripheral blood, or anti-tumor antigen directed T-cell responses may represent one factor in the complex decision making choosing second or third line treatment therapies.

Commonly shared TAA-vaccines, e.g. anti-survivin, mesothelin or NY-ESO-1 are available. Anti-Mesothelin CARs or transgenic TCRs. MHC class I or class IIrestricted NY-ESO-1 restricted TCRs are in clinical trials.

'Immuno-edited' tumor clones may be eliminated during the course of the tumor disease while progressing tumor clones are 'Immune-privileged' despite the presence of tumor-infiltrating lymphocytes. Neoantigen depletion was observed in tumors with high Immunoscore and spatial proximity between tumor cells and T-cells. Standard chemotherapy or immunotherapy may drive private mutations and clonal evolution: Treated metastases exhibit private 'driver'
Strong antigenic heterogeneity in solid tumors defined by neoepitopes may still allow to use the immunogenic cancer - testis antigen NY-ESO-1 if sufficiently expressed. Mesothelin CARs have shown to be associated with epitope spreading and induce T-cell responses against private antigens. Commonly shared TAAs may represent a cellular 'first line' treatment, enhancement possible with checkpoint inhibitors.

'Immuno-edited' tumor lesions may still be accessible to commonly shared TAAs. If neoepitope-directed therapies are contemplated, a 'fresh' tumor biopsy after chemotherapy or immunotherapy is advisable due to the tumor evolution in order to obtain the most 'updated' antigenic profile.

Private mutations bear the risk of chemoresistance. Obtain clinical material from the most recent cancer lesions to assess spatiotemporal differences of versus metastasis spatiotemporal differences. 
TABLE 2 | Continued

\begin{tabular}{|c|c|c|c|c|}
\hline Analysis & Examples of target genes & Potential biological and clinical effects & Potential practical consequences & Reference \\
\hline $\begin{array}{l}\text { Immunological } \\
\text { landscape } \\
\text { analysis, RNAseq } \\
\text { and/or immuno- } \\
\text { histology }\end{array}$ & $\begin{array}{l}\text { Cytokines, such as TGFbeta or } \\
\text { IL-17. }\end{array}$ & $\begin{array}{l}\text { mutations more frequently as compared } \\
\text { to untreated metastases. } \\
\text { TGFbeta may be strongly immuno- } \\
\text { suppressive, promote desmoplastic } \\
\text { changes in the TME that further inhibit } \\
\text { anti-cancer immune responses, IL-17 } \\
\text { may drive tumorigenesis. }\end{array}$ & $\begin{array}{l}\text { mutations in case if 'druggable' targets are } \\
\text { considered or neoepitope-directed therapies. } \\
\text { A strong immuno-suppressive TME may counteract } \\
\text { anti-cancer directed immunotherapies, e.g. neo- } \\
\text { epitope-directed vaccination. Anti-TGFbeta directed } \\
\text { therapies could be considered, either in the format } \\
\text { of monoclonal antibodies or - in the case of active } \\
\text { cellular therapies, gene-edited (TGFbeta-receptor) } \\
\text { negative T-cells. }\end{array}$ & $(313)$ \\
\hline
\end{tabular}

listed in Table 2 where we also list the impact of tumor mutations or mutations in immune response genes on anticancer directed immune responses. The list of immune response genes that are particularly scrutinized and reported in the course of a standard WES is listed in the Supplementary Data Set 1. Although a high mutational burden is generally viewed as beneficial to elicit clinically relevant tumor responses, this may be less accentuated if the tumor lesion is very heterogenous (3), also reflected in the 'hot' and 'cold' areas in the same tumor specimen (293). Also, a 'low' mutational burden does not necessarily imply that neoepitopes within a tumor lesions are not able to elicit biologically and clinically relevant $\mathrm{T}$-cell responses, as evidenced by glioblastoma-specific $\mathrm{T}$-cell expansion, discussed above, and that clonally expanded T-cells, even in 'low-mutational burden' tumors (e.g. rhabdoid tumors) show tumor-specific T-cell responses (315). The concordant analysis of the tumor-associated neoepitope landscape does not only allow to link immuno-histological detection of T-cell responses with mutational events, it also enables the spatiotemporal analysis of the molecular composition of the Tcell repertoire with tumor mutations. The TCR landscape, defined by deep TCR sequencing allows the identification of motifs in TCRs infiltrating into tumor tissue as compared to nontransformed tissue (292). A more detailed discussion of this topic is not subject of this review. Yet it may allow to validate although most likely not at this point in a routine fashion whether MHC-peptide specific clonal TCRs are present within cancer or tissue lesions by modeling T-cell MHC epitope specificity (316) using yeast-display libraries of MHC-peptide complexes tested for TCR recognition as shown for TIL in colorectal adenocarcinoma (317). This has also been confirmed for the identification of pathogen-specific epitopes - starting with T-cell receptor sequences (318). Thus, ex vivo identification of mutant epitope targets may be validated by the identification of the nominal TCR ligands modeling the TCR and MHC-peptide interaction which is beyond the scope of this review.

\section{CONCLUSIONS}

Prediction of the best neoepitope candidates for immunotherapy is a multistep process combining several technology platforms ranging from NGS to histopathology and cellular assays. The specifics of the predicted neoepitopes, e.g. defined by the interaction with the nominal classical or non-classical MHC molecules, play a central role in developing clinical products in designing PCVs or in gauging TIL reactivities in association with the spatiotemporal diversity. New findings from translational and clinical research efforts would need to account for different genetic backgrounds and TCR diversities in order to objectively describe differences in immune cells capable of reacting to tumor-associated antigens with the goal to advance personalized cancer immunotherapy to expand potential treatment modalities for patients with cancer.

\section{AUTHOR CONTRIBUTIONS}

EdS co-wrote the first draft and created figures. JL performed experiments and edited text. $\mathrm{AB}$ performed immunohistology. GP performed experiments. CCon performed experiments and wrote passages concerning T-cell subsets. JK and PA contributed to peptide vaccine overviews and edited. NF provided surgical specimens. CCar edited and conceptualized. MC-M edited and performed immunohistology. ZW edited and commented on TCR analysis. DL edited and commented on the HLA and NK part. MR wrote the first draft and combined the overall efforts for the review. MM initiated the work, wrote the final draft, and conceptualized the entire program concerning epitope-based vaccination. All authors contributed to the article and approved the submitted version.

\section{FUNDING}

This work has been funded by the Champalimaud Foundation.

\section{SUPPLEMENTARY MATERIAL}

The Supplementary Material for this article can be found online at: https://www.frontiersin.org/articles/10.3389/fimmu.2021.592031/ full\#supplementary-material 


\section{REFERENCES}

1. The Problem With Neoantigen Prediction. Nat Biotechnol (2017) 35:97. doi: $10.1038 /$ nbt. 3800

2. Rizvi NA, Hellmann MD, Snyder A, Kvistborg P, Makarov V, Havel JJ, et al. Cancer Immunology. Mutational Landscape Determines Sensitivity to PD-1 Blockade in Non-Small Cell Lung Cancer. Science (2015) 348:124-8. doi: 10.1126/science.aaa1348

3. McGranahan N, Furness AJ, Rosenthal R, Ramskov S, Lyngaa R, Saini SK, et al. Clonal Neoantigens Elicit T Cell Immunoreactivity and Sensitivity to Immune Checkpoint Blockade. Science (2016) 351:1463-9. doi: 10.1126/ science.aaf1490

4. Maleki Vareki S. High and Low Mutational Burden Tumors Versus Immunologically Hot and Cold Tumors and Response to Immune Checkpoint Inhibitors. J Immunother Cancer (2018) 6:157. doi: 10.1186/ s40425-018-0479-7

5. Smith KN, Llosa NJ, Cottrell TR, Siegel N, Fan H, Suri P, et al. Persistent Mutant Oncogene Specific T Cells in Two Patients Benefitting From AntiPD-1. J Immunother Cancer (2019) 7:40. doi: 10.1186/s40425-018-0492-x

6. Gandara DR, Paul SM, Kowanetz M, Schleifman E, Zou W, Li Y, et al. Blood-Based Tumor Mutational Burden as a Predictor of Clinical Benefit in Non-Small-Cell Lung Cancer Patients Treated With Atezolizumab. Nat Med (2018) 24:1441-8. doi: 10.1038/s41591-018-0134-3

7. Hellmann MD, Nathanson T, Rizvi H, Creelan BC, Sanchez-Vega F, Ahuja A, et al. Genomic Features of Response to Combination Immunotherapy in Patients With Advanced Non-Small-Cell Lung Cancer. Cancer Cell (2018) 33:843-852 e4. doi: 10.1016/j.ccell.2018.03.018

8. Alexandrov LB, Nik-Zainal S, Wedge DC, Aparicio SA, Behjati S, Biankin $\mathrm{AV}$, et al. Signatures of Mutational Processes in Human Cancer. Nature (2013) 500:415-21. doi: 10.1038/nature12477

9. Lu YC, Yao X, Crystal JS, Li YF, El-Gamil M, Gross C, et al. Efficient Identification of Mutated Cancer Antigens Recognized by T Cells Associated With Durable Tumor Regressions. Clin Cancer Res (2014) 20:3401-10. doi: 10.1158/1078-0432.CCR-14-0433

10. Andersen R, Donia M, Westergaard MC, Pedersen M, Hansen M, Svane IM. Tumor Infiltrating Lymphocyte Therapy for Ovarian Cancer and Renal Cell Carcinoma. Hum Vaccin Immunother (2015) 11:2790-5. doi: 10.1080/ 21645515.2015.1075106

11. Cohen CJ, Gartner JJ, Horovitz-Fried M, Shamalov K, Trebska-McGowan K, Bliskovsky VV, et al. Isolation of Neoantigen-Specific T Cells From Tumor and Peripheral Lymphocytes. J Clin Invest (2015) 125:3981-91. doi: 10.1172/ JCI82416

12. Tanyi JL, Bobisse S, Ophir E, Tuyaerts S, Roberti A, Genolet R, et al. Personalized Cancer Vaccine Effectively Mobilizes Antitumor T Cell Immunity in Ovarian Cancer. Sci Trans Med (2018) 10:eaao5931. doi: 10.1126/scitranslmed.aao5931

13. Thorsson V, Gibbs DL, Brown SD, Wolf D, Bortone DS, Ou Yang TH, et al. The Immune Landscape of Cancer. Immunity (2018) 48:812-30.e14. doi: 10.1016/j.immuni.2018.03.023

14. Valentini D, Rao M, Meng Q, von Landenberg A, Bartek J Jr., Sinclair G, et al. Identification of Neoepitopes Recognized by Tumor-Infiltrating Lymphocytes (Tils) From Patients With Glioma. Oncotarget (2018) 9:19469-80. doi: 10.18632/oncotarget.24955

15. Velcheti V, Kim ES, Mekhail T, Dakhil C, Stella PJ, Shen X, et al. Prospective Clinical Evaluation of Blood-Based Tumor Mutational Burden (Btmb) as a Predictive Biomarker for Atezolizumab (Atezo) in 1L Non-Small Cell Lung Cancer (NSCLC): Interim B-F1RST Results. J Clin Oncol (2018) 36:12001-1. doi: 10.1200/JCO.2018.36.15_suppl.12001

16. Yossef R, Tran E, Deniger DC, Gros A, Pasetto A, Parkhurst MR, et al. Enhanced Detection of Neoantigen-Reactive T Cells Targeting Unique and Shared Oncogenes for Personalized Cancer Immunotherapy. JCI Insight (2018) 3:122467. doi: 10.1172/jci.insight.122467

17. Zacharakis $\mathrm{N}$, Chinnasamy $\mathrm{H}$, Black $\mathrm{M}, \mathrm{Xu} \mathrm{H}, \mathrm{Lu} \mathrm{YC}$, Zheng Z, et al. Immune Recognition of Somatic Mutations Leading to Complete Durable Regression in Metastatic Breast Cancer. Nat Med (2018) 24:724-30. doi: 10.1038/s41591-018-0040-8

18. Meng Q, Valentini D, Rao M, Moro CF, Paraschoudi G, Jager E, et al. Neoepitope Targets of Tumour-Infiltrating Lymphocytes From Patients
With Pancreatic Cancer. Br J Cancer (2019) 120:97-108. doi: 10.1038/ s41416-018-0262-z

19. Liu S, Matsuzaki J, Wei L, Tsuji T, Battaglia S, Hu Q, et al. Efficient Identification of Neoantigen-Specific T-Cell Responses in Advanced Human Ovarian Cancer. J Immunother Cancer (2019) 7:156. doi: 10.1186/ s40425-019-0629-6

20. Jardim DL, Goodman A, de Melo Gagliato D, Kurzrock R. The Challenges of Tumor Mutational Burden as An Immunotherapy Biomarker. Cancer Cell (2021) 39:154-73. doi: 10.1016/j.ccell.2020.10.001

21. Stronen E, Toebes M, Kelderman S, van Buuren MM, Yang W, van Rooij N, et al. Targeting of Cancer Neoantigens With Donor-Derived T Cell Receptor Repertoires. Science (2016) 352:1337-41. doi: 10.1126/science.aaf2288

22. Lee C-H, Yelensky R, Jooss K, Chan TA. Update on Tumor Neoantigens and Their Utility: Why It Is Good to Be Different. Trends Immunol (2018) 39:536-48. doi: 10.1016/j.it.2018.04.005

23. Hu Z, Ott PA, Wu CJ. Towards Personalized, Tumour-Specific, Therapeutic Vaccines for Cancer. Nat Rev Immunol (2018) 18:168-82. doi: 10.1038/ nri.2017.131

24. Angelova M, Mlecnik B, Vasaturo A, Bindea G, Fredriksen T, Lafontaine L, et al. Evolution of Metastases in Space and Time Under Immune Selection. Cell (2018) 175:751-65.e16. doi: 10.1016/j.cell.2018.09.018

25. Kalaora S, Wolf Y, Feferman T, Barnea E, Greenstein E, Reshef D, et al. Combined Analysis of Antigen Presentation and T-Cell Recognition Reveals Restricted Immune Responses in Melanoma. Cancer Discov (2018) 8:136675. doi: 10.1158/2159-8290.CD-17-1418

26. Giannakis M, Mu XJ, Shukla SA, Qian ZR, Cohen O, Nishihara R, et al. Genomic Correlates of Immune-Cell Infiltrates in Colorectal Carcinoma. Cell Rep (2016) 17:1206. doi: 10.1016/j.celrep.2016.10.009

27. Cai W, Zhou D, Wu W, Tan WL, Wang J, Zhou C, et al. MHC Class II Restricted Neoantigen Peptides Predicted by Clonal Mutation Analysis in Lung Adenocarcinoma Patients: Implications on Prognostic Immunological Biomarker and Vaccine Design. BMC Genomics (2018) 19:582-2. doi: 10.1186/s12864-018-4958-5

28. Teku GN, Vihinen M. Pan-Cancer Analysis of Neoepitopes. Sci Rep (2018) 8:12735. doi: 10.1038/s41598-018-30724-y

29. Li B, Li T, Pignon JC, Wang B, Wang J, Shukla SA, et al. Landscape of Tumor-Infiltrating T Cell Repertoire of Human Cancers. Nat Genet (2016) 48:725-32. doi: 10.1038/ng.3581

30. Enfield KSS, Martin SD, Marshall EA, Kung SHY, Gallagher P, Milne K, et al. Hyperspectral Cell Sociology Reveals Spatial Tumor-Immune Cell Interactions Associated With Lung Cancer Recurrence. J ImmunoTher Cancer (2019) 7:13. doi: 10.1186/s40425-018-0488-6

31. Cioffi M, Trabulo S, Hidalgo M, Costello E, Greenhalf W, Erkan M, et al. Inhibition of CD47 Effectively Targets Pancreatic Cancer Stem Cells Via Dual Mechanisms. Clin Cancer Res (2015) 21:2325-37. doi: 10.1158/10780432.CCR-14-1399

32. Mantovani A, Marchesi F, Malesci A, Laghi L, Allavena P. TumourAssociated Macrophages as Treatment Targets in Oncology. Nat Rev Clin Oncol (2017) 14:399-416. doi: 10.1038/nrclinonc.2016.217

33. Ring NG, Herndler-Brandstetter D, Weiskopf K, Shan L, Volkmer JP, George BM, et al. Anti-Sirpalpha Antibody Immunotherapy Enhances Neutrophil and Macrophage Antitumor Activity. Proc Natl Acad Sci USA (2017) 114:E10578-85. doi: 10.1073/pnas.1710877114

34. Schurch CM, Roelli MA, Forster S, Wasmer MH, Bruhl F, Maire RS, et al. Targeting CD47 in Anaplastic Thyroid Carcinoma Enhances Tumor Phagocytosis by Macrophages and is a Promising Therapeutic Strategy. Thyroid (2019) 29:979-92. doi: 10.1089/thy.2018.0555

35. Beatty GL, Chiorean EG, Fishman MP, Saboury B, Teitelbaum UR, Sun W, et al. CD40 Agonists Alter Tumor Stroma and Show Efficacy Against Pancreatic Carcinoma in Mice and Humans. Science (2011) 331:1612-6. doi: $10.1126 /$ science. 1198443

36. Beatty GL, Torigian DA, Chiorean EG, Saboury B, Brothers A, Alavi A, et al. A Phase I Study of an Agonist CD40 Monoclonal Antibody (CP-870,893) in Combination With Gemcitabine in Patients With Advanced Pancreatic Ductal Adenocarcinoma. Clin Cancer Res (2013) 19:6286-95. doi: 10.1158/ 1078-0432.CCR-13-1320

37. Anagnostou V, Smith KN, Forde PM, Niknafs N, Bhattacharya R, White J, et al. Evolution of Neoantigen Landscape During Immune Checkpoint 
Blockade in Non-Small Cell Lung Cancer. Cancer Discov (2017) 7:264-76. doi: 10.1158/1538-7445.AM2017-NG01

38. Charoentong P, Finotello F, Angelova M, Mayer C, Efremova M, Rieder D, et al. Pan-Cancer Immunogenomic Analyses Reveal GenotypeImmunophenotype Relationships and Predictors of Response to Checkpoint Blockade. Cell Rep (2017) 18:248-62. doi: 10.1016/j.celrep. 2016.12.019

39. Luksza M, Riaz N, Makarov V, Balachandran VP, Hellmann MD, Solovyov A, et al. A Neoantigen Fitness Model Predicts Tumour Response to Checkpoint Blockade Immunotherapy. Nature (2017) 551:517-20. doi: 10.1038/nature24473

40. Tran E, Turcotte S, Gros A, Robbins PF, Lu YC, Dudley ME, et al. Cancer Immunotherapy Based on Mutation-Specific CD4+ T Cells in a Patient With Epithelial Cancer. Science (2014) 344:641-5. doi: 10.1126/science.1251102

41. Tran E, Robbins PF, Lu YC, Prickett TD, Gartner JJ, Jia L, et al. T-Cell Transfer Therapy Targeting Mutant KRAS in Cancer. N Engl J Med (2016) 375:2255-62. doi: 10.1056/NEJMoa1609279

42. Laumont CM, Vincent K, Hesnard L, Audemard É., Bonneil É., Laverdure J-P, et al. Noncoding Regions Are the Main Source of Targetable TumorSpecific Antigens. Sci Trans Med (2018) 10:eaau5516. doi: 10.1126/ scitranslmed.aau5516

43. Yang W, Lee K-W, Srivastava RM, Kuo F, Krishna C, Chowell D, et al. Immunogenic Neoantigens Derived From Gene Fusions Stimulate T Cell Responses. Nat Med (2019) 25:767-75. doi: 10.1038/s41591-019-0434-2

44. Cafri G, Yossef R, Pasetto A, Deniger DC, Lu Y-C, Parkhurst M, et al. Memory T Cells Targeting Oncogenic Mutations Detected in Peripheral Blood of Epithelial Cancer Patients. Nat Commun (2019) 10:449. doi: 10.1038/s41467-019-08304-Z

45. Chen F, Zou Z, Du J, Su S, Shao J, Meng F, et al. Neoantigen Identification Strategies Enable Personalized Immunotherapy in Refractory Solid Tumors. J Clin Invest (2019) 130(5):2056-2070. doi: 10.1172/JCI99538

46. Pasetto A, Gros A, Robbins PF, Deniger DC, Prickett TD, Matus-Nicodemos $\mathrm{R}$, et al. Tumor- and Neoantigen-Reactive T-Cell Receptors Can Be Identified Based on Their Frequency in Fresh Tumor. Cancer Immunol Res (2016) 4:734-43. doi: 10.1158/2326-6066.CIR-16-0001

47. Gros A, Parkhurst MR, Tran E, Pasetto A, Robbins PF, Ilyas S, et al. Prospective Identification of Neoantigen-Specific Lymphocytes in the Peripheral Blood of Melanoma Patients. Nat Med (2016) 22:433-8. doi: $10.1038 / \mathrm{nm} .4051$

48. Lee M, Park C, Woo J, Kim J, Kho I, Nam D-H, et al. Preferential Infiltration of Unique V $\gamma 9 J \gamma 2-\mathrm{V} \delta 2 \mathrm{~T}$ Cells Into Glioblastoma Multiforme. Front Immunol (2019) 10:555. doi: 10.3389/fimmu.2019.00555

49. Aoki H, Ueha S, Shichino S, Ogiwara H, Hashimoto S-I, Kakimi K, et al. TCR Repertoire Analysis Reveals Mobilization of Novel CD8+ T Cell Clones Into the Cancer-Immunity Cycle Following Anti-CD4 Antibody Administration. Front Immunol (2019) 9:3185. doi: 10.3389/fimmu.2018.03185

50. Balachandran VP, Luksza M, Zhao JN, Makarov V, Moral JA, Remark R, et al. Identification of Unique Neoantigen Qualities in Long-Term Survivors of Pancreatic Cancer. Nature (2017) 551:512-6. doi: 10.1038/nature24462

51. Wang QJ, Yu Z, Griffith K, Hanada K, Restifo NP, Yang JC. Identification of T-Cell Receptors Targeting KRAS-Mutated Human Tumors. Cancer Immunol Res (2016) 4:204-14. doi: 10.1158/2326-6066.CIR-15-0188

52. Matsuda T, Leisegang M, Park J-H, Ren L, Kato T, Ikeda Y, et al. Induction of Neoantigen-Specific Cytotoxic T Cells and Construction of T-Cell Receptor-Engineered T Cells for Ovarian Cancer. Clin Cancer Res (2018) 24:5357-67. doi: 10.1158/1078-0432.CCR-18-0142

53. Peng S, Peng Z, Xu L, Mei J, Tang L, Han Y, et al. Abstract LB-076: Personal Neoantigen Immunotherapy in Hepatocellular Carcinoma. Cancer Res (2019) 79:LB-076-LB-076. doi: 10.1158/1538-7445.SABCS18-LB-076

54. Tran E, Robbins PF, Rosenberg SA. 'Final Common Pathway' of Human Cancer Immunotherapy: Targeting Random Somatic Mutations. Nat Immunol (2017) 18:255-62. doi: 10.1038/ni.3682

55. Rao M, Zhenjiang L, Meng Q, Sinclair G, Dodoo E, Maeurer M. Mutant Epitopes in Cancer. In: L Zitvogel and G Kroemer, editors. Oncoimmunology: A Practical Guide for Cancer Immunotherapy. Cham: Springer International Publishing (2018). p. 41-67.

56. Ahmadzadeh M, Pasetto A, Jia L, Deniger DC, Stevanović S, Robbins PF, et al. Tumor-Infiltrating Human CD4+ Regulatory T Cells Display a Distinct
TCR Repertoire and Exhibit Tumor and Neoantigen Reactivity. Sci Immunol (2019) 4:eaao4310. doi: 10.1126/sciimmunol.aao4310

57. Robinson G, Gajjar A, Gauvain K, Basu E, Macy M, Maese L, et al. Phase 1/ 1B Trial to Assess the Activity of Entrectinib in Children and Adolescents With Recurrent or Refractory Solid Tumors Including Central Nervous System (CNS) Tumors. Am Soc Clin Oncol Annu Meeting Chicago Illinois (2019), 37:Abstract 10009. doi: 10.1200/JCO.2019.37.15_suppl.10009

58. Aldous AR, Dong JZ. Personalized Neoantigen Vaccines: A New Approach to Cancer Immunotherapy. Bioorg Med Chem (2018) 26:2842-9. doi: 10.1016/j.bmc.2017.10.021

59. Aurisicchio L, Pallocca M, Ciliberto G, Palombo F. The Perfect Personalized Cancer Therapy: Cancer Vaccines Against Neoantigens. J Exp Clin Cancer Res (2018) 37:86. doi: 10.1186/s13046-018-0751-1

60. Kenter GG, Welters MJP, Valentijn ARPM, Lowik MJG, Berends-van der Meer DMA, Vloon APG, et al. Vaccination Against HPV-16 Oncoproteins for Vulvar Intraepithelial Neoplasia. N Engl J Med (2009) 361:1838-47. doi: 10.1056/NEJMoa0810097

61. Welters MJ, van der Sluis TC, van Meir H, Loof NM, van Ham VJ, van Duikeren S, et al. Vaccination During Myeloid Cell Depletion by Cancer Chemotherapy Fosters Robust T Cell Responses. Sci Transl Med (2016) 8:334ra52. doi: 10.1126/scitranslmed.aad8307

62. Massarelli E, William W, Johnson F, Kies M, Ferrarotto R, Guo M, et al. Combining Immune Checkpoint Blockade and Tumor-Specific Vaccine for Patients With Incurable Human Papillomavirus 16-Related Cancer: A Phase 2 Clinical Trialimmune Checkpoint Blockade and Tumor-Specific Vaccine for Patients With Incurable HPV-16 Cancerimmune Checkpoint Blockade and Tumor-Specific Vaccine for Patients With Incurable HPV-16 Cancer. JAMA Oncol (2019) 5:67-73. doi: 10.1001/jamaoncol.2018.4051

63. Le DT, Brockstedt DG, Nir-Paz R, Hampl J, Mathur S, Nemunaitis J, et al. A Live-Attenuated Listeria Vaccine (ANZ-100) and a Live-Attenuated Listeria Vaccine Expressing Mesothelin (CRS-207) for Advanced Cancers: Phase I Studies of Safety and Immune Induction. Clin Cancer Res (2012) 18:858-68. doi: 10.1158/1078-0432.CCR-11-2121

64. Le DT, Wang-Gillam A, Picozzi V, Greten TF, Crocenzi T, Springett G, et al. Safety and Survival With GVAX Pancreas Prime and Listeria MonocytogenesExpressing Mesothelin (CRS-207) Boost Vaccines for Metastatic Pancreatic Cancer. J Clin Oncol (2015) 33:1325-33. doi: 10.1200/JCO.2014.57.4244

65. Le DT, Ko AH, Wainberg ZA, Picozzi VJ, Kindler HL, Wang-Gillam A, et al. Results From a Phase 2b, Randomized, Multicenter Study of GVAX Pancreas and CRS-207 Compared to Chemotherapy in Adults With Previously-Treated Metastatic Pancreatic Adenocarcinoma (ECLIPSE Study). J Clin Oncol (2017) 35:345-5. doi: 10.1200/JCO.2017.35.4_suppl.345

66. Le DT, Picozzi VJ, Ko AH, Wainberg ZA, Kindler H, Wang-Gillam A, et al. A Randomized Phase 2b Study of GVAX Pancreas and CRS-207 Compared to Chemotherapy in Previously-Treated Metastatic Pancreatic Adenocarcinoma Patients (ECLIPSE Study). Clin Cancer Res (2019) 25 (18):5493-502. doi: 10.1158/1078-0432.CCR-18-2992

67. Ramlau R, Quoix E, Rolski J, Pless M, Lena H, Levy E, et al. A Phase II Study of Tg4010 (Mva-Muc1-Il2) in Association With Chemotherapy in Patients With Stage III/IV Non-Small Cell Lung Cancer. J Thorac Oncol (2008) 3:735-44. doi: 10.1097/JTO.0b013e31817c6b4f

68. Hui EP, Taylor GS, Jia H, Ma BB, Chan SL, Ho R, et al. Phase I Trial of Recombinant Modified Vaccinia Ankara Encoding Epstein-Barr Viral Tumor Antigens in Nasopharyngeal Carcinoma Patients. Cancer Res (2013) 73:1676-88. doi: 10.1158/0008-5472.CAN-12-2448

69. Ott PA, Hu Z, Keskin DB, Shukla SA, Sun J, Bozym DJ, et al. An Immunogenic Personal Neoantigen Vaccine for Patients With Melanoma. Nature (2017) 547:217-21. doi: 10.1038/nature22991

70. Shindo Y, Hazama S, Suzuki N, Iguchi H, Uesugi K, Tanaka H, et al. Predictive Biomarkers for the Efficacy of Peptide Vaccine Treatment: Based on the Results of a Phase II Study on Advanced Pancreatic Cancer. J Exp Clin Cancer Res (2017) 36:36. doi: 10.1186/s13046-017-0509-1

71. Chen F, Zou Z, Du J, Su S, Shao J, Meng F, et al. Neoantigen Identification Strategies Enable Personalized Immunotherapy in Refractory Solid Tumors. J Clin Invest (2019) 129:2056-70. doi: 10.1172/JCI99538

72. Keskin DB, Anandappa AJ, Sun J, Tirosh I, Mathewson ND, Li S, et al. Neoantigen Vaccine Generates Intratumoral T Cell Responses in Phase Ib Glioblastoma Trial. Nature (2019) 565:234-9. doi: 10.1038/s41586-018-0792-9 
73. Müller M, Gfeller D, Coukos G, Bassani-Sternberg M. 'Hotspots' of Antigen Presentation Revealed by Human Leukocyte Antigen Ligandomics for Neoantigen Prioritization. Front Immunol (2017) 8:1367-7. doi: 10.3389/ fimmu.2017.01367

74. Bharathan M, Trebska-McGowan K, Anna P, Deniger DC, Hanada K-I, Gartner JJ, et al. Tetramer Based Approach for Efficient Identification and Isolation of Neo-Antigen Specific CD8 T Cells From Peripheral Blood (PBL) of Patients With Metastatic Cancers. J Immunother Cancer (2015) 3:P47-7. doi: 10.1186/2051-1426-3-S2-P47

75. Bezu L, Kepp O, Cerrato G, Pol J, Fucikova J, Spisek R, et al. Trial Watch: Peptide-Based Vaccines in Anticancer Therapy. Oncoimmunology (2018) 7: e1511506-e1511506. doi: 10.1080/2162402X.2018.1511506

76. Sahin U, Derhovanessian E, Miller M, Kloke BP, Simon P, Lower M, et al. Personalized RNA Mutanome Vaccines Mobilize Poly-Specific Therapeutic Immunity Against Cancer. Nature (2017) 547:222-6. doi: 10.1038/ nature23003

77. Wheeler CJ, Black KL. Dcvax ${ }^{\circledR}$-Brain and DC Vaccines in the Treatment of GBM. Expert Opin Invest Drugs (2009) 18:509-19. doi: 10.1517/13543780902841951

78. Guo Y, Lei K, Tang L. Neoantigen Vaccine Delivery for Personalized Anticancer Immunotherapy. Front Immunol (2018) 9:1499-9. doi: 10.3389/fimmu.2018.01499

79. Mastelic-Gavillet B, Balint K, Boudousquie C, Gannon PO, Kandalaft LE. Personalized Dendritic Cell Vaccines-Recent Breakthroughs and Encouraging Clinical Results. Front Immunol (2019) 10:766-6. doi: 10.3389/fimmu.2019.00766

80. Carreno BM, Magrini V, Becker-Hapak M, Kaabinejadian S, Hundal J, Petti AA, et al. A Dendritic Cell Vaccine Increases the Breadth and Diversity of Melanoma Neoantigen-Specific T Cells. Science (2015) 348:803-8. doi: 10.1126/science.aaa3828

81. Cormier JN, Salgaller ML, Prevette T, Barracchini KC, Rivoltini L, Restifo NP, et al. Enhancement of Cellular Immunity in Melanoma Patients Immunized With a Peptide From MART-1/Melan a. Cancer J Sci Am (1997) 3:37-44.

82. Wang F, Bade E, Kuniyoshi C, Spears L, Jeffery G, Marty V, et al. Phase I Trial of a MART-1 Peptide Vaccine With Incomplete Freund's Adjuvant for Resected High-Risk Melanoma. Clin Cancer Res (1999) 5:2756-65.

83. Yamshchikov GV, Barnd DL, Eastham S, Galavotti H, Patterson JW, Deacon DH, et al. Evaluation of Peptide Vaccine Immunogenicity in Draining Lymph Nodes and Peripheral Blood of Melanoma Patients. Int J Cancer (2001) 92:703-11. doi: 10.1002/1097-0215(20010601)92:5<703::AIDIJC1250>3.0.CO;2-5

84. Karbach J, Gnjatic S, Bender A, Neumann A, Weidmann E, Yuan J, et al. Tumor-Reactive CD8+ T-Cell Responses After Vaccination With NY-ESO1 Peptide, Cpg 7909 and Montanide ISA-51: Association With Survival. Int J Cancer (2010) 126:909-18. doi: 10.1002/ijc.24850

85. Bigaeva E, Doorn EV, Liu H, Hak E. Meta-Analysis on Randomized Controlled Trials of Vaccines With QS-21 or ISCOMATRIX Adjuvant: Safety and Tolerability. PLoS One (2016) 11:e0154757-e0154757. doi: 10.1371/journal.pone.0154757

86. Zhu D, Tuo W. Qs-21: A Potent Vaccine Adjuvant. Natural Products Chem Res (2016) 3:e113. doi: 10.4172/2329-6836.1000e113

87. Wells DK, van Buuren MM, Dang KK, Hubbard-Lucey VM, Sheehan KCF, Campbell KM, et al. Key Parameters of Tumor Epitope Immunogenicity Revealed Through a Consortium Approach Improve Neoantigen Prediction. Cell (2020) 183:818-34.e13. doi: 10.1016/j.cell.2020.09.015

88. Hilf N, Kuttruff-Coqui S, Frenzel K, Bukur V, Stevanovic S, Gouttefangeas C, et al. Actively Personalized Vaccination Trial for Newly Diagnosed Glioblastoma. Nature (2019) 565:240-5. doi: 10.1038/s41586-018-0810-y

89. Kidman J, Principe N, Watson M, Lassmann T, Holt RA, Nowak AK, et al. Characteristics of TCR Repertoire Associated With Successful Immune Checkpoint Therapy Responses. Front Immunol (2020) 11:587014. doi: 10.3389/fimmu.2020.587014

90. Krishna S, Lowery FJ, Copeland AR, Bahadiroglu E, Mukherjee R, Jia L, et al. StemLike CD8 T Cells Mediate Response of Adoptive Cell Immunotherapy Against Human Cancer. Science (2020) 370:1328-34. doi: 10.1126/science.abb9847

91. Ren Z, Peng H, Fu Y-X. PD-1 Shapes B Cells as Evildoers in the Tumor Microenvironment. Cancer Discov (2016) 6:477-8. doi: 10.1158/21598290.CD-16-0307
92. Xiao X, Lao XM, Chen MM, Liu RX, Wei Y, Ouyang FZ, et al. PD-1hi Identifies a Novel Regulatory B-Cell Population in Human Hepatoma That Promotes Disease Progression. Cancer Discov (2016) 6:546-59. doi: 10.1158/ 2159-8290.CD-15-1408

93. Zhao Y, Shen M, Feng Y, He R, Xu X, Xie Y, et al. Regulatory B Cells Induced by Pancreatic Cancer Cell-Derived Interleukin-18 Promote Immune Tolerance Via the PD-1/PD-L1 Pathway. Oncotarget (2017) 9:14803-14. doi: 10.18632/oncotarget.22976

94. Kumari N, Dwarakanath BS, Das A, Bhatt AN. Role of Interleukin-6 in Cancer Progression and Therapeutic Resistance. Tumour Biol (2016) 37:11553-72. doi: 10.1007/s13277-016-5098-7

95. Vainer N, Dehlendorff C, Johansen JS. Systematic Literature Review of IL-6 as a Biomarker or Treatment Target in Patients With Gastric, Bile Duct, Pancreatic and Colorectal Cancer. Oncotarget (2018) 9:29820-41. doi: 10.18632 /oncotarget.25661

96. Lippitz BE, Harris RA. Cytokine Patterns in Cancer Patients: A Review of the Correlation Between Interleukin 6 and Prognosis. Oncoimmunology (2016) 5:e1093722-e1093722. doi: 10.1080/2162402X.2015.1093722

97. Kristiansen OP, Mandrup-Poulsen T. Interleukin-6 and Diabetes: The Good, the Bad, or the Indifferent? Diabetes (2005) 54(Suppl 2):S114-24. doi: 10.2337/diabetes.54.suppl_2.S114

98. Ohmoto K, Yamamoto S. Serum Interleukin-6 and Interleukin-10 in Patients With Acute Pancreatitis: Clinical Implications. Hepatogastroenterology (2005) 52:990-4.

99. Zhang Y, Yan W, Collins MA, Bednar F, Rakshit S, Zetter BR, et al. Interleukin-6 is Required for Pancreatic Cancer Progression by Promoting MAPK Signaling Activation and Oxidative Stress Resistance. Cancer Res (2013) 73:6359-74. doi: 10.1158/0008-5472.CAN-13-1558-T

100. Holmer R, Goumas FA, Waetzig GH, Rose-John S, Kalthoff H. Interleukin-6: A Villain in the Drama of Pancreatic Cancer Development and Progression. Hepatobiliary Pancreat Dis Int (2014) 13:371-80. doi: 10.1016/S1499-3872 (14)60259-9

101. Flint TR, Janowitz T, Connell CM, Roberts EW, Denton AE, Coll AP, et al. Tumor-Induced IL-6 Reprograms Host Metabolism to Suppress Anti-Tumor Immunity. Cell Metab (2016) 24:672-84. doi: 10.1016/j.cmet.2016.10.010

102. Rossi J-F, Lu Z-Y, Jourdan M, Klein B. Interleukin-6 as a Therapeutic Target. Clin Cancer Res (2015) 21:1248-57. doi: 10.1158/1078-0432.CCR-14-2291

103. Lee DW, Gardner R, Porter DL, Louis CU, Ahmed N, Jensen M, et al. Current Concepts in the Diagnosis and Management of Cytokine Release Syndrome. Blood (2014) 124:188-95. doi: 10.1182/blood-2014-05-552729

104. Kato T, Nishida T, Ito Y, Murase M, Murata M, Naoe T. Correlations of Programmed Death 1 Expression and Serum IL-6 Level With Exhaustion of Cytomegalovirus-Specific T Cells After Allogeneic Hematopoietic Stem Cell Transplantation. Cell Immunol (2014) 288:53-9. doi: 10.1016/ j.cellimm.2014.02.007

105. Hou W, Jin YH, Kang HS, Kim BS. Interleukin-6 (IL-6) and IL-17 Synergistically Promote Viral Persistence by Inhibiting Cellular Apoptosis and Cytotoxic T Cell Function. J Virol (2014) 88:8479-89. doi: 10.1128/JVI.00724-14

106. Chen XW, Zhou SF. Inflammation, Cytokines, the IL-17/IL-6/STAT3/NFKappab Axis, and Tumorigenesis. Drug Des Devel Ther (2015) 9:2941-6. doi: 10.2147/DDDT.S86396

107. Chang SH. T Helper 17 (Th17) Cells and Interleukin-17 (IL-17) in Cancer. Arch Pharm Res (2019) 42(7):549-59. doi: 10.1007/s12272-019-01146-9

108. Tsukamoto H, Fujieda K, Miyashita A, Fukushima S, Ikeda T, Kubo Y, et al. Combined Blockade of IL6 and PD-1/PD-L1 Signaling Abrogates Mutual Regulation of Their Immunosuppressive Effects in the Tumor Microenvironment. Cancer Res (2018) 78:5011-22. doi: 10.1158/0008-5472. CAN-18-0118

109. Bialkowski L, Van der Jeught K, Bevers S, Tjok Joe P, Renmans D, Heirman C, et al. Immune Checkpoint Blockade Combined With IL-6 and TGF-Beta Inhibition Improves the Therapeutic Outcome of Mrna-Based Immunotherapy. Int J Cancer (2018) 143:686-98. doi: 10.1002/ijc.31331

110. Vennin C, Murphy KJ, Morton JP, Cox TR, Pajic M, Timpson P. Reshaping the Tumor Stroma for Treatment of Pancreatic Cancer. Gastroenterology (2018) 154:820-38. doi: 10.1053/j.gastro.2017.11.280

111. Roma-Rodrigues C, Mendes R, Baptista PV, Fernandes AR. Targeting Tumor Microenvironment for Cancer Therapy. Int J Mol Sci (2019) 20 (4):840. doi: $10.3390 / \mathrm{ijms} 20040840$ 
112. Poh AR, Ernst M. Targeting Macrophages in Cancer: From Bench to Bedside. Front Oncol (2018) 8:49. doi: 10.3389/fonc.2018.00049

113. Vigneron N. Human Tumor Antigens and Cancer Immunotherapy. BioMed Res Int (2015) 2015:948501. doi: 10.1155/2015/948501

114. Abelin JG, Keskin DB, Sarkizova S, Hartigan CR, Zhang W, Sidney J, et al. Mass Spectrometry Profiling of HLA-Associated Peptidomes in MonoAllelic Cells Enables More Accurate Epitope Prediction. Immunity (2017) 46:315-26. doi: 10.1016/j.immuni.2017.02.007

115. Keskin DB, Anandappa AJ, Sun J, Tirosh I, Mathewson ND, Li S, et al. Neoantigen Vaccine Generates Intratumoral T Cell Responses in Phase Ib Glioblastoma Trial. Nature (2019) 565:234-9. doi: 10.1038/s41586-018-0792-9

116. Yost KE, Satpathy AT, Wells DK, Qi Y, Wang C, Kageyama R, et al. Clonal Replacement of Tumor-Specific T Cells Following PD-1 Blockade. Nat Med (2019) 25:1251-9. doi: 10.1038/s41591-019-0522-3

117. Philip M, Fairchild L, Sun L, Horste EL, Camara S, Shakiba M, et al. Chromatin States Define Tumour-Specific T Cell Dysfunction and Reprogramming. Nature (2017) 545:452-6. doi: 10.1038/nature22367

118. Germeau C, Ma W, Schiavetti F, Lurquin C, Henry E, Vigneron N, et al. High Frequency of Antitumor T Cells in the Blood of Melanoma Patients Before and After Vaccination With Tumor Antigens. J Exp Med (2005) 201:241-8. doi: 10.1084/jem.20041379

119. Richters MM, Xia H, Campbell KM, Gillanders WE, Griffith OL, Griffith M. Best Practices for Bioinformatic Characterization of Neoantigens for Clinical Utility. Genome Med (2019) 11:56. doi: 10.1186/s13073-019-0666-2

120. Hernandez C, Huebener P, Schwabe RF. Damage-Associated Molecular Patterns in Cancer: A Double-Edged Sword. Oncogene (2016) 35:5931-41. doi: 10.1038/onc.2016.104

121. Krysko O, Løve Aaes T, Bachert C, Vandenabeele P, Krysko DV. Many Faces of Damps in Cancer Therapy. Cell Death Dis (2013) 4:e631. doi: 10.1038/ cddis.2013.156

122. Peter ME, Hadji A, Murmann AE, Brockway S, Putzbach W, Pattanayak A, et al. The Role of CD95 and CD95 Ligand in Cancer. Cell Death Differ (2015) 22:549. doi: $10.1038 / \mathrm{cdd} .2015 .3$

123. Chatterjee S, Burns TF. Targeting Heat Shock Proteins in Cancer: A Promising Therapeutic Approach. Int J Mol Sci (2017) 18:1978. doi: $10.3390 /$ ijms 18091978

124. Ghadially H, Brown L, Lloyd C, Lewis L, Lewis A, Dillon J, et al. MHC Class I Chain-Related Protein a and B (MICA and MICB) Are Predominantly Expressed Intracellularly in Tumour and Normal Tissue. Br J Cancer (2017) 116:1208-17. doi: 10.1038/bjc.2017.79

125. Zhao Y, Chen N, Yu Y, Zhou L, Niu C, Liu Y, et al. Prognostic Value of MICA/B in Cancers: A Systematic Review and Meta-Analysis. Oncotarget (2017) 8:96384-95. doi: 10.18632/oncotarget.21466

126. Li X. The Inducers of Immunogenic Cell Death for Tumor Immunotherapy. Tumori (2018) 104:1-8. doi: 10.5301/tj.5000675

127. Cruickshank B, Giacomantonio M, Marcato P, McFarland S, Pol J, Gujar S. Dying to Be Noticed: Epigenetic Regulation of Immunogenic Cell Death for Cancer Immunotherapy. Front Immunol (2018) 9:654. doi: 10.3389/ fimmu.2018.00654

128. Ranoa DR, Parekh AD, Pitroda SP, Huang X, Darga T, Wong AC, et al. Cancer Therapies Activate RIG-I-Like Receptor Pathway Through Endogenous Non-Coding Rnas. Oncotarget (2016) 7:26496-515. doi: 10.18632 /oncotarget.8420

129. Wu Y, Wu X, Wu L, Wang X, Liu Z. The Anticancer Functions of RIG-I-Like Receptors, RIG-I and MDA5, and Their Applications in Cancer Therapy. Transl Res (2017) 190:51-60. doi: 10.1016/j.trsl.2017.08.004

130. Schwickert A, Weghake E, Brüggemann K, Engbers A, Brinkmann BF, Kemper B, et al. MicroRNA miR-142-3p Inhibits Breast Cancer Cell Invasiveness by Synchronous Targeting of WASL, Integrin Alpha V, and Additional Cytoskeletal Elements. PLoS One (2015) 10:e0143993. doi: 10.1371/journal.pone.0143993

131. Zhang J, Zhang J, Zhang J, Qiu W, Xu S, Yu Q, et al. Microrna-625 Inhibits the Proliferation and Increases the Chemosensitivity of Glioma by Directly Targeting AKT2. Am J Cancer Res (2017) 7:1835-49.

132. Anandagoda N, Willis JCD, Hertweck A, Roberts LB, Jackson I, Gökmen MR, et al. MicroRNA-142-Mediated Repression of Phosphodiesterase 3B Critically Regulates Peripheral Immune Tolerance. J Clin Invest (2019) 129 (3):1257-71. doi: 10.1172/JCI124725
133. Corrales L, McWhirter SM, Dubensky TW Jr, Gajewski TF. The Host STING Pathway At the Interface of Cancer and Immunity. J Clin Invest (2016) 126:2404-11. doi: 10.1172/JCI86892

134. Zhou X, Jiang Z. STING-Mediated DNA Sensing in Cancer Immunotherapy. Sci China Life Sci (2017) 60:563-74. doi: 10.1007/s11427-016-9066-0

135. Barber GN. STING: Infection, Inflammation and Cancer. Nat Rev Immunol (2015) 15:760-70. doi: 10.1038/nri3921

136. Walker MM, Crute BW, Cambier JC, Getahun A. B Cell-Intrinsic STING Signaling Triggers Cell Activation, Synergizes With B Cell Receptor Signals, and Promotes Antibody Responses. J Immunol (2018) 201(9):2641-53. doi: 10.4049/jimmunol.1701405

137. Xia T, Konno H, Ahn J, Barber GN. Deregulation of STING Signaling in Colorectal Carcinoma Constrains DNA Damage Responses and Correlates With Tumorigenesis. Cell Rep (2016) 14:282-97. doi: 10.1016/j.celrep. 2015.12.029

138. Luo M, Wang H, Wang Z, Cai H, Lu Z, Li Y, et al. A STING-Activating Nanovaccine for Cancer Immunotherapy. Nat Nanotechnol (2017) 12:64854. doi: 10.1038/nnano.2017.52

139. Kinkead HL, Hopkins A, Lutz E, Wu AA, Yarchoan M, Cruz K, et al. Combining STING-Based Neoantigen-Targeted Vaccine With Checkpoint Modulators Enhances Antitumor Immunity in Murine Pancreatic Cancer. JCI Insight (2018) 3:e122857. doi: 10.1172/jci.insight.122857

140. Sivick KE, Desbien AL, Glickman LH, Reiner GL, Corrales L, Surh NH, et al. Magnitude of Therapeutic STING Activation Determines CD8+ T CellMediated Anti-Tumor Immunity. Cell Rep (2018) 25:3074-85.e5. doi: 10.1016/j.celrep.2018.11.047

141. Satgé D. A Tumor Profile in Primary Immune Deficiencies Challenges the Cancer Immune Surveillance Concept. Front Immunol (2018) 9:1149-9. doi: 10.3389/fimmu.2018.01149

142. Haas OA. Primary Immunodeficiency and Cancer Predisposition Revisited: Embedding Two Closely Related Concepts Into an Integrative Conceptual Framework. Front Immunol (2019) 9:3136-6. doi: 10.3389/fimmu.2018.03136

143. de Jong D, Roemer MGM, Chan JKC, Goodlad J, Gratzinger D, Chadburn A, et al. B-Cell and Classical Hodgkin Lymphomas Associated With Immunodeficiency: 2015 SH/EAHP Workshop Report-Part 2. Am J Clin Pathol (2017) 147:153-70. doi: 10.1093/ajcp/aqw216

144. Sánchez-Ramón S, Bermúdez A, González-Granado LI, Rodríguez-Gallego C, Sastre A, Soler-Palacín P, et al. Primary and Secondary Immunodeficiency Diseases in Oncohaematology: Warning Signs, Diagnosis, and Management. Front Immunol (2019) 10:586. doi: 10.3389/fimmu.2019.00586

145. Abbas A, Lichtman A, Pilai S. Basic Immunology: Functions and Disorders of the Immune System. Philadelphia: Elsevier Saunders (2014).

146. Piskurich JF, Wang Y, Linhoff MW, White LC, Ting JP. Identification of Distinct Regions of 5' Flanking DNA That Mediate Constitutive, IFNGamma, STAT1, and TGF-Beta-Regulated Expression of the Class II Transactivator Gene. J Immunol (1998) 160:233-40.

147. Zhou J, Zhao W, Wu J, Lu J, Ding Y, Wu S, et al. Neoantigens Derived From Recurrently Mutated Genes as Potential Immunotherapy Targets for Gastric Cancer. BioMed Res Int (2019) 2019:11. doi: 10.1155/2019/8103142

148. Bräunlein E, Krackhardt AM. Identification and Characterization of Neoantigens as Well as Respective Immune Responses in Cancer Patients. Front Immunol (2017) 8:1702-2. doi: 10.3389/fimmu.2017.01702

149. Seliger B, Maeurer MJ, Ferrone S. TAP Off-Tumors on. Immunol Today (1997) 18:292-9. doi: 10.1016/S0167-5699(97)80026-6

150. Seliger B, Maeurer MJ, Ferrone S. Antigen-Processing Machinery Breakdown and Tumor Growth. Immunol Today (2000) 21:455-64. doi: 10.1016/S01675699(00)01692-3

151. Atkins D, Breuckmann A, Schmahl GE, Binner P, Ferrone S, Krummenauer F, et al. MHC Class I Antigen Processing Pathway Defects, Ras Mutations and Disease Stage in Colorectal Carcinoma. Int J Cancer (2004) 109:265-73. doi: $10.1002 /$ ijc. 11681

152. Maccalli C, Parmiani G, Ferrone S. Immunomodulating and Immunoresistance Properties of Cancer-Initiating Cells: Implications for the Clinical Success of Immunotherapy. Immunol Invest (2017) 46:221-38. doi: 10.1080/ 08820139.2017.1280051

153. Seliger B, Kloor M, Ferrone S. HLA Class II Antigen-Processing Pathway in Tumors: Molecular Defects and Clinical Relevance. Oncoimmunology (2017) 6:e1171447. doi: 10.1080/2162402X.2016.1171447 
154. Zaretsky JM, Garcia-Diaz A, Shin DS, Escuin-Ordinas H, Hugo W, HuLieskovan S, et al. Mutations Associated With Acquired Resistance to PD-1 Blockade in Melanoma. N Engl J Med (2016) 375:819-29. doi: 10.1056/ NEJMoa1604958

155. Haworth KB, Leddon JL, Chen CY, Horwitz EM, Mackall CL, Cripe TP. Going Back to Class I: MHC and Immunotherapies for Childhood Cancer. Pediatr Blood Cancer (2015) 62:571-6. doi: 10.1002/pbc.25359

156. McGranahan N, Rosenthal R, Hiley CT, Rowan AJ, Watkins TBK, Wilson GA, et al. Allele-Specific HLA Loss and Immune Escape in Lung Cancer Evolution. Cell (2017) 171:1259-71.e11. doi: 10.1016/j.cell.2017.10.001

157. Chowell D, Morris LGT, Grigg CM, Weber JK, Samstein RM, Makarov V, et al. Patient HLA Class I Genotype Influences Cancer Response to Checkpoint Blockade Immunotherapy. Science (2018) 359:582-7. doi: 10.1126/science.aao4572

158. Arakawa A, Vollmer S, Tietze J, Galinski A, Heppt MV, Burdek M, et al. Clonality of CD4(+) Blood T Cells Predicts Longer Survival With CTLA4 or PD-1 Checkpoint Inhibition in Advanced Melanoma. Front Immunol (2019) 10:1336. doi: 10.3389/fimmu.2019.01336

159. Koopman LA, van Der Slik AR, Giphart MJ, Fleuren GJ. Human Leukocyte Antigen Class I Gene Mutations in Cervical Cancer. J Natl Cancer Inst (1999) 91:1669-77. doi: 10.1093/jnci/91.19.1669

160. Leone P, Shin EC, Perosa F, Vacca A, Dammacco F, Racanelli V. MHC Class I Antigen Processing and Presenting Machinery: Organization, Function, and Defects in Tumor Cells. J Natl Cancer Inst (2013) 105:1172-87. doi: 10.1093/jnci/djt184

161. Nangalia J, Massie CE, Baxter EJ, Nice FL, Gundem G, Wedge DC, et al. Somatic CALR Mutations in Myeloproliferative Neoplasms With Nonmutated JAK2. N Engl J Med (2013) 369:2391-405. doi: 10.1056/NEJMoa1312542

162. Li L, Dong M, Wang XG. The Implication and Significance of Beta 2 Microglobulin: A Conservative Multifunctional Regulator. Chin Med J (Engl) (2016) 129:448-55. doi: 10.4103/0366-6999.176084

163. Leney AC, Pashley CL, Scarff CA, Radford SE, Ashcroft AE. Insights Into the Role of the Beta-2 Microglobulin D-Strand in Amyloid Propensity Revealed by Mass Spectrometry. Mol Biosyst (2014) 10:412-20. doi: 10.1039/ C3MB70420C

164. Valleix S, Gillmore JD, Bridoux F, Mangione PP, Dogan A, Nedelec B, et al. Hereditary Systemic Amyloidosis Due to Asp76Asn Variant Beta2Microglobulin. NEnglJMed (2012) 366:2276-83. doi: 10.1056/NEJMoa1201356

165. Belicha-Villanueva A, Golding M, McEvoy S, Sarvaiya N, Cresswell P, Gollnick SO, et al. Identification of an Alternate Splice Form of Tapasin in Human Melanoma. Hum Immunol (2010) 71:1018-26. doi: 10.1016/ j.humimm.2010.05.019

166. Michel S, Linnebacher M, Alcaniz J, Voss M, Wagner R, Dippold W, et al. Lack of HLA Class II Antigen Expression in Microsatellite Unstable Colorectal Carcinomas Is Caused by Mutations in HLA Class II Regulatory Genes. Int J Cancer (2010) 127:889-98. doi: 10.1002/ijc.25106

167. Surmann E-M, Voigt AY, Michel S, Bauer K, Reuschenbach M, Ferrone S, et al. Association of High CD4-Positive T Cell Infiltration With Mutations in HLA Class II-Regulatory Genes in Microsatellite-Unstable Colorectal Cancer. Cancer Immunol Immunother (2015) 64:357-66. doi: 10.1007/ s00262-014-1638-4

168. Sconocchia G, Eppenberger-Castori S, Zlobec I, Karamitopoulou E, Arriga R, Coppola A, et al. HLA Class II Antigen Expression in Colorectal Carcinoma Tumors as a Favorable Prognostic Marker. Neoplasia (2014) 16:31-42. doi: 10.1593/neo.131568

169. Zehbe I, Hohn H, Pilch H, Neukirch C, Freitag K, Maeurer MJ. Differential MHC Class II Component Expression in HPV-Positive Cervical Cancer Cells: Implication for Immune Surveillance. Int J Cancer (2005) 117:807-15. doi: $10.1002 /$ ijc. 21226

170. Kamma H, Yazawa T, Ogata T, Horiguchi H, Iijima T. Expression of MHC Class II Antigens in Human Lung Cancer Cells. Virchows Arch B Cell Pathol Incl Mol Pathol (1991) 60:407-12. doi: 10.1007/BF02899573

171. Park IA, Hwang SH, Song IH, Heo SH, Kim YA, Bang WS, et al. Expression of the MHC Class II in Triple-Negative Breast Cancer is Associated With Tumor-Infiltrating Lymphocytes and Interferon Signaling. PLoS One (2017) 12:e0182786. doi: 10.1371/journal.pone.0182786

172. Johnson DB, Estrada MV, Salgado R, Sanchez V, Doxie DB, Opalenik SR, et al. Melanoma-Specific MHC-II Expression Represents a Tumour-
Autonomous Phenotype and Predicts Response to Anti-PD-1/PD-L1 Therapy. Nat Commun (2016) 7:10582. doi: 10.1038/ncomms10582

173. Scupoli MT, Sartoris S, Tosi G, Ennas MG, Nicolis M, Cestari T, et al. and Class II Antigens in Pancreatic Adenocarcinomas. Tissue Antigens (1996) 48:301-11. doi: 10.1111/j.1399-0039.1996.tb02649.x

174. Kreiter S, Vormehr M, van de Roemer N, Diken M, Lower M, Diekmann J, et al. Mutant MHC Class II Epitopes Drive Therapeutic Immune Responses to Cancer. Nature (2015) 520:692-6. doi: 10.1038/nature14426

175. Sun Z, Chen F, Meng F, Wei J, Liu B. MHC Class II Restricted Neoantigen: A Promising Target in Tumor Immunotherapy. Cancer Lett (2017) 392:17-25. doi: $10.1016 /$ j.canlet.2016.12.039

176. Gooden M, Lampen M, Jordanova ES, Leffers N, Trimbos JB, van der Burg SH, et al. HLA-E Expression by Gynecological Cancers Restrains TumorInfiltrating CD8(+) T Lymphocytes. Proc Natl Acad Sci USA (2011) 108:10656-61. doi: 10.1073/pnas.1100354108

177. Lin A, Yan WH. HLA-G Expression in Cancers: Roles in Immune Evasion, Metastasis and Target for Therapy. Mol Med (2015) 21(1):782-91. doi: 10.2119/molmed.2015.00083

178. Vacchini A, Chancellor A, Spagnuolo J, Mori L, De Libero G. Mr1-Restricted T Cells are Unprecedented Cancer Fighters. Front Immunol (2020) 11:751. doi: 10.3389/fimmu.2020.00751

179. Chong TW, Goh FY, Sim MY, Huang HH, Thike AA, Lim WK, et al. CD1d Expression in Renal Cell Carcinoma is Associated With Higher Relapse Rates, Poorer Cancer-Specific and Overall Survival. J Clin Pathol (2015) 68:200-5. doi: 10.1136/jclinpath-2014-202735

180. Yang PM, Lin PJ, Chen CC. CD1d Induction in Solid Tumor Cells by Histone Deacetylase Inhibitors Through Inhibition of HDAC1/2 and Activation of Sp1. Epigenetics (2012) 7:390-9. doi: 10.4161/epi.19373

181. Chaudhry MS, Karadimitris A. Role and Regulation of CD1d in Normal and Pathological B Cells. J Immunol (2014) 193:4761-8. doi: 10.4049/ jimmunol.1401805

182. Yarchoan M, Johnson BA, Lutz 3ER, Laheru DA, Jaffee EM. Targeting Neoantigens to Augment Antitumour Immunity. Nat Rev Cancer (2017) 17:209-22. doi: 10.1038/nrc.2016.154

183. Rossig C, Kailayangiri S, Jamitzky S, Altvater B. Carbohydrate Targets for CAR T Cells in Solid Childhood Cancers. Front Oncol (2018) 8:513. doi: 10.3389/fonc.2018.00513

184. Sun L, Middleton DR, Wantuch PL, Ozdilek A, Avci FY. Carbohydrates as TCell Antigens With Implications in Health and Disease. Glycobiology (2016) 26:1029-40. doi: 10.1093/glycob/cww062

185. Berglund E, Maaskola J, Schultz N, Friedrich S, Marklund M, Bergenstråhle J, et al. Spatial Maps of Prostate Cancer Transcriptomes Reveal an Unexplored Landscape of Heterogeneity. Nat Commun (2018) 9:2419. doi: 10.1038/ s41467-018-04724-5

186. Balli D, Rech AJ, Stanger BZ, Vonderheide RH. Immune Cytolytic Activity Stratifies Molecular Subsets of Human Pancreatic Cancer. Clin Cancer Res (2017) 23:3129-38. doi: 10.1158/1078-0432.CCR-16-2128

187. Neelamraju Y, Gonzalez-Perez A, Bhat-Nakshatri P, Nakshatri H, Janga SC. Mutational Landscape of RNA-Binding Proteins in Human Cancers. RNA Biol (2017) 15(1):115-29. doi: 10.1080/15476286.2017.1391436

188. Trujillo JA, Sweis RF, Bao R, Luke JJ. T Cell-Inflamed Versus Non-T CellInflamed Tumors: A Conceptual Framework for Cancer Immunotherapy Drug Development and Combination Therapy Selection. Cancer Immunol Res (2018) 6:990-1000. doi: 10.1158/2326-6066.CIR-18-0277

189. Blank CU, Haanen JB, Ribas A, Schumacher TN. The "Cancer Immunogram". Science (2016) 352:658-60. doi: 10.1126/science.aaf2834

190. Karasaki T, Nagayama K, Kuwano H, Nitadori JI, Sato M, Anraku M, et al. An Immunogram for the Cancer-Immunity Cycle: Towards Personalized Immunotherapy of Lung Cancer. J Thorac Oncol (2017) 12(5):791-803. doi: 10.1016/j.jtho.2017.01.005

191. Rosenberg SA, Restifo NP. Adoptive Cell Transfer as Personalized Immunotherapy for Human Cancer. Science (2015) 348:62-8. doi: 10.1126/science.aaa 4967

192. Morgan RA, Dudley ME, Wunderlich JR, Hughes MS, Yang JC, Sherry RM, et al. Cancer Regression in Patients After Transfer of Genetically Engineered Lymphocytes. Science (2006) 314:126-9. doi: 10.1126/science.1129003

193. Dudley ME, Yang JC, Sherry R, Hughes MS, Royal R, Kammula U, et al. Adoptive Cell Therapy for Patients With Metastatic Melanoma: Evaluation 
of Intensive Myeloablative Chemoradiation Preparative Regimens. J Clin Oncol (2008) 26:5233-9. doi: 10.1200/JCO.2008.16.5449

194. Chu H, Du F, Gong Z, Lian P, Wang Z, Li P, et al. Better Clinical Efficiency of Tils for Malignant Pleural Effusion and Ascites Than Cisplatin Through Intrapleural and Intraperitoneal Infusion. Anticancer Res (2017) 37:4587-91. doi: 10.21873 /anticanres.11857

195. Domagala-Kulawik J, Guzman J, Costabel U. Immune Cells in Bronchoalveolar Lavage in Peripheral Lung Cancer-Analysis of 140 Cases. Respiration (2003) 70:43-8. doi: 10.1159/000068414

196. Subira D, Castanon S, Aceituno E, Hernandez J, Jimenez-Garofano C, Jimenez A, et al. Flow Cytometric Analysis of Cerebrospinal Fluid Samples and Its Usefulness in Routine Clinical Practice. Am J Clin Pathol (2002) 117:952-8. doi: 10.1309/123P-CE6V-WYAK-BB1F

197. Khan AB, Carpenter B, Santos ESP, Pospori C, Khorshed R, Griffin J, et al. Redirection to the Bone Marrow Improves T Cell Persistence and Antitumor Functions. J Clin Invest (2018) 128:2010-24. doi: 10.1172/JCI97454

198. Miller KD, Siegel RL, Lin CC, Mariotto AB, Kramer JL, Rowland JH, et al. Cancer Treatment and Survivorship Statistics, 2016. CA: A Cancer J Clin (2016) 66:271-89. doi: 10.3322/caac.21349

199. Themeli M, Riviere I, Sadelain M. New Cell Sources for T Cell Engineering and Adoptive Immunotherapy. Cell Stem Cell (2015) 16:357-66. doi: 10.1016/j.stem.2015.03.011

200. Met O, Jensen KM, Chamberlain CA, Donia M, Svane IM. Principles of Adoptive T Cell Therapy in Cancer. Semin Immunopathol (2019) 41:49-58. doi: 10.1007/s00281-018-0703-z

201. Mueller SN, Mackay LK. Tissue-Resident Memory T Cells: Local Specialists in Immune Defence. Nat Rev Immunol (2016) 16:79-89. doi: 10.1038/ nri.2015.3

202. Park SL, Gebhardt T, Mackay LK. Tissue-Resident Memory T Cells in Cancer Immunosurveillance. Trends Immunol (2019) 40:735-47. doi: 10.1016/j.it.2019.06.002

203. Schenkel JM, Fraser KA, Beura LK, Pauken KE, Vezys V, Masopust D. T Cell Memory. Resident Memory CD8 T Cells Trigger Protective Innate and Adaptive Immune Responses. Science (2014) 346:98-101. doi: 10.1126/ science. 1254536

204. Mackay LK, Rahimpour A, Ma JZ, Collins N, Stock AT, Hafon ML, et al. The Developmental Pathway for CD103(+)CD8+ Tissue-Resident Memory T Cells of Skin. Nat Immunol (2013) 14:1294-301. doi: 10.1038/ni.2744

205. Gebhardt T, Wakim LM, Eidsmo L, Reading PC, Heath WR, Carbone FR. Memory T Cells in Nonlymphoid Tissue That Provide Enhanced Local Immunity During Infection With Herpes Simplex Virus. Nat Immunol (2009) 10:524-30. doi: 10.1038/ni.1718

206. Cheuk S, Schlums H, Gallais Serezal I, Martini E, Chiang SC, Marquardt N, et al. CD49a Expression Defines Tissue-Resident CD8(+) T Cells Poised for Cytotoxic Function in Human Skin. Immunity (2017) 46:287-300. doi: 10.1016/j.immuni.2017.01.009

207. Naik S, Bouladoux N, Linehan JL, Han SJ, Harrison OJ, Wilhelm C, et al. Commensal-Dendritic-Cell Interaction Specifies a Unique Protective Skin Immune Signature. Nature (2015) 520:104-8. doi: 10.1038/nature14052

208. Harrison OJ, Linehan JL, Shih HY, Bouladoux N, Han SJ, Smelkinson M, et al. Commensal-Specific T Cell Plasticity Promotes Rapid Tissue Adaptation to Injury. Science (2019) 363(6422):eaat6280. doi: 10.1126/ science.aat6280

209. Boddupalli CS, Bar N, Kadaveru K, Krauthammer M, Pornputtapong N, Mai $Z$, et al. Interlesional Diversity of $\mathrm{T}$ Cell Receptors in Melanoma With Immune Checkpoints Enriched in Tissue-Resident Memory T Cells. JCI Insight (2016) 1:e88955. doi: 10.1172/jci.insight.88955

210. Djenidi F, Adam J, Goubar A, Durgeau A, Meurice G, de Montpreville V, et al. CD8+CD103+ Tumor-Infiltrating Lymphocytes Are Tumor-Specific Tissue-Resident Memory T Cells and a Prognostic Factor for Survival in Lung Cancer Patients. J Immunol (2015) 194:3475-86. doi: 10.4049/ jimmunol.1402711

211. Wang B, Wu S, Zeng H, Liu Z, Dong W, He W, et al. CD103+ Tumor Infiltrating Lymphocytes Predict a Favorable Prognosis in Urothelial Cell Carcinoma of the Bladder. J Urol (2015) 194:556-62. doi: 10.1016/ j.juro.2015.02.2941

212. Webb JR, Wick DA, Nielsen JS, Tran E, Milne K, McMurtrie E, et al. Profound Elevation of CD8+ T Cells Expressing the Intraepithelial
Lymphocyte Marker CD103 (Alphae/Beta7 Integrin) in High-Grade Serous Ovarian Cancer. Gynecol Oncol (2010) 118:228-36. doi: 10.1016/ j.ygyno.2010.05.016

213. Komdeur FL, Prins TM, van de Wall S, Plat A, Wisman GBA, Hollema H, et al. CD103+ Tumor-Infiltrating Lymphocytes Are Tumor-Reactive Intraepithelial CD8 $+\mathrm{T}$ Cells Associated With Prognostic Benefit and Therapy Response in Cervical Cancer. Oncoimmunology (2017) 6: e1338230. doi: 10.1080/2162402X.2017.1338230

214. Wang ZQ, Milne K, Derocher H, Webb JR, Nelson BH, Watson PH. CD103 and Intratumoral Immune Response in Breast Cancer. Clin Cancer Res (2016) 22:6290-7. doi: 10.1158/1078-0432.CCR-16-0732

215. Quinn E, Hawkins N, Yip YL, Suter C, Ward R. CD103+ Intraepithelial Lymphocytes-A Unique Population in Microsatellite Unstable Sporadic Colorectal Cancer. Eur J Cancer (2003) 39:469-75. doi: 10.1016/S09598049(02)00633-0

216. Edwards J, Wilmott JS, Madore J, Gide TN, Quek C, Tasker A, et al. CD103 (+) Tumor-Resident CD8(+) T Cells Are Associated With Improved Survival in Immunotherapy-Naive Melanoma Patients and Expand Significantly During Anti-PD-1 Treatment. Clin Cancer Res (2018) 24:3036-45. doi: 10.1158/1078-0432.CCR-17-2257

217. Bosmuller HC, Wagner P, Peper JK, Schuster H, Pham DL, Greif K, et al. Combined Immunoscore of CD103 and CD3 Identifies Long-Term Survivors in High-Grade Serous Ovarian Cancer. Int $J$ Gynecol Cancer (2016) 26:671-9. doi: 10.1097/IGC.0000000000000672

218. Savas P, Virassamy B, Ye C, Salim A, Mintoff CP, Caramia F, et al. Single-Cell Profiling of Breast Cancer T Cells Reveals a Tissue-Resident Memory Subset Associated With Improved Prognosis. Nat Med (2018) 24:986-93. doi: 10.1038/s41591-018-0078-7

219. Workel HH, Komdeur FL, Wouters MC, Plat A, Klip HG, Eggink FA, et al. CD103 Defines Intraepithelial CD8+ PD1+ Tumour-Infiltrating Lymphocytes of Prognostic Significance in Endometrial Adenocarcinoma. Eur J Cancer (2016) 60:1-11. doi: 10.1016/j.ejca.2016.02.026

220. Guo X, Zhang Y, Zheng L, Zheng C, Song J, Zhang Q, et al. Global Characterization of T Cells in Non-Small-Cell Lung Cancer by Single-Cell Sequencing. Nat Med (2018) 24:978-85. doi: 10.1038/s41591-018-0045-3

221. Darvin P, Toor SM, Sasidharan Nair V, Elkord E. Immune Checkpoint Inhibitors: Recent Progress and Potential Biomarkers. Exp Mol Med (2018) 50:165-5. doi: 10.1038/s12276-018-0191-1

222. Sahin U, Türeci Ö. Personalized Vaccines for Cancer Immunotherapy. Science (2018) 359:1355-60. doi: 10.1126/science.aar7112

223. Chowell D, Morris LGT, Grigg CM, Weber JK, Samstein RM, Makarov V, et al. Patient HLA Class I Genotype Influences Cancer Response to Checkpoint Blockade Immunotherapy. Science (New York, NY) (2018) 359:582-7. doi: 10.1126/science.aao4572

224. Durgeau A, Virk Y, Corgnac S, Mami-Chouaib F. Recent Advances in Targeting CD8 T-Cell Immunity for More Effective Cancer Immunotherapy. Front Immunol (2018) 9:14-4. doi: 10.3389/fimmu.2018.00014

225. Ali M, Foldvari Z, Giannakopoulou E, Boschen ML, Stronen E, Yang W, et al. Induction of Neoantigen-Reactive T Cells From Healthy Donors. Nat Protoc (2019) 14:1926-43. doi: 10.1038/s41596-019-0170-6

226. Audehm S, Glaser M, Pecoraro M, Bräunlein E, Mall S, Klar R, et al. Key Features Relevant to Select Antigens and TCR From the MHC-Mismatched Repertoire to Treat Cancer. Front Immunol (2019) 10:1485. doi: 10.3389/ fimmu. 2019.01485

227. Lu YC, Parker LL, Lu T, Zheng Z, Toomey MA, White DE, et al. Treatment of Patients With Metastatic Cancer Using a Major Histocompatibility Complex Class II-Restricted T-Cell Receptor Targeting the Cancer Germline Antigen MAGE-A3. J Clin Oncol (2017) 35:3322-9. doi: 10.1200/JCO.2017.74.5463

228. Rapoport AP, Stadtmauer EA, Binder-Scholl GK, Goloubeva O, Vogl DT, Lacey SF, et al. NY-ESO-1-Specific TCR-Engineered T Cells Mediate Sustained Antigen-Specific Antitumor Effects in Myeloma. Nat Med (2015) 21:914-21. doi: 10.1038/nm.3910

229. Robbins PF, Kassim SH, Tran TL, Crystal JS, Morgan RA, Feldman SA, et al. A Pilot Trial Using Lymphocytes Genetically Engineered With An NY-ESO1-Reactive T-Cell Receptor: Long-Term Follow-Up and Correlates With Response. Clin Cancer Res (2015) 21:1019-27. doi: 10.1158/1078-0432.CCR$14-2708$ 
230. D’Angelo SP, Melchiori L, Merchant MS, Bernstein D, Glod J, Kaplan R, et al. Antitumor Activity Associated With Prolonged Persistence of Adoptively Transferred NY-ESO-1 (C259)T Cells in Synovial Sarcoma. Cancer Discov (2018) 8:944-57. doi: 10.1158/2159-8290.CD-17-1417

231. Legut M, Cole DK, Sewell AK. The Promise of Gammadelta T Cells and the Gammadelta T Cell Receptor for Cancer Immunotherapy. Cell Mol Immunol (2015) 12:656-68. doi: 10.1038/cmi.2015.28

232. Kobayashi H, Tanaka Y, Yagi J, Osaka Y, Nakazawa H, Uchiyama T, et al. Safety Profile and Anti-Tumor Effects of Adoptive Immunotherapy Using GammaDelta T Cells Against Advanced Renal Cell Carcinoma: A Pilot Study. Cancer Immunol Immunother (2007) 56:469-76. doi: 10.1007/s00262-006-0199-6

233. Kobayashi H, Tanaka Y, Shimmura H, Minato N, Tanabe K. Complete Remission of Lung Metastasis Following Adoptive Immunotherapy Using Activated Autologous Gammadelta T-Cells in a Patient With Renal Cell Carcinoma. Anticancer Res (2010) 30:575-9.

234. Kobayashi H, Tanaka Y, Yagi J, Minato N, Tanabe K. Phase I/II Study of Adoptive Transfer of Gammadelta T Cells in Combination With Zoledronic Acid and IL-2 to Patients With Advanced Renal Cell Carcinoma. Cancer Immunol Immunother (2011) 60:1075-84. doi: 10.1007/s00262-011-1021-7

235. Nakajima J, Murakawa T, Fukami T, Goto S, Kaneko T, Yoshida Y, et al. A Phase I Study of Adoptive Immunotherapy for Recurrent Non-Small-Cell Lung Cancer Patients With Autologous Gammadelta T Cells. Eur J Cardiothorac Surg (2010) 37:1191-7. doi: 10.1016/j.ejcts.2009.11.051

236. Sakamoto M, Nakajima J, Murakawa T, Fukami T, Yoshida Y, Murayama T, et al. Adoptive Immunotherapy for Advanced Non-Small Cell Lung Cancer Using Zoledronate-Expanded Gammadeltatcells: A Phase I Clinical Study. J Immunother (2011) 34:202-11. doi: 10.1097/CJI.0b013e318207ecfb

237. Ferreira LM. Gammadelta T Cells: Innately Adaptive Immune Cells? Int Rev Immunol (2013) 32:223-48. doi: 10.3109/08830185.2013.783831

238. Silva-Santos B, Mensurado S, Coffelt SB. Gammadelta T Cells: Pleiotropic Immune Effectors With Therapeutic Potential in Cancer. Nat Rev Cancer (2019) 19(7):392-404. doi: 10.1038/s41568-019-0153-5

239. Coffelt SB, Kersten K, Doornebal CW, Weiden J, Vrijland K, Hau CS, et al. IL17-Producing Gammadelta T Cells and Neutrophils Conspire to Promote Breast Cancer Metastasis. Nature (2015) 522:345-8. doi: 10.1038/nature14282

240. Kimura Y, Nagai N, Tsunekawa N, Sato-Matsushita M, Yoshimoto T, Cua DJ, et al. IL-17A-Producing CD30(+) Vdelta1 T Cells Drive Inflammation-Induced Cancer Progression. Cancer Sci (2016) 107:1206-14. doi: 10.1111/cas.13005

241. Akitsu A, Iwakura Y. Interleukin-17-Producing Gammadelta T (Gammadelta17) Cells in Inflammatory Diseases. Immunology (2018) 155:418-26. doi: 10.1111/ imm. 12993

242. Kenna T, Golden-Mason L, Norris S, Hegarty JE, O’Farrelly C, Doherty DG. Distinct Subpopulations of Gamma Delta T Cells Are Present in Normal and Tumor-Bearing Human Liver. . Clin Immunol (Orlando Fla.) (2004) 113:5663. doi: 10.1016/j.clim.2004.05.003

243. Correia DV, Fogli M, Hudspeth K, da Silva MG, Mavilio D, Silva-Santos B. Differentiation of Human Peripheral Blood Vdeltal+ T Cells Expressing the Natural Cytotoxicity Receptor Nkp30 for Recognition of Lymphoid Leukemia Cells. Blood (2011) 118:992-1001. doi: 10.1182/blood-2011-02-339135

244. Wu D, Wu P, Qiu F, Wei Q, Huang J. Human Gammadeltat-Cell Subsets and Their Involvement in Tumor Immunity. Cell Mol Immunol (2017) 14:24553. doi: $10.1038 / \mathrm{cmi} .2016 .55$

245. Daley D, Zambirinis CP, Seifert L, Akkad N, Mohan N, Werba G, et al. Gammadelta T Cells Support Pancreatic Oncogenesis by Restraining Alphabeta T Cell Activation. Cell (2016) 166:1485-99.e15. doi: 10.1016/ j.cell.2016.07.046

246. Maeurer M, Zitvogel L, Elder E, Storkus WJ, Lotze MT. Human Intestinal V Delta 1+ T Cells Obtained From Patients With Colon Cancer Respond Exclusively to SEB But Not to SEA. Nat Immun (1995) 14:188-97.

247. Maeurer MJ, Martin D, Walter W, Liu K, Zitvogel L, Halusczcak K, et al. Human Intestinal Vdelta1+ Lymphocytes Recognize Tumor Cells of Epithelial Origin. J Exp Med (1996) 183:1681-96. doi: 10.1084/jem.183.4.1681

248. Wolf BJ, Choi JE, Exley MA. Novel Approaches to Exploiting Invariant NKT Cells in Cancer Immunotherapy. Front Immunol (2018) 9:384. doi: 10.3389/ fimmu.2018.00384

249. Giaccone G, Punt CJ, Ando Y, Ruijter R, Nishi N, Peters M, et al. A Phase I Study of the Natural Killer T-Cell Ligand Alpha-Galactosylceramide (KRN7000) in Patients With Solid Tumors. Clin Cancer Res (2002) 8:3702-9.
250. Uchida T, Horiguchi S, Tanaka Y, Yamamoto H, Kunii N, Motohashi S, et al Phase I Study of Alpha-Galactosylceramide-Pulsed Antigen Presenting Cells Administration to the Nasal Submucosa in Unresectable or Recurrent Head and Neck Cancer. Cancer Immunol Immunother (2008) 57:337-45. doi: 10.1007/s00262-007-0373-5

251. Kabelitz D, Serrano R, Kouakanou L, Peters C, Kalyan S. Cancer Immunotherapy With Gammadelta T Cells: Many Paths Ahead of Us. Cell Mol Immunol (2020) 17:925-39. doi: 10.1038/s41423-020-0504-x

252. Garg K, Maurer M, Griss J, Bruggen MC, Wolf IH, Wagner C, et al. TumorAssociated B Cells in Cutaneous Primary Melanoma and Improved Clinical Outcome. Hum Pathol (2016) 54:157-64. doi: 10.1016/j.humpath.2016.03.022

253. Fremd C, Stefanovic S, Beckhove P, Pritsch M, Lim H, Wallwiener M, et al. Mucin 1-Specific B Cell Immune Responses and Their Impact on Overall Survival in Breast Cancer Patients. Oncoimmunology (2016) 5:e1057387. doi: 10.1080/2162402X.2015.1057387

254. Chen JL, Dawoodji A, Tarlton A, Gnjatic S, Tajar A, Karydis I, et al. NYESO-1 Specific Antibody and Cellular Responses in Melanoma Patients Primed With NY-ESO-1 Protein in ISCOMATRIX and Boosted With Recombinant NY-ESO-1 Fowlpox Virus. Int J Cancer (2015) 136:E590601. doi: 10.1002/ijc.29118

255. Meng Q, Valentini D, Rao M, Maeurer M. KRAS RENAISSANCE(S) in Tumor Infiltrating B Cells in Pancreatic Cancer. Front Oncol (2018) 8:384. doi: 10.3389 /fonc.2018.00384

256. van Dam GM, Themelis G, Crane LMA, Harlaar NJ, Pleijhuis RG, Kelder W, et al. Intraoperative Tumor-Specific Fluorescence Imaging in Ovarian Cancer by Folate Receptor-A Targeting: First in-Human Results. Nat Med (2011) 17:1315. doi: 10.1038/nm.2472

257. Zhang Y, Chang L, Yang Y, Fang W, Guan Y, Wu A, et al. The Correlations of Tumor Mutational Burden Among Single-Region Tissue, Multi-Region Tissues and Blood in Non-Small Cell Lung Cancer. J ImmunoTher Cancer (2019) 7:98. doi: 10.1186/s40425-019-0581-5

258. Das R, Bar N, Ferreira M, Newman AM, Zhang L, Bailur JK, et al. Early B Cell Changes Predict Autoimmunity Following Combination Immune Checkpoint Blockade. J Clin Invest (2018) 128(2):715-20. doi: 10.1172/JC196798

259. Meng Q, Valentini D, Rao M, Dodoo E, Maeurer M. CMV and EBV Targets Recognized by Tumor-Infiltrating B Lymphocytes in Pancreatic Cancer and Brain Tumors. Sci Rep (2018) 8:17079-89. doi: 10.1038/s41598-018-34710-2

260. Waltari E, McGeever A, Friedland N, Kim PS, McCutcheon KM. Functional Enrichment and Analysis of Antigen-Specific Memory B Cell Antibody Repertoires in Pbmcs. Front Immunol (2019) 10:1452. doi: 10.3389/ fimmu.2019.01452

261. Singh M, Al-Eryani G, Carswell S, Ferguson JM, Blackburn J, Barton K, et al. High-Throughput Targeted Long-Read Single Cell Sequencing Reveals the Clonal and Transcriptional Landscape of Lymphocytes. Nat Commun (2019) 10:3120. doi: 10.1038/s41467-019-11049-4

262. Nicodemus CF. Antibody-Based Immunotherapy of Solid Cancers: Progress and Possibilities. Immunotherapy (2015) 7(8):923-39. doi: 10.2217/imt.15.57

263. Garaud S, Buisseret L, Solinas C, Gu-Trantien C, de Wind A, Van den Eynden G, et al. Tumor Infiltrating B-Cells Signal Functional Humoral Immune Responses in Breast Cancer. JCI Insight (2019) 5(18):e129641. doi: 10.1172/jci.insight.129641

264. Petitprez F, de Reynies A, Keung EZ, Chen TW, Sun CM, Calderaro J, et al. B Cells are Associated With Survival and Immunotherapy Response in Sarcoma. Nature (2020) 577:556-60. doi: 10.1038/s41586-019-1906-8

265. Helmink BA, Reddy SM, Gao J, Zhang S, Basar R, Thakur R, et al. B Cells and Tertiary Lymphoid Structures Promote Immunotherapy Response. Nature (2020) 577:549-55. doi: 10.1038/s41586-019-1922-8

266. Ogino T, Wang X, Kato S, Miyokawa N, Harabuchi Y, Ferrone S. Endoplasmic Reticulum Chaperone-Specific Monoclonal Antibodies for Flow Cytometry and Immunohistochemical Staining. Tissue Antigens (2003) 62:385-93. doi: 10.1034/j.1399-0039.2003.00114.x

267. Kikuchi E, Yamazaki K, Torigoe T, Cho Y, Miyamoto M, Oizumi S, et al. HLA Class I Antigen Expression is Associated With a Favorable Prognosis in Early Stage Non-Small Cell Lung Cancer. Cancer Sci (2007) 98:1424-30. doi: 10.1111/j.1349-7006.2007.00558.x

268. Torigoe T, Asanuma H, Nakazawa E, Tamura Y, Hirohashi Y, Yamamoto E, et al. Establishment of a Monoclonal Anti-Pan HLA Class I Antibody Suitable for Immunostaining of Formalin-Fixed Tissue: Unusually High 
Frequency of Down-Regulation in Breast Cancer Tissues. Pathol Int (2012) 62:303-8. doi: 10.1111/j.1440-1827.2012.02789.x

269. Twomey JD, Kim SR, Zhao L, Bozza WP, Zhang B. Spatial Dynamics of TRAIL Death Receptors in Cancer Cells. Drug Resist Update (2015) 19:1321. doi: 10.1016/j.drup.2015.02.001

270. Z'Graggen K, Centeno BA, Fernandez-del Castillo C, Jimenez RE, Werner J, Warshaw AL. Biological Implications of Tumor Cells in Blood and Bone Marrow of Pancreatic Cancer Patients. Surgery (2001) 129:537-46. doi: 10.1067/msy.2001.113819

271. Sho S, Court CM, Winograd P, Lee S, Hou S, Graeber TG, et al. Precision Oncology Using a Limited Number of Cells: Optimization of Whole Genome Amplification Products for Sequencing Applications. BMC Cancer (2017) 17:457. doi: 10.1186/s12885-017-3447-6

272. Lin E, Cao T, Nagrath S, King MR. Circulating Tumor Cells: Diagnostic and Therapeutic Applications. Annu Rev BioMed Eng (2018) 20:329-52. doi: 10.1146/annurev-bioeng-062117-120947

273. Moritz A, Anjanappa R, Wagner C, Bunk S, Hofmann M, Pszolla G, et al. High-Throughput Peptide-MHC Complex Generation and Kinetic Screenings of Tcrs With Peptide-Receptive HLA-a ${ }^{*} 02: 01$ Molecules. Sci Immunol (2019) 4:eaav0860. doi: 10.1126/sciimmunol.aav0860

274. Saini SK, Tamhane T, Anjanappa R, Saikia A, Ramskov S, Donia M, et al. Empty Peptide-Receptive MHC Class I Molecules for Efficient Detection of Antigen-Specific T Cells. Sci Immunol (2019) 4:eaau9039. doi: 10.1126/ sciimmunol.aau9039

275. Danova M, Torchio M, Comolli G, Sbrana A, Antonuzzo A, Mazzini G. The Role of Automated Cytometry in the New Era of Cancer Immunotherapy. Mol Clin Oncol (2018) 9:355-61. doi: 10.3892/mco.2018.1701

276. Coelho MA, de Carne Trecesson S, Rana S, Zecchin D, Moore C, MolinaArcas $M$, et al. Oncogenic RAS Signaling Promotes Tumor Immunoresistance by Stabilizing PD-L1 Mrna. Immunity (2017) 47 (6):1083-99.e6. doi: 10.1016/j.immuni.2017.11.016

277. Dong ZY, Zhong WZ, Zhang XC, Su J, Xie Z, Liu SY, et al. Potential Predictive Value of TP53 and KRAS Mutation Status for Response to PD-1 Blockade Immunotherapy in Lung Adenocarcinoma. Clin Cancer Res (2017) 23:3012-24. doi: 10.1016/j.jtho.2016.11.504

278. Bachinsky MM, Guillen DE, Patel SR, Singleton J, Chen C, Soltis DA, et al. Mapping and Binding Analysis of Peptides Derived From the TumorAssociated Antigen Survivin for Eight HLA Alleles. Cancer Immun (2005) 5:6.

279. Axelsson-Robertson R, Ahmed RK, Weichold FF, Ehlers MM, Kock MM, Sizemore D, et al. Human Leukocyte Antigens $a^{\star} 3001$ and $a^{\star} 3002$ Show Distinct Peptide-Binding Patterns of the Mycobacterium Tuberculosis Protein TB10.4: Consequences for Immune Recognition. Clin Vaccine Immunol (2011) 18:125-34. doi: 10.1128/CVI.00302-10

280. Axelsson-Robertson R, Weichold F, Sizemore D, Wulf M, Skeiky YA, Sadoff J, et al. Extensive Major Histocompatibility Complex Class I Binding Promiscuity for Mycobacterium Tuberculosis TB10.4 Peptides and Immune Dominance of Human Leucocyte Antigen (HLA)-B*0702 and HLA-B ${ }^{*} 0801$ Alleles in TB10.4 CD8 T-Cell Responses. Immunology (2010) 129:496-505. doi: 10.1111/j.1365-2567.2009.03201.x

281. van der Burg SH, Visseren MJ, Brandt RM, Kast WM, Melief CJ. Immunogenicity of Peptides Bound to MHC Class I Molecules Depends on the MHC-Peptide Complex Stability. J Immunol (1996) 156:3308-14.

282. Spierings E, Gras S, Reiser J-B, Mommaas B, Almekinders M, Kester MGD, et al. Steric Hindrance and Fast Dissociation Explain the Lack of Immunogenicity of the Minor Histocompatibility HA-1Arg Null Allele. J Immunol (2009) 182:4809-16. doi: 10.4049/jimmunol.0803911

283. Micheletti F, Guerrini R, Formentin A, Canella A, Marastoni M, Bazzaro M, et al. Selective Amino Acid Substitutions of a Subdominant Epstein-Barr Virus LMP2-Derived Epitope Increase HLA/Peptide Complex Stability and Immunogenicity: Implications for Immunotherapy of Epstein-Barr VirusAssociated Malignancies. Eur J Immunol (1999) 29:2579-89. doi: 10.1002/ (SICI) 1521-4141(199908)29:08<2579::AID-IMMU2579>3.0.CO;2-E

284. van Stipdonk MJB, Badia-Martinez D, Sluijter M, Offringa R, van Hall T, Achour A. Design of Agonistic Altered Peptides for the Robust Induction of CTL Directed Towards H-2Db in Complex With the Melanoma-Associated Epitope Gp100. Cancer Res (2009) 69:7784-92. doi: 10.1158/0008-5472.CAN-09-1724

285. Lazarski CA, Chaves FA, Jenks SA, Wu S, Richards KA, Weaver JM, et al. The Kinetic Stability of MHC Class II: Peptide Complexes Is a Key Parameter
That Dictates Immunodominance. Immunity (2005) 23:29-40. doi: 10.1016/ j.immuni.2005.05.009

286. Burrows JM, Wynn KK, Tynan FE, Archbold J, Miles JJ, Bell MJ, et al. The Impact of HLA-B Micropolymorphism Outside Primary Peptide Anchor Pockets on the CTL Response to CMV. Eur J Immunol (2007) 37:946-53. doi: $10.1002 /$ eji. 200636588

287. Harndahl M, Rasmussen M, Roder G, Dalgaard Pedersen I, Sorensen M, Nielsen M, et al. Peptide-MHC Class I Stability Is a Better Predictor Than Peptide Affinity of CTL Immunogenicity. Eur J Immunol (2012) 42:1405-16. doi: $10.1002 /$ eji.201141774

288. Rasmussen M, Fenoy E, Harndahl M, Kristensen AB, Nielsen IK, Nielsen M, et al. Pan-Specific Prediction of Peptide-MHC Class I Complex Stability, a Correlate of T Cell Immunogenicity. J Immunol (2016) 197:1517-24. doi: 10.4049/jimmunol.1600582

289. Nicholls S, Piper KP, Mohammed F, Dafforn TR, Tenzer S, Salim M, et al. Secondary Anchor Polymorphism in the HA-1 Minor Histocompatibility Antigen Critically Affects MHC Stability and TCR Recognition. Proc Natl Acad Sci (2009) 106:3889-94. doi: 10.1073/pnas.0900411106

290. Dudley ME, Rosenberg SA. Adoptive-Cell-Transfer Therapy for the Treatment of Patients With Cancer. Nat Rev Cancer (2003) 3:666-75. doi: $10.1038 / \mathrm{nrc1} 167$

291. Maeurer MJ, Martin D, Elder E, Storkus WJ, Lotze MT. Detection of Naturally Processed and HLA-A1-Presented Melanoma T-Cell Epitopes Defined by CD8(+) T-Cells' Release of Granulocyte-Macrophage ColonyStimulating Factor But Not by Cytolysis. Clin Cancer Res (1996) 2:87-95.

292. Ostmeyer J, Christley S, Toby IT, Cowell LG. Biophysicochemical Motifs in T-Cell Receptor Sequences Distinguish Repertoires From Tumor-Infiltrating Lymphocyte and Adjacent Healthy Tissue. Cancer Res (2019) 79:1671-80. doi: 10.1158/0008-5472.CAN-18-2292

293. Rosenthal R, Cadieux EL, Salgado R, Bakir MA, Moore DA, Hiley CT, et al. And T.R. Consortium. Neoantigen-Directed Immune Escape Lung Cancer Evol Nat (2019) 567:479-85. doi: 10.1038/s41586-019-1032-7

294. Benjamin D, Sato T, Cibulskis K, Getz G, Stewart C, Lichtenstein L. Calling Somatic Snvs and Indels With Mutect2. bioRxiv (2019) 861054. doi: 10.1101/861054

295. Koboldt DC, Zhang Q, Larson DE, Shen D, McLellan MD, Lin L, et al. Varscan 2: Somatic Mutation and Copy Number Alteration Discovery in Cancer by Exome Sequencing. Genome Res (2012) 22:568-76. doi: 10.1101/gr.129684.111

296. Kim S, Scheffler K, Halpern AL, Bekritsky MA, Noh E, Källberg M, et al. Strelka2: Fast and Accurate Calling of Germline and Somatic Variants. Nat Methods (2018) 15:591-4. doi: 10.1038/s41592-018-0051-x

297. Narzisi G, Corvelo A, Arora K, Bergmann EA, Shah M, Musunuri R, et al. Genome-Wide Somatic Variant Calling Using Localized Colored De Bruijn Graphs. Commun Biol (2018) 1:20-0. doi: 10.1038/s42003-018-0023-9

298. Hundal J, Kiwala S, McMichael J, Miller CA, Xia H, Wollam AT, et al. Pvactools: A Computational Toolkit to Identify and Visualize Cancer Neoantigens. Cancer Immunol Res (2020) 8:409-20. doi: 10.1158/2326-6066.CIR-19-0401

299. Olcina MM, Balanis NG, Kim RK, Aksoy BA, Kodysh J, Thompson MJ, et al. Mutations in an Innate Immunity Pathway Are Associated With Poor Overall Survival Outcomes and Hypoxic Signaling in Cancer. Cell Rep (2018) 25:3721-32.e6. doi: 10.1016/j.celrep.2018.11.093

300. Porta-Pardo E, Godzik A. Mutation Drivers of Immunological Responses to Cancer. Cancer Immunol Res (2016) 4:789-98. doi: 10.1158/2326-6066.CIR15-0233

301. Li J, Wang W, Zhang Y, Cieslik M, Guo J, Tan M, et al. Epigenetic Driver Mutations in ARID1A Shape Cancer Immune Phenotype and Immunotherapy. J Clin Invest (2020) 130:2712-26. doi: 10.1172/JCI134402

302. Looney TJ, Topacio-Hall D, Lowman G, Conroy J, Morrison C, Oh D, et al. TCR Convergence in Individuals Treated With Immune Checkpoint Inhibition for Cancer. Front Immunol (2019) 10:2985. doi: 10.3389/ fimmu.2019.02985

303. Hu Z, Leet DE, Allesoe RL, Oliveira G, Li S, Luoma AM, et al. Personal Neoantigen Vaccines Induce Persistent Memory T Cell Responses and Epitope Spreading in Patients With Melanoma. Nat Med (2021) 27:51525. doi: 10.1038/s41591-020-01206-4

304. Meng Q, Valentini D, Rao M, Liu Z, Xie S, Morgell A, et al. Prediction of Improved Survival in Patients With Pancreatic Cancer Via IL-21 Enhanced Detection of Mesothelin Epitope-Reactive T-Cell Responses. Oncotarget (2018) 9:22451-9. doi: 10.18632/oncotarget.25121 
305. Zhenjiang L, Rao M, Luo X, Sandberg E, Bartek J Jr, Schoutrop E, et al. Mesothelin-Specific Immune Responses Predict Survival of Patients With Brain Metastasis. EBioMedicine (2017) 23:20-4. doi: 10.1016/j.ebiom.2017.08.024

306. Zhenjiang L, Rao M, Luo X, Valentini D, von Landenberg A, Meng Q, et al. Cytokine Networks and Survivin Peptide-Specific Cellular Immune Responses Predict Improved Survival in Patients With Glioblastoma Multiforme. EBioMedicine (2018) 33:49-56. doi: 10.1016/j.ebiom.2018.06.014

307. Alcantara M, Du Rusquec P, Romano E. Current Clinical Evidence and Potential Solutions to Increase Benefit of CAR T-Cell Therapy for Patients With Solid Tumors. OncoImmunology (2020) 9:1777064. doi: 10.1080/ 2162402X.2020.1777064

308. Smith SM, Iwenofu OH. NY-ESO-1: A Promising Cancer Testis Antigen for Sarcoma Immunotherapy and Diagnosis. Chin Clin Oncol (2018) 7:44. doi: $10.21037 / \mathrm{cco} .2018 .08 .11$

309. Thomas R, Al-Khadairi G, Roelands J, Hendrickx W, Dermime S, Bedognetti D, et al. NY-ESO-1 Based Immunotherapy of Cancer: Current Perspectives. Front Immunol (2018) 9:947. doi: 10.3389/fimmu.2018.00947

310. Klampatsa A, Dimou V, Albelda SM. Mesothelin-Targeted CAR-T Cell Therapy for Solid Tumors. Expert Opin Biol Ther (2020) 21(4):473-86. doi: $10.1080 / 14712598.2021 .1843628$

311. Angelova M, Mlecnik B, Vasaturo A, Bindea G, Fredriksen T, Lafontaine L, et al. Evolution of Metastases in Space and Time Under Immune Selection. Cell (2018) 175:751-65.e16. doi: 10.1016/j.cell.2018.09.018

312. Hu Z, Li Z, Ma Z, Curtis C. Multi-Cancer Analysis of Clonality and the Timing of Systemic Spread in Paired Primary Tumors and Metastases. Nat Genet (2020) 52:701-8. doi: 10.1038/s41588-020-0628-z

313. Thorsson V, Gibbs DL, Brown SD, Wolf D, Bortone DS, Ou Yang TH, et al. The Immune Landscape of Cancer. Immunity (2018) 48:812-30.e14. doi: 10.1016/j.immuni.2018.03.023
314. Trinh A, Polyak K. Tumor Neoantigens: When Too Much of a Good Thing is Bad. Cancer Cell (2019) 36:466-7. doi: 10.1016/j.ccell.2019.10.009

315. Leruste A, Tosello J, Ramos RN, Tauziede-Espariat A, Brohard S, Han ZY, et al. Clonally Expanded T Cells Reveal Immunogenicity of Rhabdoid Tumors. Cancer Cell (2019) 36:597-612.e8. doi: 10.1016/j.ccell.2019.10.008

316. Dash P, Fiore-Gartland AJ, Hertz T, Wang GC, Sharma S, Souquette A, et al. Quantifiable Predictive Features Define Epitope-Specific T Cell Receptor Repertoires. Nature (2017) 547:89-93. doi: 10.1038/nature22383

317. Gee MH, Han A, Lofgren SM, Beausang JF, Mendoza JL, Birnbaum ME, et al. Antigen Identification for Orphan T Cell Receptors Expressed on TumorInfiltrating Lymphocytes. Cell (2018) 172:549-63.e16. doi: 10.1016/ j.cell.2017.11.043

318. Huang H, Wang C, Rubelt F, Scriba TJ, Davis MM. Analyzing the Mycobacterium Tuberculosis Immune Response by T-Cell Receptor Clustering With GLIPH2 and Genome-Wide Antigen Screening. Nat Biotechnol (2020) 38(10):1194-202. doi: 10.1038/s41587-020-0505-4

Conflict of Interest: The authors declare that the research was conducted in the absence of any commercial or financial relationships that could be construed as a potential conflict of interest.

Copyright (๑) 2021 de Sousa, Lérias, Beltran, Paraschoudi, Condeço, Kamiki, António, Figueiredo, Carvalho, Castillo-Martin, Wang, Ligeiro, Rao and Maeurer. This is an open-access article distributed under the terms of the Creative Commons Attribution License (CC BY). The use, distribution or reproduction in other forums is permitted, provided the original author(s) and the copyright owner(s) are credited and that the original publication in this journal is cited, in accordance with accepted academic practice. No use, distribution or reproduction is permitted which does not comply with these terms. 